\title{
Multi-Phase Smart Converter for PV System
}

\author{
Zhongsheng Cao \\ Thesis submitted to the Faculty of the \\ Virginia Polytechnic Institute and State University \\ in partial fulfillment of the requirements for the degree of \\ Master of Science \\ in \\ Electrical Engineering
}

Qiang Li, Chair

Fred C. Lee

Louis J. Guido

August $12^{\text {th }}, 2014$
Blacksburg, Virginia

Keywords: PV panel, MPPT, smart converter, multi-phase converter

(C) 2014, Zhongsheng Cao 


\title{
Multi-Phase Smart Converter for PV System \\ Zhongsheng Cao
}

\begin{abstract}
Recent research and industrial accomplishment has revealed the advantages of cascaded smart converter PV system over traditional centralized and string PV system. However, even by adopting the cascaded smart converter, it is not always possible to track maximum power point (MPP) for all the panels under heavy shading condition, and a central converter is still required to track the peak power point of PV array.

Based on the analysis of system configurations for smart converter PV system, an alternative PV system configuration is introduced which can extract peak power from all the panels under different mismatch condition and connect PV array to 380V DC bus without central converter.

Based on this alternative PV system configuration, a multi-phase smart converter with single controller is proposed as a low cost panel-level MPPT solution. This proposal can largely reduce cost by saving MPPT controllers, current and voltage sensors without sacrificing energy production. The effectiveness of the proposal has been verified by both simulation and experiment results.
\end{abstract}




\section{Acknowledgements}

I would like to express my sincere appreciation to my advisor, Dr. Qiang Li for his guidance, encouragement and support. I deeply admire his extensive knowledge, meticulous attitude and genial personality. It was an invaluable learning experience to be one of his students, which will benefit me a lot in my future career.

I am also grateful to my committee members, Dr. Fred C. Lee, and Dr. Louis Guido. I would like to thank Dr. Fred C. Lee for all the discussions during weekly meeting and all the great suggestions that inspired me a lot. I'd like also thank Dr. Louis Guido for being so kind to be my committee member and the precious suggestions regarding this thesis.

It has been a great pleasure to work in the Center for Power Electronics Systems (CPES). I would like to acknowledge the CPES administrative and management staff, Ms. Teresa Shaw, Ms. Marianne Hawthorne, Ms. Teresa Rose, Ms. Linda Long, Mr. David Gilham, Dr. Xuning Zhang, Dr. Zhiyu Shen, Dr. Mingkai Mu, Dr. Igor Cvetkovic.

It has been really tough for the past two years for all the frustration and struggling during the process of learning. However, it also has been my honor and pleasant to work with all the great people in CPES and it would really be my most unforgettable years in all my life to be colleague to so many elites. I would like to thank all of them: Daocheng Huang, Dr. Yingyi Yan, Dr. Weiyi Feng, Dr. Alex Ji, Mr. Shuilin Tian, Mr. Yipeng Su, Mr. Xiucheng Huang, Mr. Zhengyang Liu, Mr. Dongbin Hou, Mr. Pei-Hsin Liu, Mr. Yuchen Yang, Mr. Syed Bari, Mr. Chao Fei, Mr. Xuebing Chen, Ms. Yincan Mao, Mr. Li Jiang, Mr. Ming Lu, Mr. Zhemin Zhang, Mr. Wei Zhang, Mr. Lingxiao Xue, Mr. Fang Chen, Mr. Jun Wang, Mr. Qiong Wang, Mr. Chi Li, Mr. 
Shishuo Zhao, Ms. Bingyao Sun, Mr. Yang Jiao, Mr. Bo Wen, Ms. Han Cui, Ms. Christina DiMarino, Ms. Niloofar Rashidi Mehrabadi, Mr. Bin Li, Mr. Tao Liu.

Finally yet importantly, I want to thank my family: my father Xiangwen Cao, my mother Lanyu Ke, my elder sister Zhonghui Cao and Zhongfang Cao, my younger sister Zhongfen Cao. I could not have gone so far without your encouragement and support. Thank you for your devotions for me in the past almost thirty years. You are the most important person in the world to me, and I will always love you.

This work was supported by CPES Power Management Consortium (Chicony Power, CSR Zhuzhou Institute Co., Ltd., Delta Electronics, Huawei Technologies, International Rectifier, Linear Technology, Macroblock, Inc., Murata Manufacturing Co., Ltd., NEC TOKIN Corporation, NXP Semiconductors, Richtek Technology, Texas Instruments), and the Engineering Research Center Shared Facilities supported by the National Science Foundation under NSF Award Number EEC-9731677. Any opinions, findings and conclusions or recommendations expressed in this material are those of the author and do not necessarily reflect those of the National Science Foundation. 


\section{Table of Contents}

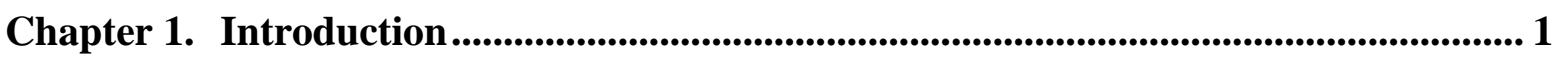

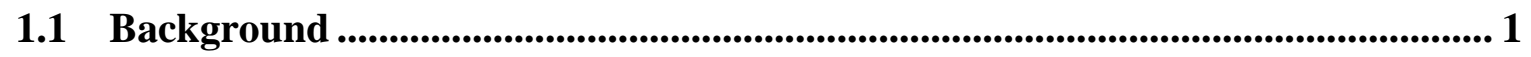

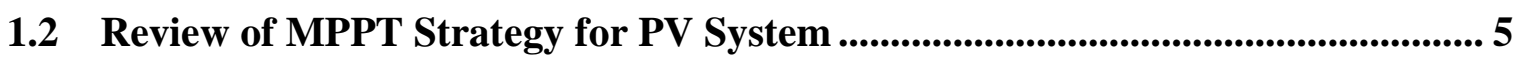

1.3 Smart Converter PV System........................................................................................ 11

1.4 Thesis Outline................................................................................................................. 14

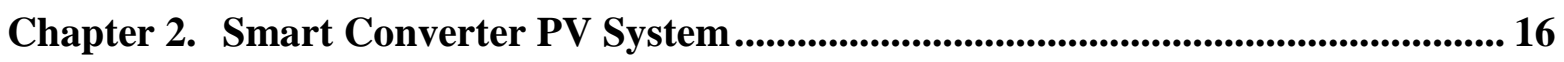

2.1 Introduction....................................................................................................... 16

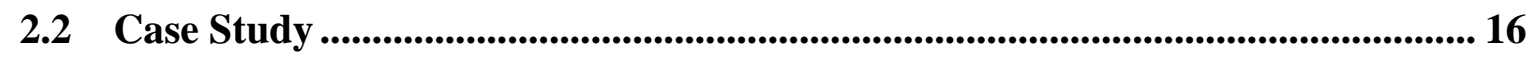

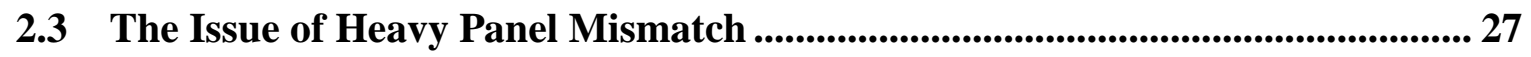

2.4 The Issue of 2nd stage Central MPPT Converter............................................. 31

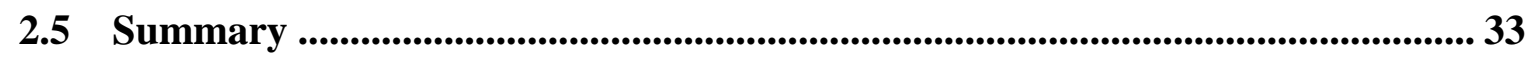

Chapter 3. Proposed Multi-Phase Smart Converter for PV System ............................... 34

3.1 The Concept of Multi-Phase Smart Converter ....................................................... 34

3.2 Implementation of Proposed Multi-Phase Smart Converter................................ 41

3.3 Simulation Verification of Multi-Phase Smart Converter ................................... 43

3.4 Experimental Verification of Multi-Phase Smart Converter .............................. 58

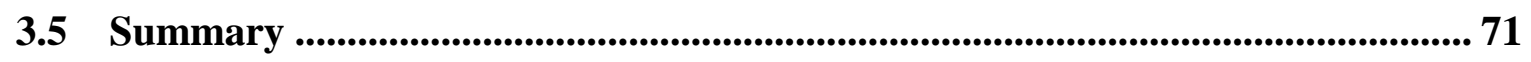

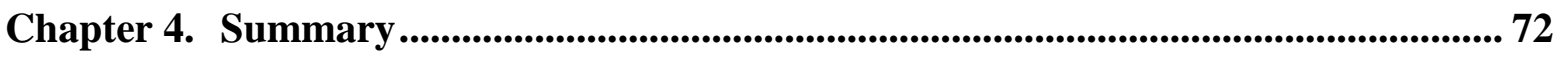

References............................................................................................................................................ 73 
Appendix

Main function for MCU controller ..................................................................................... 75 


\section{List of Figures}

Figure 1.1 DC nano-grid structure in future home ................................................ 1

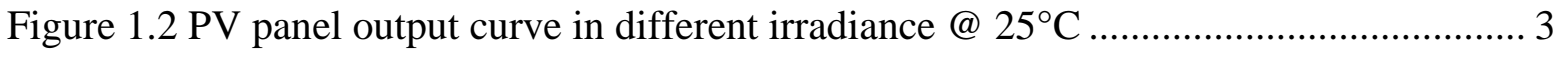

Figure 1.3 PV panel output curve in different temperature @ $1 \mathrm{~kW} / \mathrm{m}^{2}$ irradiance ................. 3

Figure 1.4 Central level MPPT PV system .............................................................. 5

Figure 1.5 String level MPPT PV system................................................................ 7

Figure 1.6 Differential power converter PV system ...................................................... 8

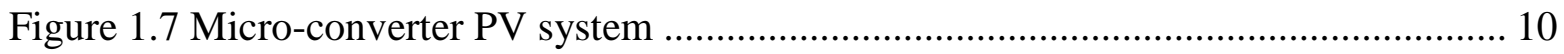

Figure 1.8 Smart Converter PV system ............................................................... 10

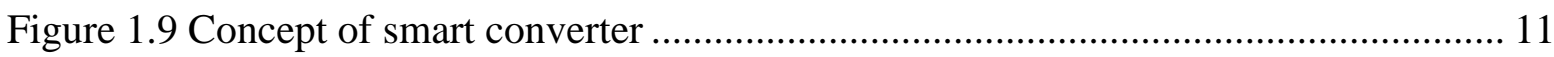

Figure 1.10 Buck type smart converter.................................................................... 12

Figure 1.11 Buck-boost type smart converter............................................................... 13

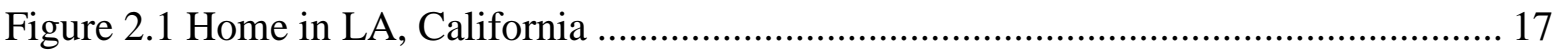

Figure 2.2 Real measurement data for solar irradiance .............................................. 17

Figure 2.3 Sun position for LA, California................................................................ 18

Figure 2.4 Solar irradiance received by panel ....................................................... 18

Figure 2.5 Solar irradiance distribution on the PV array ............................................ 20

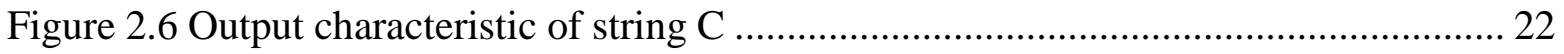

Figure 2.7 Output characteristics of each string and PV array ...................................... 23

Figure 2.8 Smart converter PV system .................................................................... 25

Figure 2.9 Output characteristic of string $\mathrm{C}$ with smart converter ................................. 26

Figure 2.10 Output characteristics of each string and PV array with smart converter ......... 26

Figure 2.11 Case study of heavy mismatch condition ................................................ 28 
Figure 2.12 Alternative system configuration

Figure 2.13 Case study of alternative system configuration in heavy mismatch condition .. 30

Figure 2.14 The $2^{\text {nd }}$ stage converter in smart converter PV system ............................... 31

Figure 2.15 Optimized system configuration for smart converter PV system .................... 32

Figure 3.1 Traditional single phase smart converter ................................................. 34

Figure 3.2 Proposed Two-phase smart converter with single controller .......................... 35

Figure 3.3 Optimized two-phase smart converter with single controller .......................... 35

Figure 3.4 Proposed multi-phase smart converter with single controller .......................... 36

Figure 3.5 Extended architecture for proposed multi-phase smart converter..................... 38

Figure 3.6 Unified output MPPT control structure for subpanel converter......................... 39

Figure 3.7 Proposed multi-phase subpanel converter with single controller...................... 40

Figure 3.8 Power stage of four-phase buck converter. ........................................... 41

Figure 3.9 Time sharing of MPPT controller ........................................................ 42

Figure 3.10 Flowchart diagram of MPPT algorithm during tracking panel 1 period........... 42

Figure 3.11 Simulation schematic of smart converter based on switching model .............. 43

Figure 3.12 Simulation schematic of smart converter based on average model ................ 44

Figure 3.13 Simulation of smart converter with switching and average model .................. 46

Figure 3.14 Simulation of four-phase buck converter ............................................. 48

Figure 3.15 Simulation results of four-phase buck converter..................................... 50

Figure 3.16 Data of variant solar irradiance ….......................................................... 52

Figure 3.17 Simulation with variant solar irradiance .............................................. 52

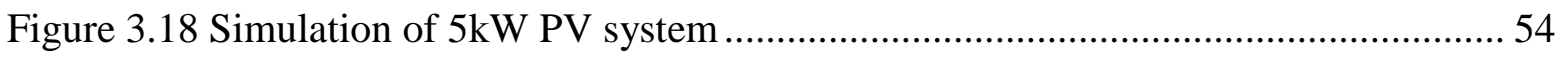

Figure 3.19 Solar irradiance distribution for extended architecture ................................ 56 
Figure 3.20 Output power of each panel in extended architecture

Figure 3.21 Impact of output current limit on P-V curve for PV array ............................. 58

Figure 3.22 The output voltage and current of buck converter in non-shading case............ 59

Figure 3.23 Normal operation condition of single phase buck converter......................... 61

Figure 3.24 Simplified schematic of hardware implementation.................................... 64

Figure 3.25 Experiment hardware of four-phase buck converter .................................. 65

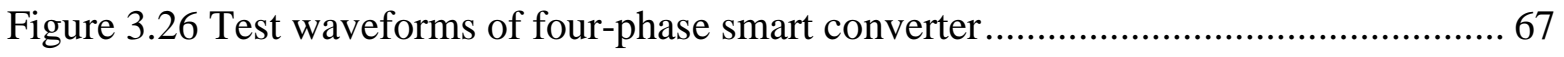

Figure 3.27 Efficiency curve for non-shading condition ............................................ 69

Figure 3.28 Efficiency curve for partial shading condition ........................................ 71 


\section{List of Tables}

Table 2.1 PV panel datasheet of STP170S-24/Ab-1 ................................................ 20

Table 3.1 Simulation parameters for four-phase buck converter ................................... 48

Table 3.2 Comparison between traditional and proposed smart converter. ........................ 55

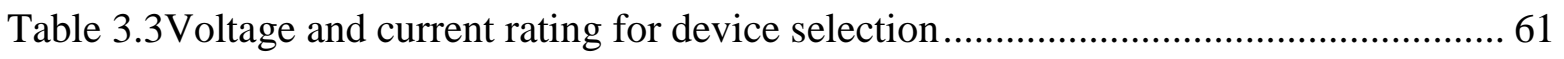

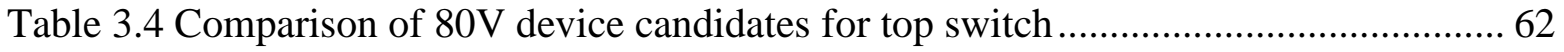

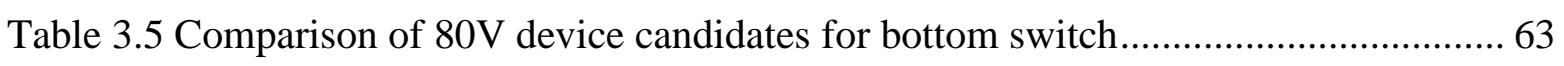

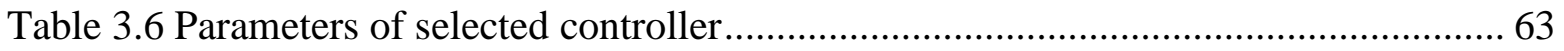




\section{Chapter 1. Introduction}

\subsection{Background}

As the global demand for energy has vastly increased over the last few decades, energy and the environment have become serious concerns in the world today [1]. Renewable energy sources (RES) have drawn more and more attention in recent years, which have given rise to the fast development of Electronic Power Distribution Systems (EPDS), such as micro-grid, utilizing multiple RES as supplementary energy source to utility grid [2]. DC nano-grid is one kind of micro-grid EPDS at low power level (10-100kW).

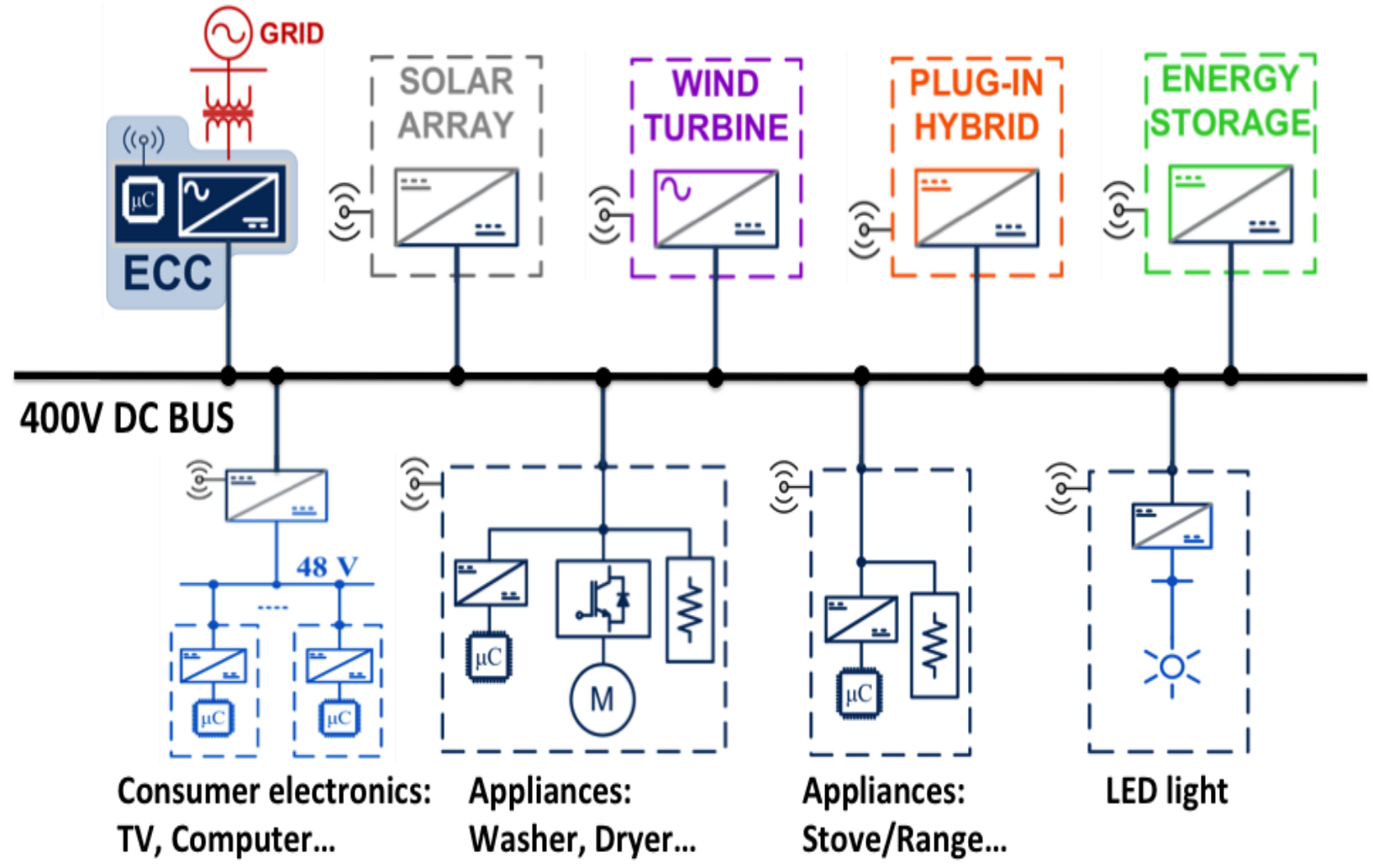

Figure 1.1 DC nano-grid structure in future home 
Fig.1.1 shows a typical DC nano-grid system structure for future home. The 380V DC bus in the DC nano-grid provides an interface for all RES while the energy control center (ECC) takes charge of interfacing DC bus with utility AC grid. In [3], it is addressed that a DC nano-grid is a promising EPDS since it features more efficient way to deliver energy, fast control and protection capability comparing to AC nano-grid system.

Solar or photovoltaic (PV) source, a suitable RES for DC nano-grid due to its dc output characteristics, is one of the significant players in the world's energy portfolio and will become the biggest contribution to the energy consumption among all renewable energy candidates by year 2040[4]. Solar power system installations have rapidly increased thanks to the concerns about the global climate change and energy supplies. With the encouragement of governments' incentive programs, PV systems in recent years have begun to expand into residential areas.

However, PV panel output is of strong nonlinearity, and panel output characteristic can be impacted by solar irradiance and temperature. Taking a typical commercial PV panel as an example, the panel output characteristics under different irradiances at $25^{\circ} \mathrm{C}$ are presented in Fig. 1.2 where it clearly shows output current decreases with less sunlight but panel output voltage doesn't change much with varying sunlight. Maximum power points can be found on each curve as the solid dots in Fig.1.2. The sunlight mainly has influence on the panel output current but has very little effect on panel output voltage. 

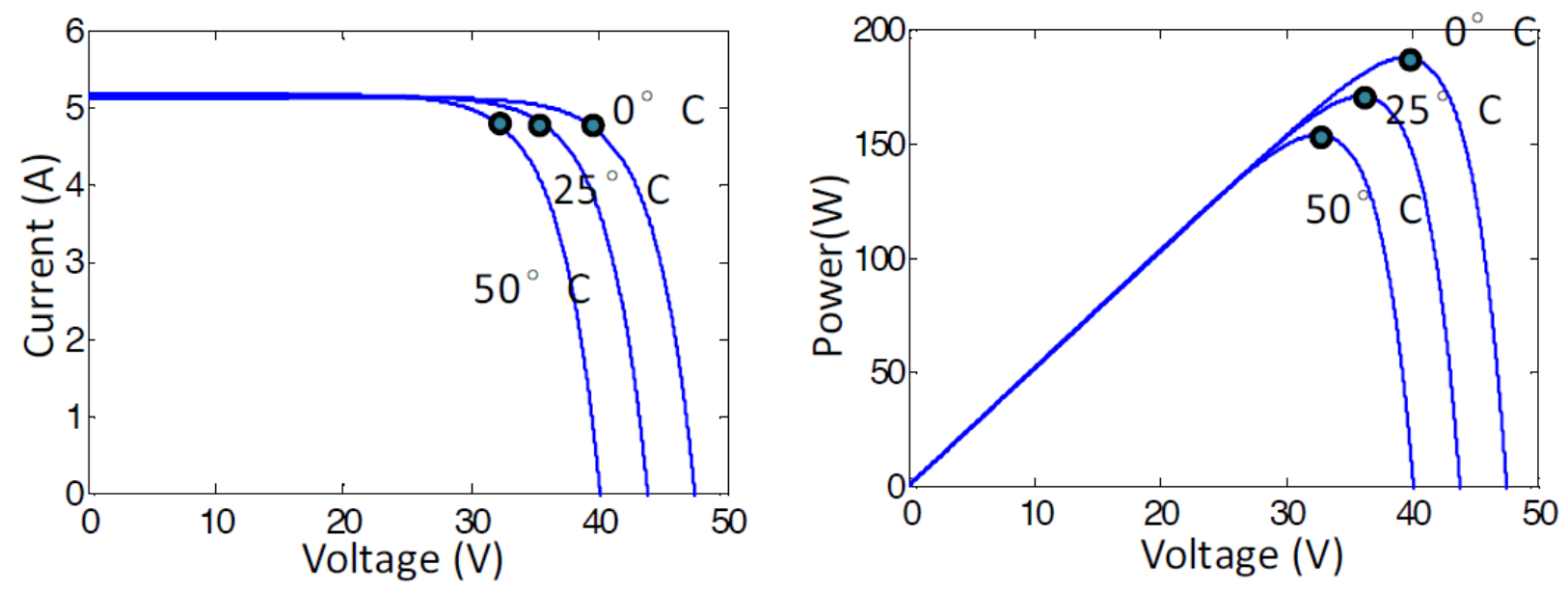

Figure 1.2 PV panel output curve in different irradiance @ $25^{\circ} \mathrm{C}$

Fig.1.3 shows panel output with different temperature with constant $1 \mathrm{~kW} / \mathrm{m}^{2}$ sunlight. On the contrary to the previous case, the temperature has much more effect on panel output voltage than current. That is the panel tends to output higher voltage with lower temperature.
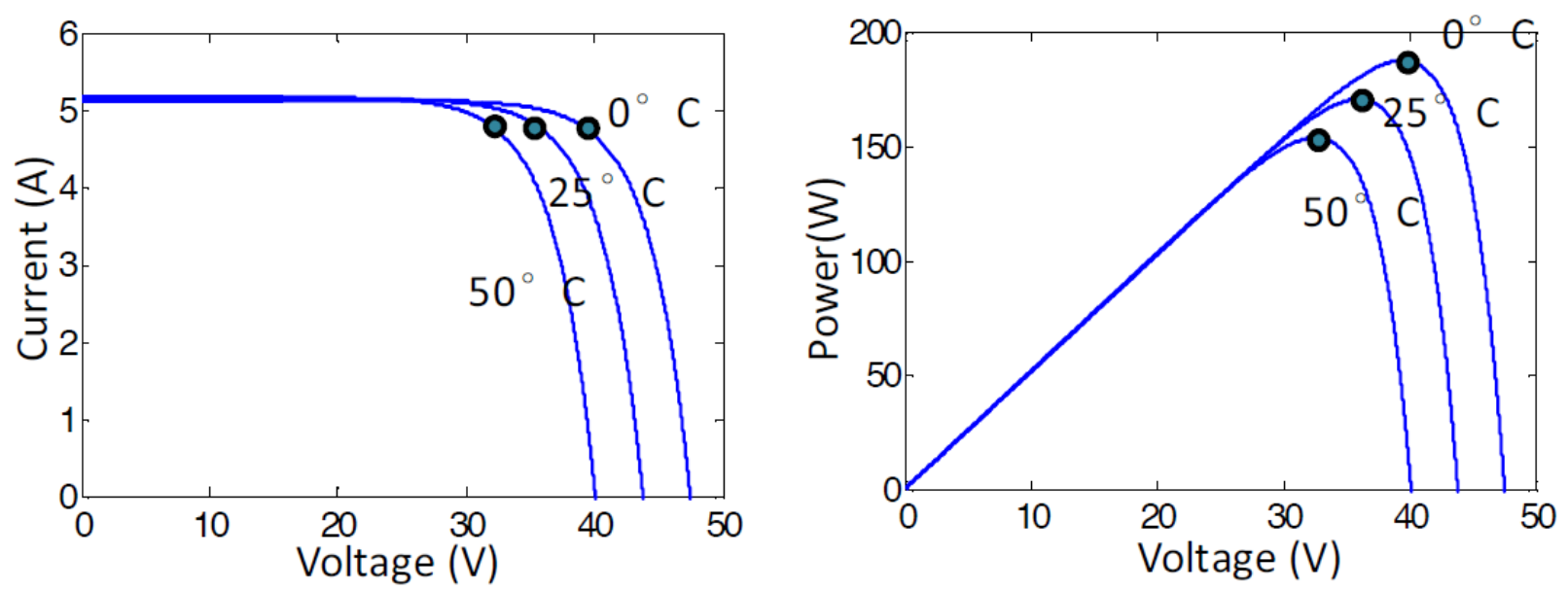

Figure 1.3 PV panel output curve in different temperature @ $1 \mathrm{~kW} / \mathrm{m}^{2}$ irradiance

From the above demonstration, we can see that both irradiance and temperature will influence PV panel output characteristics. However, given a particular location, the temperature change will be relatively small within a predictable range. The solar irradiance could change very dramatically and thus has larger effect on panel characteristic variation. 
The strong nonlinearity of PV panel output can reduce the energy harvesting efficiency of PV system with non-uniform irradiance. For most residential PV systems which are at medium power level, e.g. $1 \mathrm{~kW} \sim 10 \mathrm{~kW}$, the system consists of 10 50 PV panels. Even if a few PV panels are shaded, the overall PV system output can be much less than the total available power. Therefore, different system structures and MPPT strategies for residential PV system should be analyzed. 


\subsection{Review of MPPT Strategy for PV System}

Generally, there are three architectures for the residential PV system based on the MPPT target level: (1) Central level MPPT PV system; (2) String level MPPT PV system; (3) Panel level MPPT PV system [5].

\section{(1) Central level MPPT PV system}

Fig.1.4 shows the configuration of central level MPPT PV system. In centralized system, multiple PV panels are connected in series as PV string to reach certain voltage level. Parallelconnected strings are then wired into a centralized PV converter interfacing PV array with DC bus.

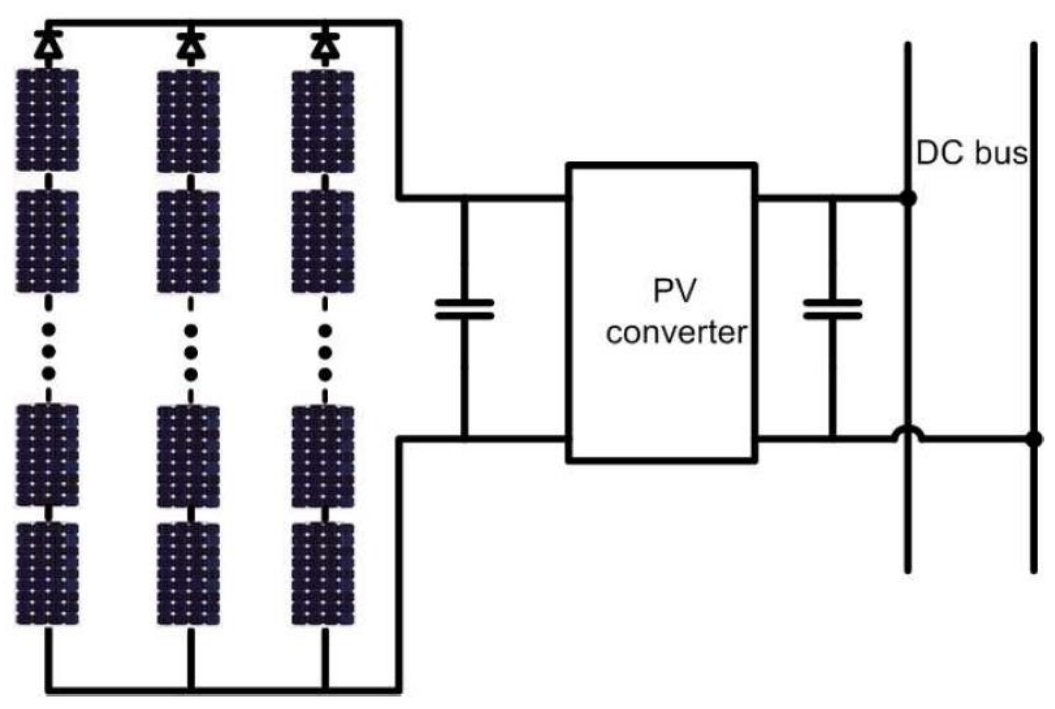

Figure 1.4 Central level MPPT PV system

The main advantage for centralized system is low cost because only one central converter is used. However, the main drawback is low energy harvesting efficiency under non-uniform solar irradiance condition which can be caused by shadows, dirtiness, manufacturing tolerances, thermal gradients, aging, different module orientations and tilts, etc. The mismatch cases impact 
the performance of the PV system on two aspects. Firstly, mismatch cause multiple peak power points on the power-voltage curve of PV array. Therefore, MPPT algorithms can fail to track the global peak power point. Secondly, even if the global peak power point can be tracked by some complicated MPPT algorithms, the tracked peak power is still lower than the sum of the available maximum powers of all the panels in PV array. Because the mismatch make each panel have different maximum power point (MPP), but panels in one string are forced to drive the same current, which means it is impossible to make all the panels output peak power. Detail analysis will follow in the next chapter.

From a safety point of view, high DC voltages are present in centralized PV system and pose risks of electrocution to installers, maintenance personnel and firefighters. In electrical systems, safety extra-low voltage (SELV) indicates a safe voltage below $120 \mathrm{~V}$. Under these conditions there is a low risk of electrocution. Given that PV panels typically have an output voltage of 30$60 \mathrm{~V}$, connecting several of these modules serially in a string creates a high voltage which can be dangerous to installers and maintenance personnel. Actually the string voltage can reach $600 \mathrm{~V}$ in residential systems or up to $1000 \mathrm{~V}$ in commercial systems, and this high dc voltage, which can

be dangerous to firefighter who need to work on or near the system, cannot be reduced even if disconnecting PV systems from DC bus because PV panels are always energized when exposed to sunlight.

\section{(2) String level MPPT PV system}

Fig.1.5 shows the configuration of string level MPPT PV system. The difference with centralized PV system is it splits the second stage converter into individual converters for each PV panel string. Each individual string converter does MPPT for each string leaving no 
interaction between different strings. Under mismatch condition, string PV system has higher energy harvest than centralized PV system. However, for each string, multiple peak power point issue mentioned above still exist. Besides, the safety risk caused by high dc voltage also exist even if the string converter is shut down.

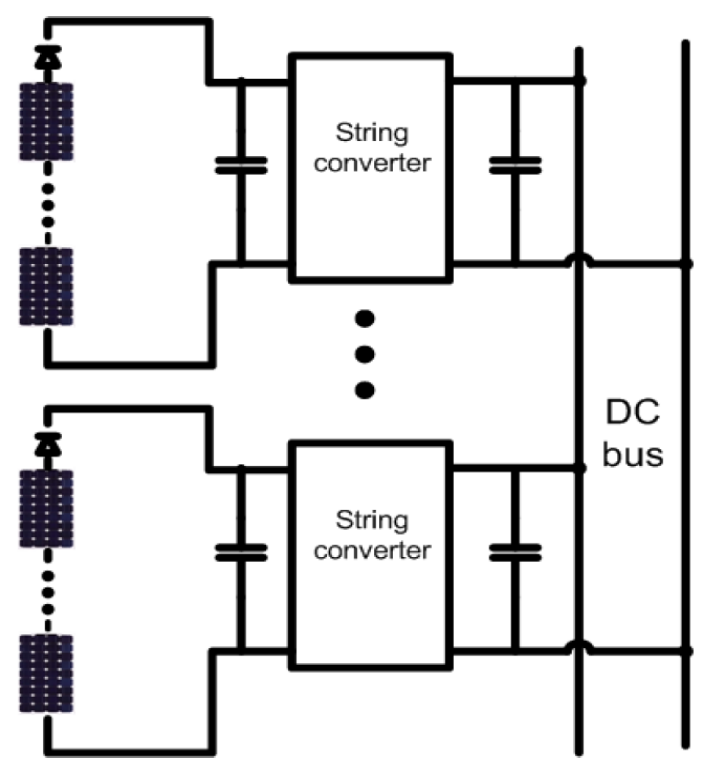

Figure 1.5 String level MPPT PV system

\section{(3) Panel level MPPT PV system}

Basically there are three architectures for panel level MPPT PV system: (a) Differential power converter PV system; (b) Micro-converter PV system; (c) Smart converter PV system.

(a) Differential power converter PV system

Figure 1.6 shows the configuration of differential power converter PV system. The differential power processing approach has been proposed to overcome the challenge of mismatched MPP current in series PV strings while facilitating efficient power processing and system scaling. Local MPPs are achieved with small differential power converters that provide the difference in MPP current of two adjacent PV panels. Other research that has employed 
similar approaches includes a generation control circuit [6], bypass converters [7], returned energy current converters [8] and switched capacitor DC-DC Converters [9].

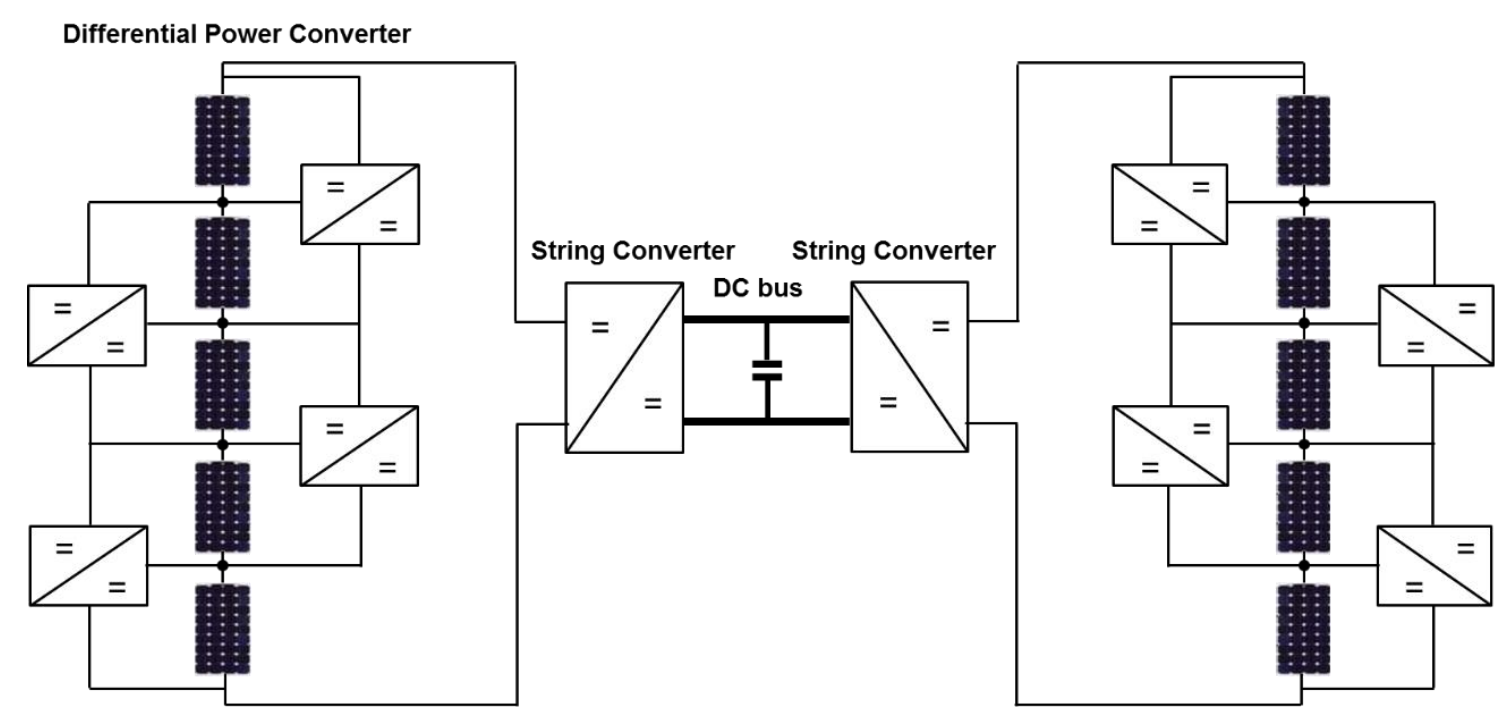

Figure 1.6 Differential power converter PV system

The main advantages of differential power processing are the ability to operate converters only when necessary, to process only a fraction of the total energy produced, and to employ converters with modest ratings based only on expected PV mismatch. When the MPP currents of series PV elements are matched, produced energy can be sent directly to a string converter. Differential converters do not need to process any power. When MPP currents are mismatched, differential converters act as controllable current sources with limited ratings to support only the difference in the MPP currents of two adjacent PV elements. Differential converters can be implemented using a variety of dc-dc converter topologies. Many follow from battery equalization circuits [10] and have similar objectives.

However, the drawback of differential power converter PV system is obvious. Firstly, besides differential power converter for each PV panel, each string must be equipped with a string converter to track string level MPP, which means it is not a cost-effective solution for residential PV system. Secondly, even if the differential power converter for each panel only 
processes partial power, the string converter in this PV system still need to handle full power of all panels, which means high efficiency, is required for the string converter. Thirdly, the control algorithm for differential power converter is complicated. To achieve MPPT, all the differential power converter must cooperate with each other. For long string PV system, the MPPT procedure for differential power processing solution is very time consuming. Finally, the safety risk caused by high de voltage still exists even if the string converter is shut down.

(b) Micro-converter PV system

Figure 1.7 shows the configuration of micro-converter PV system [11]. Micro-converter with MPPT function interfaces each PV panel (20V 50V) directly with high voltage DC bus, e.g. 250V 400V DC bus, and then all the available energy in the PV array can be harvested. Nevertheless, the drawbacks of micro-converter are mainly about high cost and low efficiency due to the high voltage ratio.

From a safety point of view, micro-converter PV system has no high dc voltage except the high voltage DC bus. If the micro-converter is shut down, PV panels cannot produce hazardous voltages to installers, maintenance personnel and firefighters. 


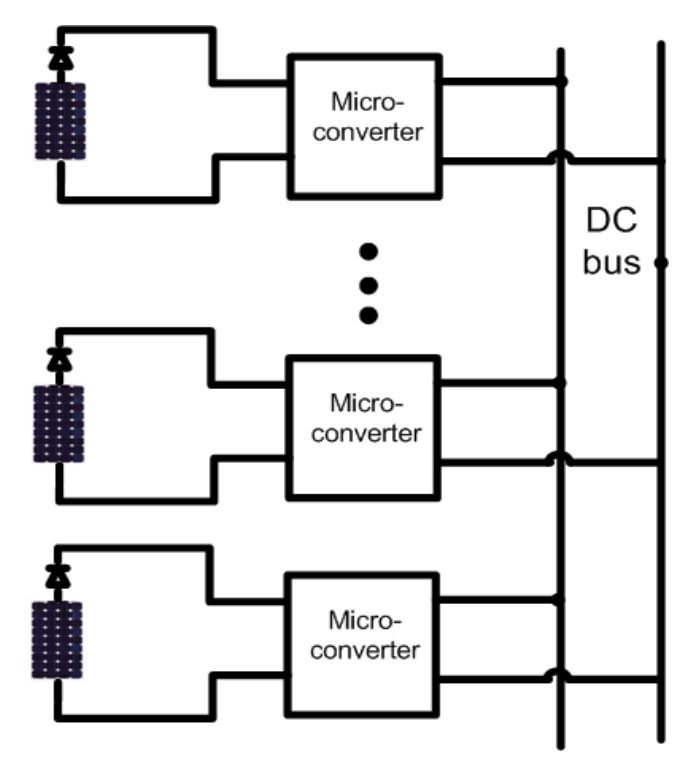

Figure 1.7 Micro-converter PV system

(c) Smart converter PV system

Figure 1.8 shows the configuration of smart converter PV system [12]. PV panel is decoupled from the others by smart converter, then its output curve is mapped to a wide MPPT range shown in Fig.1.9.

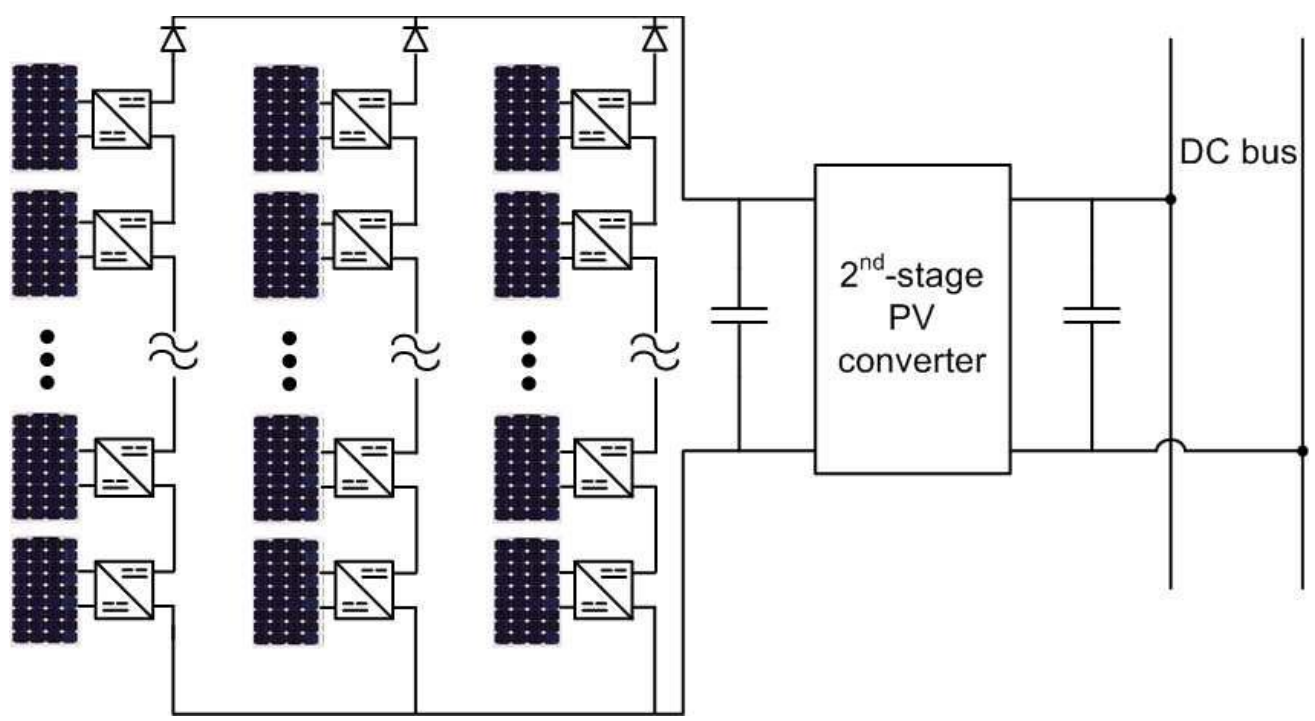

Figure 1.8 Smart Converter PV system

Normally, the converter performs MPPT which continuously forces the operating point of PV panel at MPP. The output then behaves as a constant power source which is hyperbolic curve. 
Essentially, the MPPT region is extended from single panel MPP into a much wider range via smart converter. The width of this MPPT region is determined by the converter output current limit and voltage limit. Therefore, the advantage is obvious comparing to conventional centralized and string PV system. If the MPPT regions of smart converters connected in one string share certain current overlapping, it is then guaranteed that all the panels in this string can generate maximum power.

As well as the micro-converter system, the smart converter PV system can reduce the safety risk caused by high dc voltage. If the PV system is disconnected from DC bus, the string voltage in PV system can be very low to prevent the electrocution because each panel is equipped with a smart converter and the smart converter will output very low voltage under this condition.

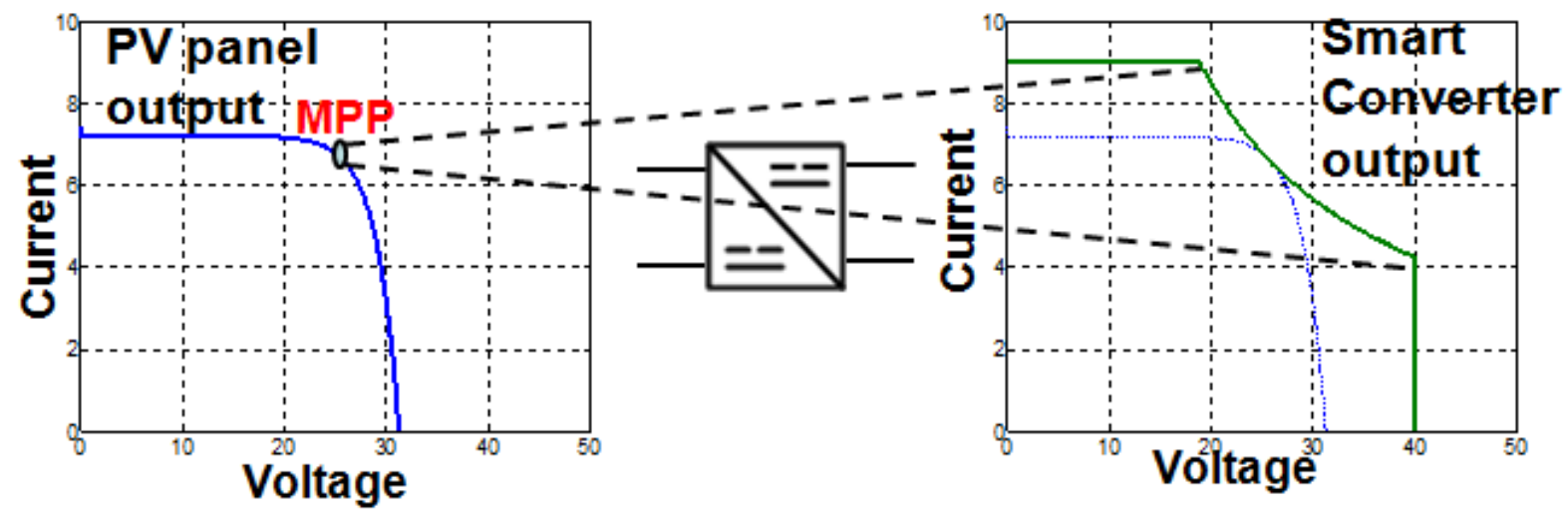

Figure 1.9 Concept of smart converter

Comparing to micro-converter, smart converters are nearly of unity voltage gain and allow both series and parallel connection, thus enabling more flexible system configuration. The drawbacks for smart converter PV system are low energy harvesting efficiency under heavy mismatch and the necessity for $2^{\text {nd }}$ stage converter, which will follow in the next chapter.

\subsection{Smart Converter PV System}


Several different DC-DC converter topologies are available for use with individual PV panels, each with different strengths and operating uses. The simplest DC-DC converter is buck converter, which uses a single converter stage to reduce the output voltage of a PV panel. A slightly more advanced DC-DC converter is the buck-boost converter, which uses both buck and boost stages to allow the converter to either increase or decrease the output voltage of a PV panel. In either case, the PV panel output voltage is MPP tracked by the control algorithm in the device.

In a system using buck converters as shown in fig. 1.10(a), the output voltage from a shaded panel is decreased, and the output current is increased to match the operating current of the unshaded modules in series with it as shown in fig. 1.10(b). Because the current is boosted, there is no mismatch in current between the series-connected modules. There is no longer any need for the shaded module's bypass diodes to begin conducting. Therefore, the shaded panel equipped with the buck converter can produce power at a reduced level (due to the diffuse component of irradiance that is still present even under shaded conditions) rather than no power at all.

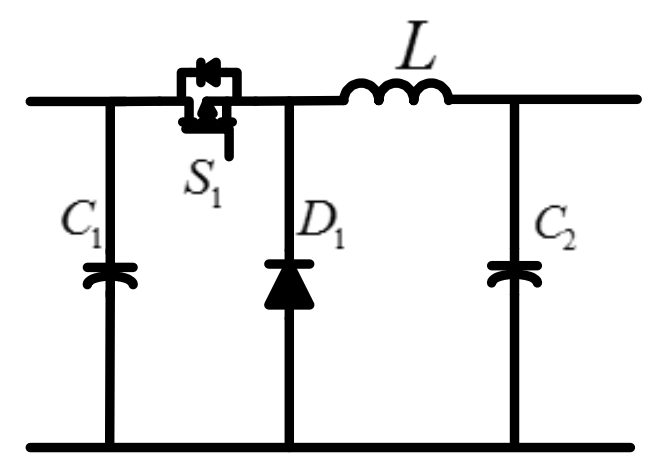

(a)

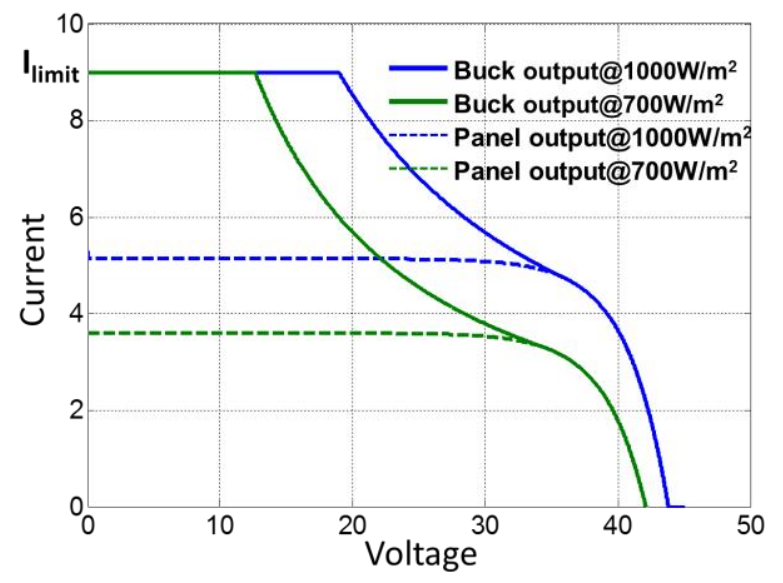

(b)

Figure 1.10 Buck type smart converter

In a system using buck-boost converters as shown in fig. 1.11(a), the converter uses buck and boost stages to allow the converter to generate an output voltage both above and below the input 
MPPT voltage, this is very flexible to design a system. Especially when parallel strings are of different lengths, buck-boost converters on the shorter string will increase the operating voltage of the string to match the other longer strings. Fig. 11(b) shows the input I-V curve (dash line) and output I-V curve (solid line) of the converter: it consists of a constant power curve and current limit and voltage limit. The common MPPT region of the buck-boost converter mainly depends on its limit rating. Basically higher limit rating can extend common MPPT region to mitigate the partial shading effect, but also reduce the conversion efficiency and increase the cost. Detail analysis about the impact of limit rating on MPPT will be given in the chapter 3 .

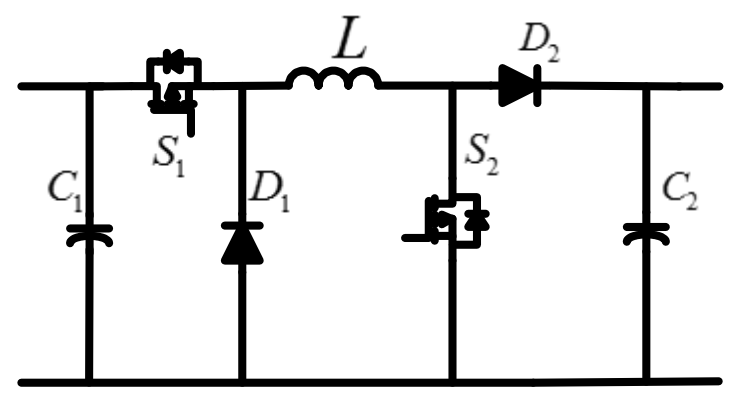

(a)

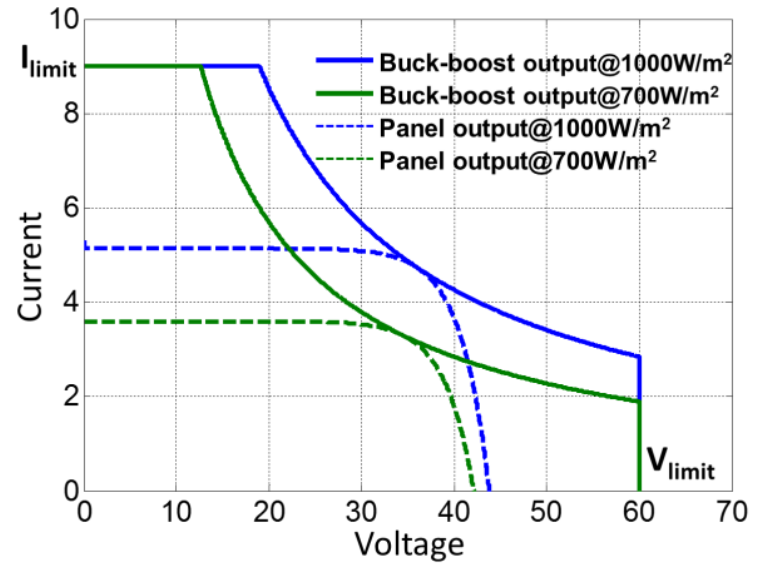

(b)

Figure 1.11 Buck-boost type smart converter

Compared to buck converter, the advantage of a buck-boost converter is its wider output maximum power range and better ability to handle greater amount of system mismatch cases. However, a buck-boost smart converter includes two conversion stages, so the increasing flexibility comes at the cost of efficiency reduction, control complexity and possible size and cost increases relative to a buck converter.

In this work, buck converter is selected to demonstrate the merit of smart converter PV system due to its low cost and high efficiency. However, further analysis on smart converter PV 
system shows that under heavy shading condition, it is not always possible to deliver maximum power from all the panels. Meanwhile, the $2^{\text {nd }}$ stage PV converter, which increases cost and decreases system efficiency, is still required in the smart converter PV system to enlarge the MPPT region and connect PV array to DC bus. Besides, panel level MPPT can improve energy production but also increase the initial equipment cost. This thesis is aimed at proposing a costeffective and energy-efficient solution for residential smart converter PV system, which can mitigate heavy shading issue, save the $2^{\text {nd }}$ stage PV converter and simplify the control solution for panel level smart converter to reduce the cost.

\subsection{Thesis Outline}

The content of this thesis contains the following aspects.

In Chapter 1, the conventional and up-to-date PV system structure and MPPT strategies are introduced and reviewed. The pros and cons of different system structure and MPPT strategies are addressed and compared. It is briefly pointed out that smart converter PV system can mitigate the mismatch issue and reduce safety risk of electrocution.

In Chapter 2, the detailed analysis of smart converter PV system is presented. The comparison of centralized system, string system and smart converter PV system is then conducted based on the MATLAB model. The advantage and drawback of smart converter system is clearly illustrated. Further analysis of smart converter system presents the alternative system architecture which can deal with heavy mismatch condition and save the $2^{\text {nd }}$ stage central PV converter. 
In Chapter 3, multi-phase smart converter are proposed and analyzed based on the alternative system architecture. The concept and control strategy for the proposed solution, which can largely reduce MPPT controllers, voltage and current sensors for smart converter PV system, is discussed in detail. Simulation results for a $5 \mathrm{~kW}$ PV system based on proposed multi-phase smart converter shows the effectiveness and experiment results are presented for verification.

In Chapter 4, this thesis ends with some concluding remarks. 


\section{Chapter 2. Smart Converter PV System}

\subsection{Introduction}

In residential PV system, partial shading occurs frequently when part of a panel or panels are shaded by the building itself, light posts, chimneys, trees, and other light-blocking obstacles. Partial shading causes different levels of solar irradiance on the panels. Besides, different orientation of panels can also cause non-uniform irradiance on the panels. The non-uniform irradiance on the panels, which called panel mismatch, can lead to the issue that large amount of available power fail to be delivered in the traditional centralized PV system.

To solve this issue, distributed panel level maximum power point tracking method is adopted in the smart converter PV system which is introduced in the previous chapter and is shown in Fig. 1.8. The smart converter (SC) are equipped to each panel to form a PV array and a $2^{\text {nd }}$ stage central converter interfaces the PV array with high voltage DC bus (360-400V).

To demonstrate how the smart converter system can enhance the MPPT performance, a case study is given in the following part. After that, power management issue exists in the smart converter PV system is analyzed and addressed.

\subsection{Case Study}

\section{A. Case study of centralized PV system}

A typical case is studied in this section. Fig. 2.1 shows a rooftop PV system in LA, California. The PV system consists of three PV strings called string A, string B and string C 
respectively with ten $170 \mathrm{~W}$ mono-crystalline PV panels in each string, forming a typical $5 \mathrm{~kW}$ residential PV system.

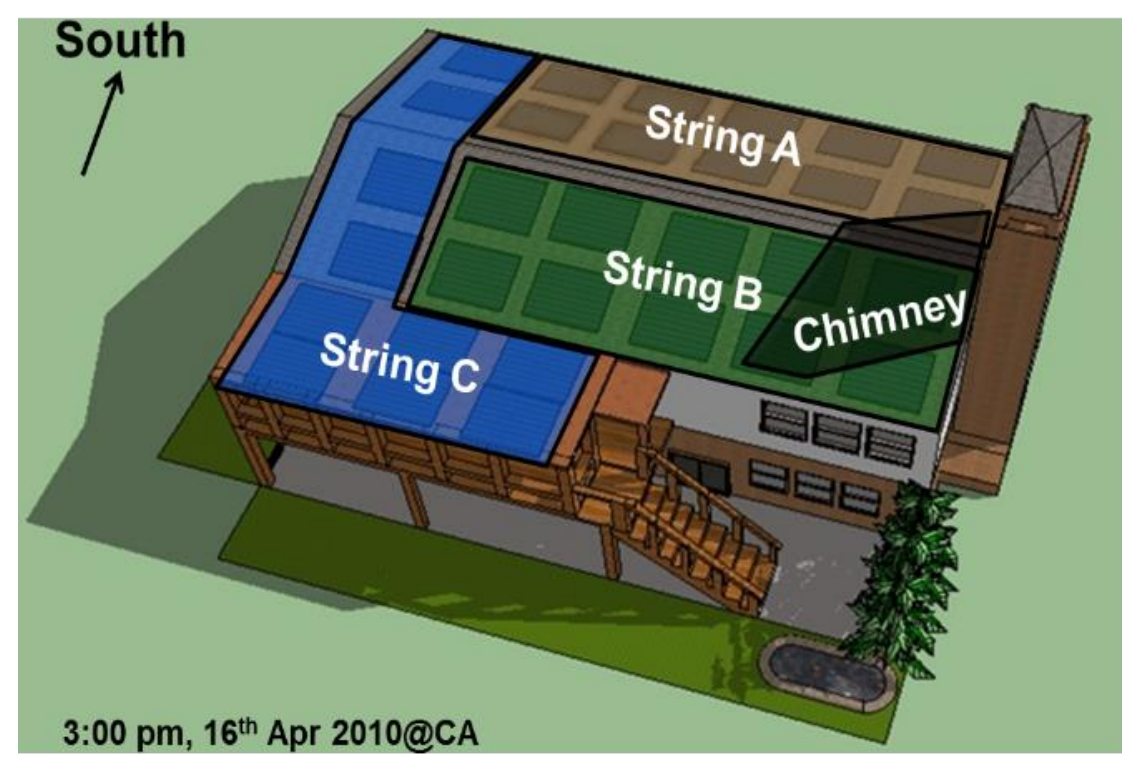

Figure 2.1 Home in LA, California

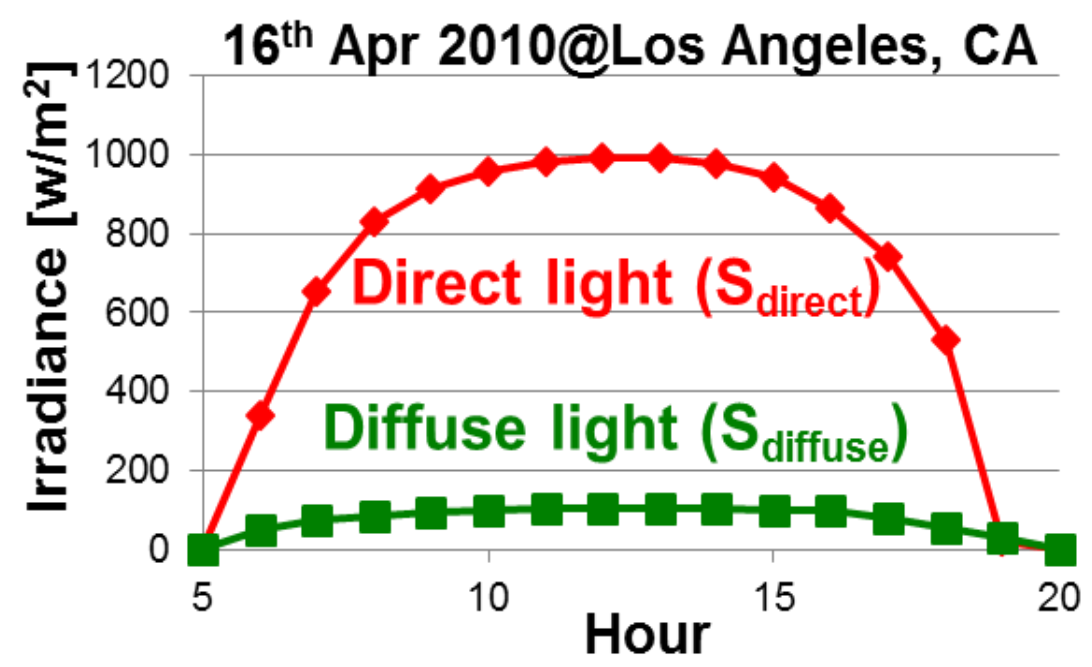

Figure 2.2 Real measurement data for solar irradiance

In order to quantify the analysis, detail information of solar irradiance is needed to calculate the irradiance on each panel. Fig. 2.2 gives the real measurement solar irradiance during the daytime, which includes direct sunlight and diffuse sunlight. Fig. 2.3 gives the precise position of 
sun. Based on these information, solar irradiance received by a panel can be calculated according to the method shown in Fig 2.4.

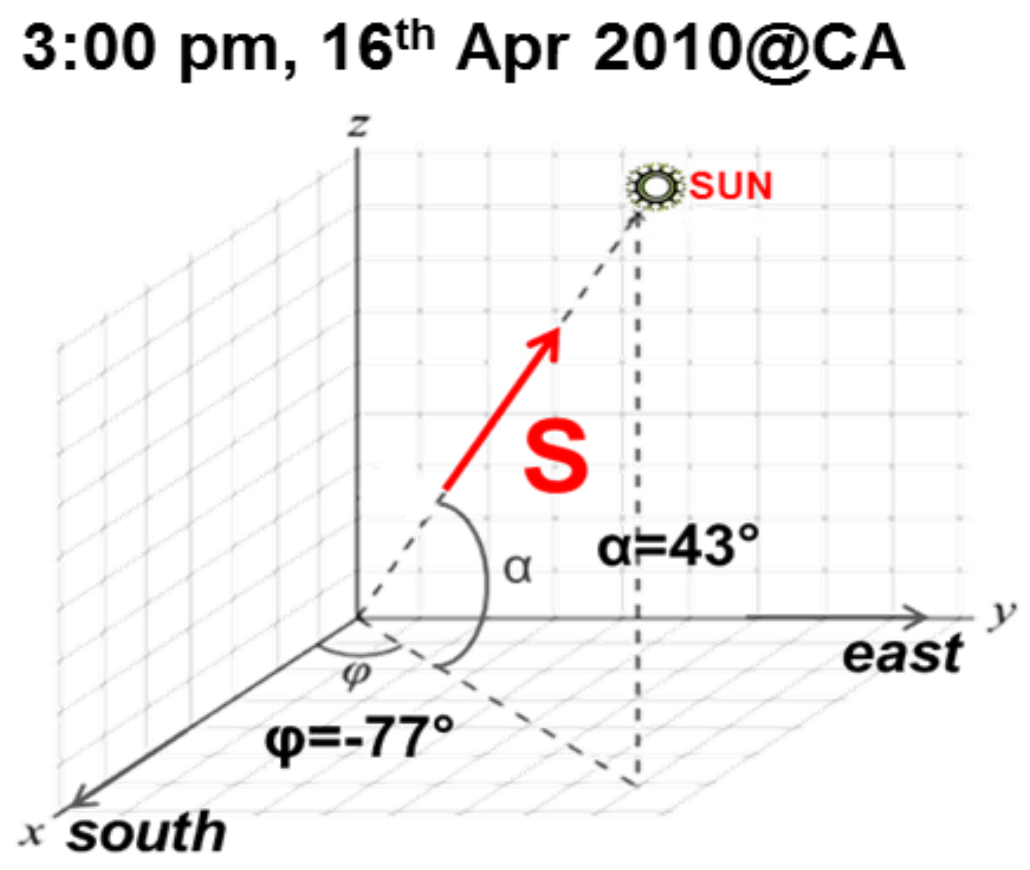

Figure 2.3 Sun position for LA, California

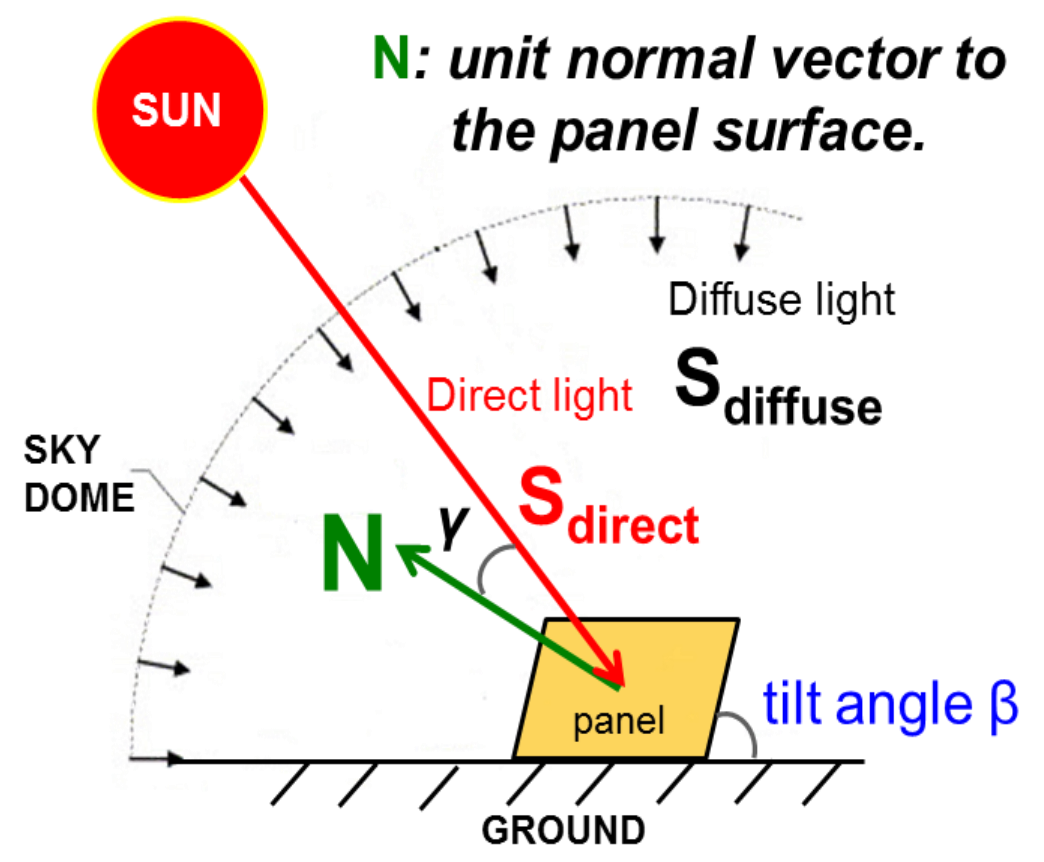

Figure 2.4 Solar irradiance received by panel 
As shown in Fig 2.4, the panel receives two major types of solar irradiance, which are direct sunlight and diffuse sunlight. Both two components are impacted by the panel tilt angle. If the panel is completely shaded, then the irradiance on the panel is given as follows.

$$
S_{\text {panel }}=S_{\text {diffuse }} \cdot \frac{1+\cos \beta}{2}
$$

If the panel is completely non-shaded, then the irradiance on the panel is given as follows.

$$
S_{\text {panel }}=S_{\text {direct }} \cdot \cos \gamma+S_{\text {diffuse }} \cdot \frac{1+\cos \beta}{2}
$$

If the panel is partially shaded, assuming that the direct light component declines linearly according to the shading area, then the irradiance on the panel is given as follows.

$$
S_{\text {panel }}=S_{\text {direct }} \cdot \cos \gamma \cdot(1-k)+S_{\text {diffuse }} \cdot \frac{1+\cos \beta}{2}
$$

The parameters in the above equations are defined as follows.

$\mathrm{S}_{\text {panel }}:$ solar irradiance received by panel;

$S_{\text {direct }}$ : direct sunlight from the sun;

$\mathrm{S}_{\text {diffuse }}$ : diffuse sunlight from the sun;

$\gamma:$ the angle between direct sunlight and unit normal vector to the panel surface;

$\beta:$ the tilt angle of the panel suface;

$\mathrm{k}$ : the percentage of shading area in a panel;

Using the above calculation method, the solar irradiance distribution on the PV array can be derived and shown in Fig. 2.5. 


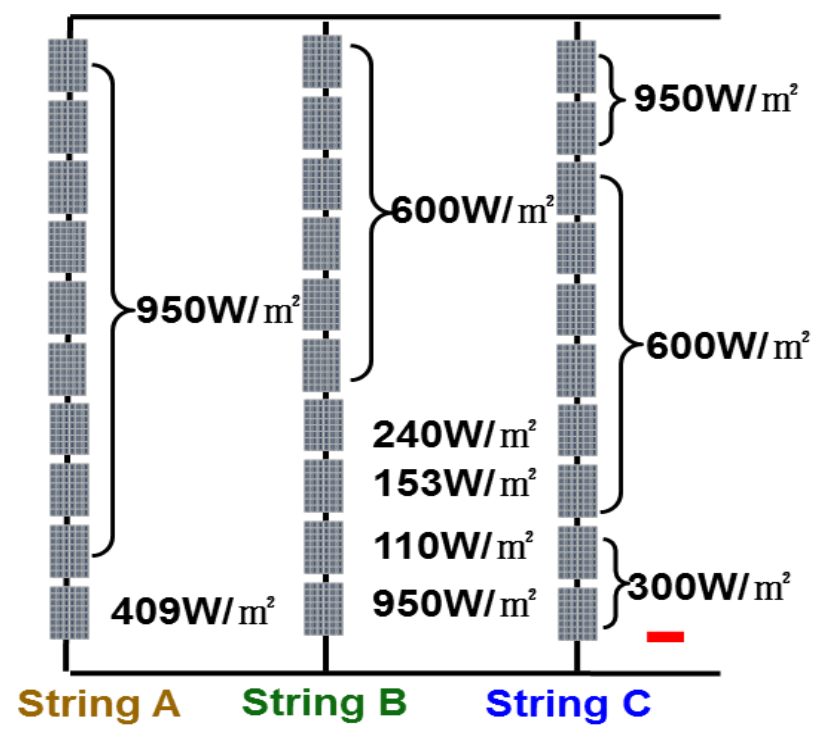

Figure 2.5 Solar irradiance distribution on the PV array

In order to analyze the energy production, a MATLAB electrical model for the PV panel is built based on the parameters of the PV panel which are given by the manufacturer. The datasheet of PV panel is given in the following table.

Table 2.1 PV panel datasheet of STP170S-24/Ab-1

\begin{tabular}{|c|c|}
\hline Open-circuit voltage $\left(\mathrm{V}_{\mathrm{oc}}\right)$ & $43.8 \mathrm{~V}$ \\
\hline Optimum operating voltage $\left(\mathrm{V}_{\mathrm{mp}}\right)$ & $35.2 \mathrm{~V}$ \\
\hline Short-circuit current $\left(\mathrm{I}_{\mathrm{sc}}\right)$ & $5.14 \mathrm{~A}$ \\
\hline Optimum operating current $\left(\mathrm{I}_{\mathrm{mp}}\right)$ & $4.83 \mathrm{~A}$ \\
\hline Maximum power at STC $\left(\mathrm{P}_{\mathrm{max}}\right)$ & $170 \mathrm{~W}$ \\
\hline STC: lrradiance $1000 \mathrm{~W} / \mathrm{m} 2$, Module temperature $25^{\circ} \mathrm{C}, \mathrm{AM}=1.5$ & \\
\hline Operating temperature range & $-40^{\circ} \mathrm{C}$ to $+85^{\circ} \mathrm{C}$ \\
\hline
\end{tabular}


The PV panel output can then be derived based on the following simplified model.

$$
I_{p v}=I_{s c}\left[1-c_{1}\left(e^{\frac{V+D V}{c_{2} V_{o c}}}-1\right)\right]+D I
$$

The terms in the above equation are defined as follows.

$$
\left\{\begin{aligned}
c_{1}= & \left(1-\frac{I_{m p}}{I_{s c}}\right) e^{\frac{V_{m p}}{c_{2} V_{o c}}} \\
c_{2}= & \frac{\frac{V_{m p}}{V_{o c}}-1}{\ln \left(1-\frac{I_{m p}}{I_{s c}}\right)} \\
D I= & \alpha \cdot \frac{R}{R_{r e f}} \cdot D T+\left(\frac{R}{R_{r e f}}-1\right) \cdot I_{s c} \\
D V= & \delta \cdot D T-R_{s} \cdot D I \\
D I= & T_{c}-T_{r e f}
\end{aligned}\right.
$$

The parameters in the above equations are defined below.

$\alpha$ : Open-circuit voltage temperature coefficient;

$\delta:$ Short-circuit current temperature coefficient;

R: actual irradiance;

$\mathrm{R}_{\text {ref }}$ : Reference irradiance;

$\mathrm{T}_{\mathrm{c}}:$ actual temperature;

$\mathrm{T}_{\text {ref }}:$ Reference temperature;

Based on the above PV panel model and the solar irradiance distribution on the PV array, the output characteristic of each panel can be derived and plotted. Once the output I-V curve of each 
individual panel is given, the system output under this particular mismatch condition can be also derived.

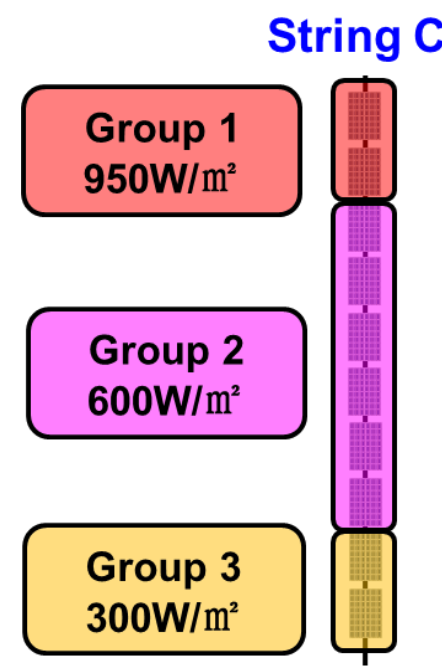

(a) Solar irradiance on string $\mathrm{C}$

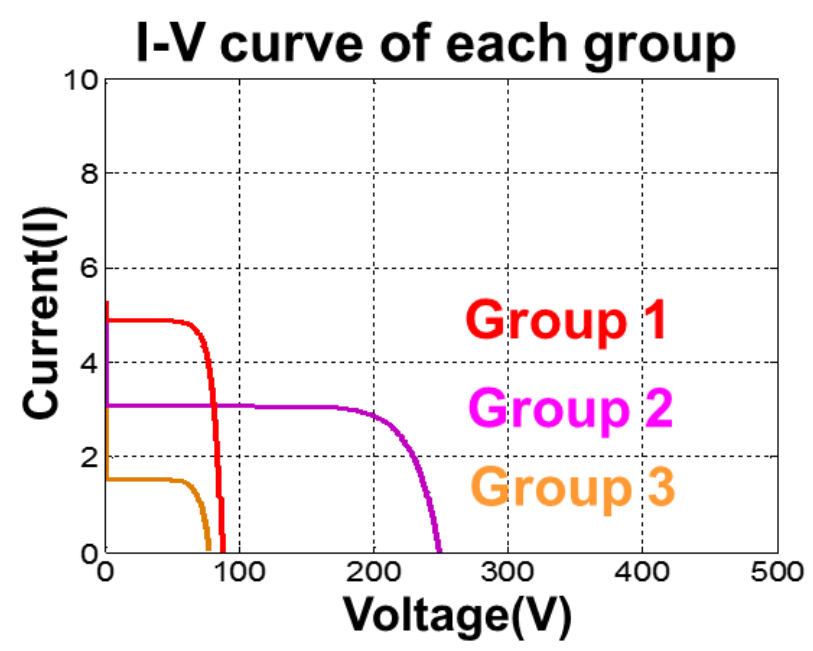

(c) Current-voltage curve of each group

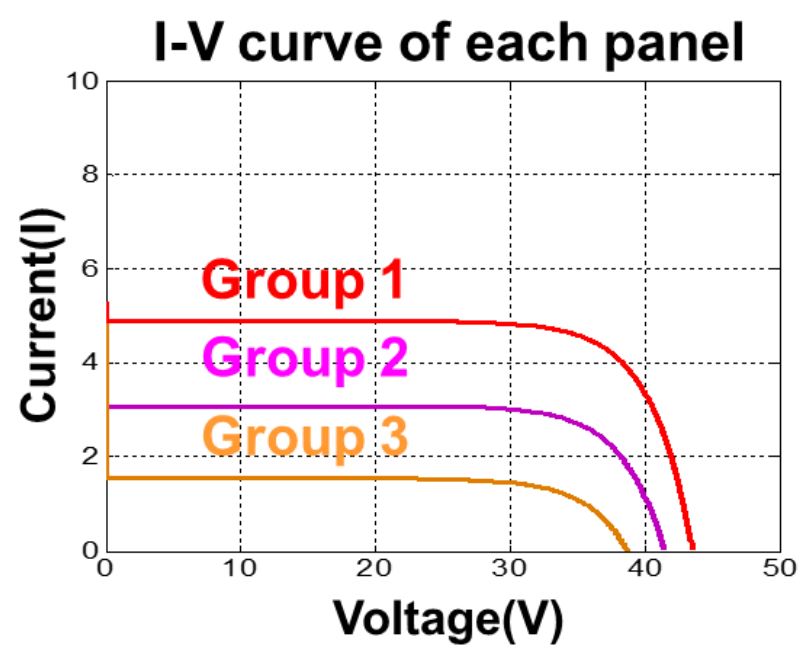

(b) Current-voltage curve of each panel

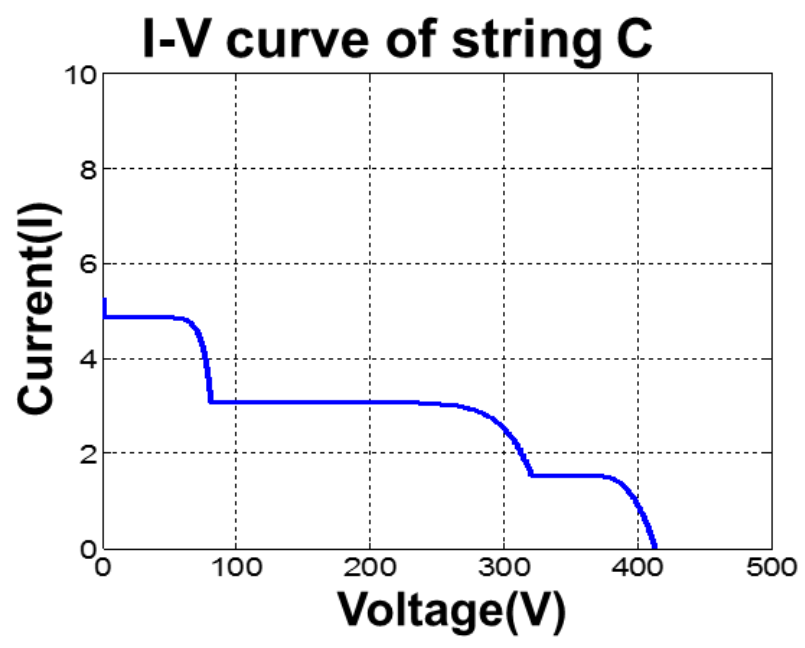

(d) Current-voltage curve of string $\mathrm{C}$

Figure 2.6 Output characteristic of string C

Taking string $\mathrm{C}$ as an example, firstly the solar irradiance on string $\mathrm{C}$ is given in Fig. 2.6 (a). Given that there are three different irradiance levels on string $\mathrm{C}$, panels in string $\mathrm{C}$ can be categorized into three groups. Fig. 2.6 (b) shows the output I-V curves of each panel, and Fig. 2.6 (c) shows the output I-V curves of each group in string C. Since all groups share the same current, the string output can be plotted by directly stacking all group curves along horizontal 
axis which renders the I-V curve as shown in Fig. 2.6 (d). Thus, it shows that the total output of the string has multiple turning points due to the fact that the MPP currents of panels with different irradiance levels are different.

According to the I-V curve, the output P-V curve of string $\mathrm{C}$ can be plotted which is shown in Fig. 2.7 (a). It clearly shows that multiple peak points exists on the P-V curve. The maximum delivered power of string $\mathrm{C}$ is $810 \mathrm{~W}$, but the total available power in string $\mathrm{C}$ is $980 \mathrm{~W}$. In string c, there is $170 \mathrm{~W}$ power which cannot be delivered.

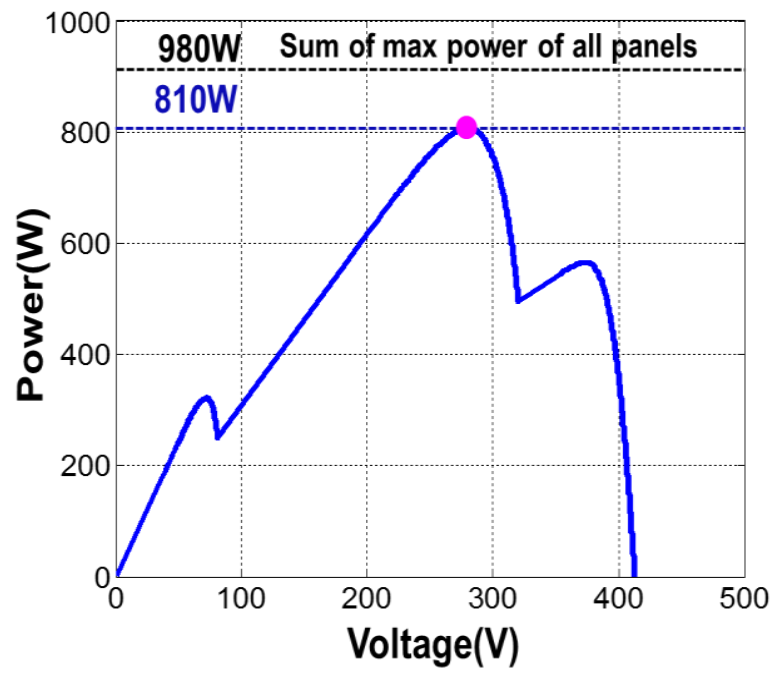

(a) P-V curve of string $\mathrm{C}$

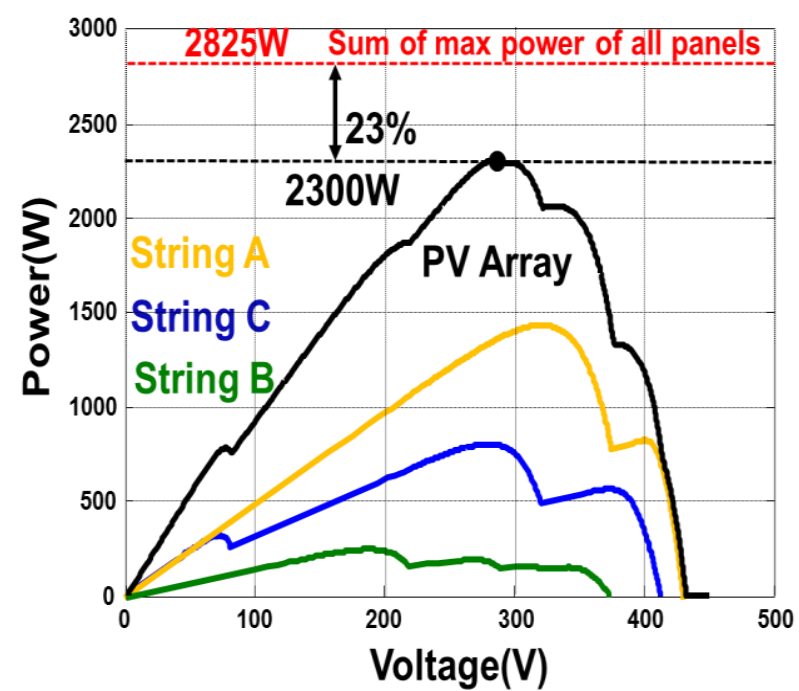

(b) P-V curves of PV array

Figure 2.7 Output characteristics of each string and PV array

However, this number goes much higher if taking sting A and string B into consideration.

Fig. 2.7 (b) shows the P-V curves of three strings and PV array by using the same process as plotting P-V curves of string $\mathrm{C}$. In this case, three strings are connected in parallel, thus the system output P-V curve can be plotted by directly adding string P-V curves together along power axis. It demonstrates that there are multiple peak points on system total output curve due to panel mismatch. Even though the MPPT method can successfully track the highest peak point, the PV system can only deliver $2300 \mathrm{~W}$ power, while the total available power, which is the sum 
of all the panel maximum power, is $2825 \mathrm{~W}$. There is $23 \%$ of the available energy is wasted, which indicates panel mismatch can cause serious reduction on energy production.

\section{B. Case study of smart converter PV system}

In the same mismatch condition, if the smart converter is equipped to improve energy harvesting efficiency, PV system in previous case can be configured as in Fig. 2.8 (a). The smart converter topology is assuming to be buck converter, which has simple structure, low cost and high efficiency. The smart converter continuously track the maximum power point of connected PV panel, and the output of the smart converter behaves as a constant power source after the peak power point is tracked. The maximum output voltage and current of converter is limited by the power device rating. The converter works in three modes: output current limit mode, MPPT mode, and pass through mode. The operation mode is impacted by panel mismatch condition, which will explain in the later sector. Fig 2.8 (b) shows the I-V curve of buck type smart converter with typical current limit 9A.

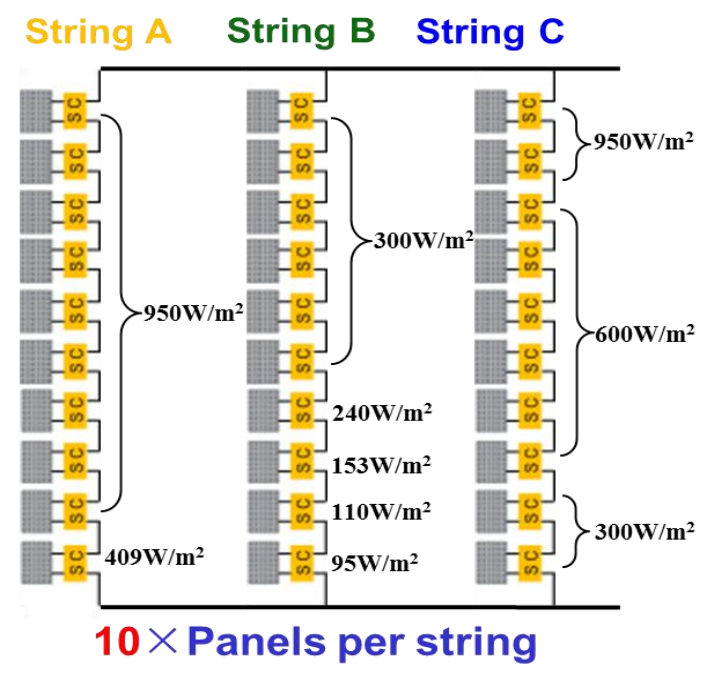

(a) System structure of smart converter PV system 

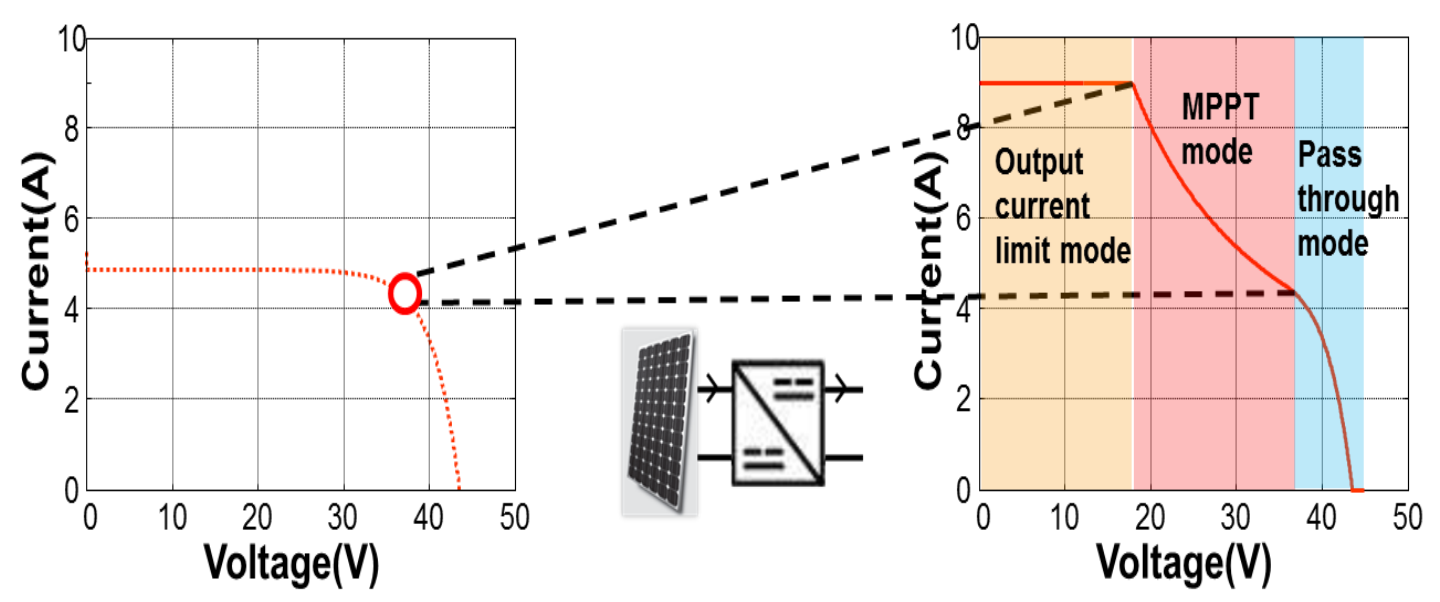

(b) Input and output characteristics of buck type smart converter

Figure 2.8 Smart converter PV system

Taking string $\mathrm{C}$ as an example, Fig. 2.9 (a) gives the solar irradiance distribution. Fig. 2.9 (b) shows the output I-V curves of each smart converter, and Fig. 2.9 (c) shows the output I-V curves of string C. Since all converters share the same current, and there exists common MPPT region to make all the panels deliver maximum power. Therefore, Fig. 2.9 (d) shows that string $\mathrm{C}$ can deliver $980 \mathrm{~W}$ power, which is the total available power in this mismatch condition. Compared to the dot line which represents the P-V curve of string without smart converter, using smart converter can obviously improve energy harvesting performance.

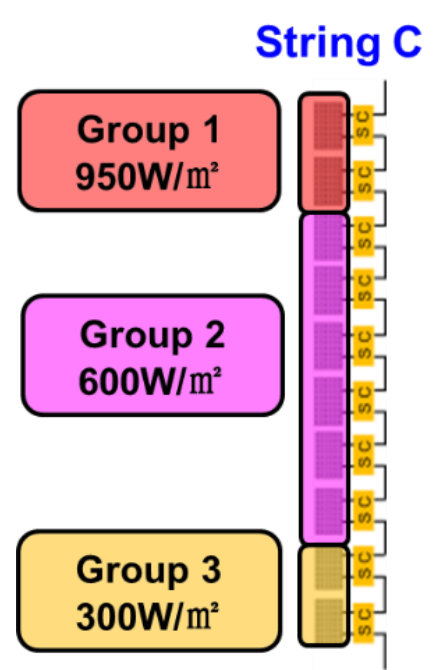

(a) Solar irradiance on string $\mathrm{C}$

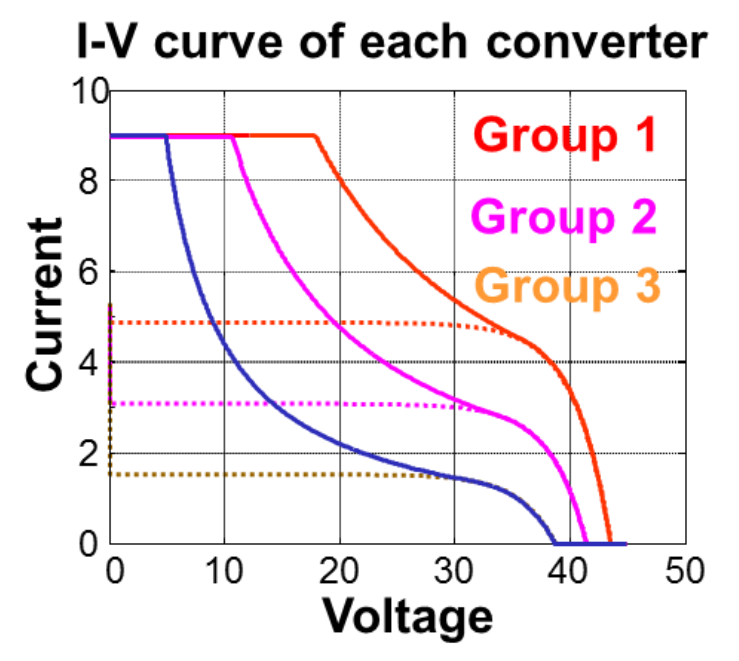

(b) Current-voltage curve of each converter 


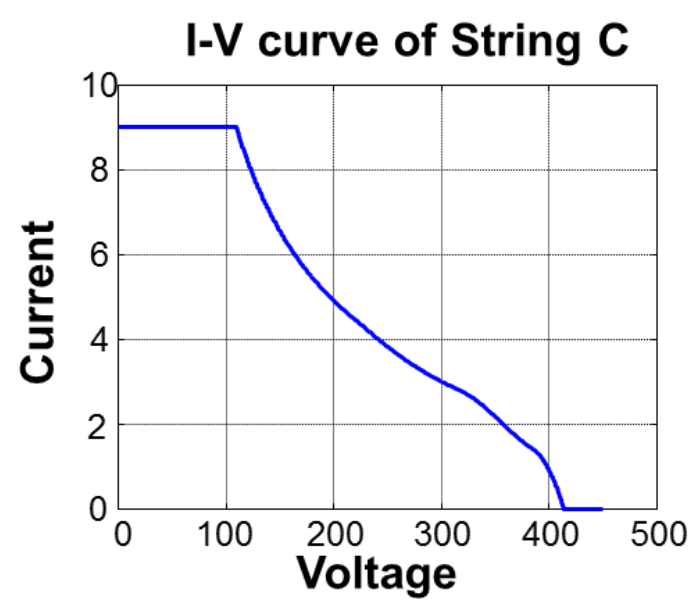

(a) Current-voltage curve of string $\mathrm{C}$

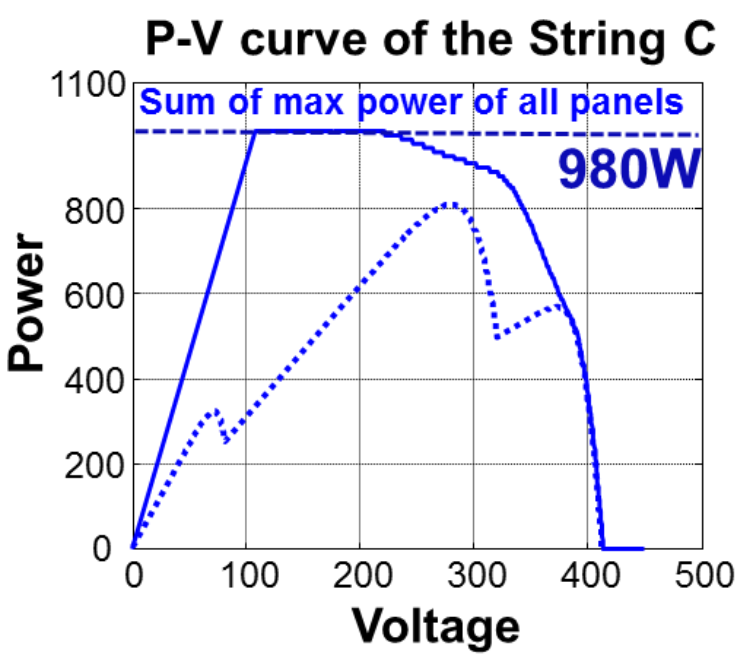

(b) Power-voltage curve of string $\mathrm{C}$

Figure 2.9 Output characteristic of string $\mathrm{C}$ with smart converter

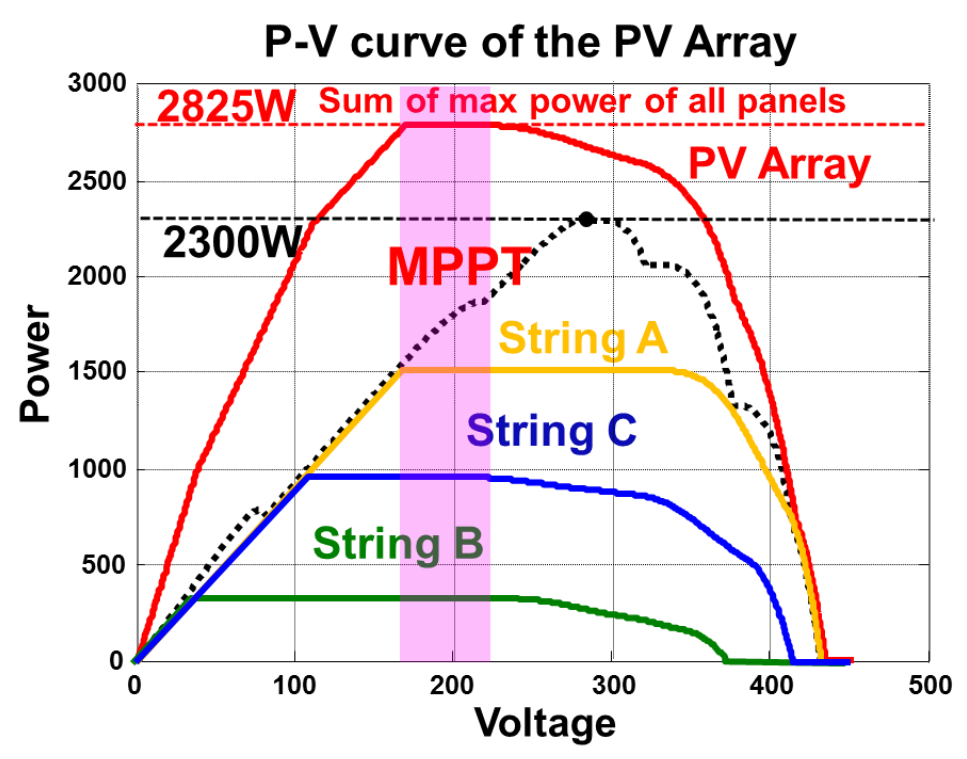

Figure 2.10 Output characteristics of each string and PV array with smart converter

If taking string $\mathrm{A}$ and string $\mathrm{B}$ into account, the improvement of energy production can be much higher. Fig 2. 10 gives the P-V curves of three strings and PV array with smart converter. It demonstrates that there are not multiple peak points on system total output curve even though panel mismatch still exists, which means it is very easy for the $2^{\text {nd }}$ stage central converter to track the maximum power point of PV array. Moreover, the PV system can deliver $2825 \mathrm{~W}$ power, 
which is the sum of all the panel maximum power. Compared to the black dash line, which represents the output curve of PV array without smart converter, there is $525 \mathrm{~W}$ power recovered by smart converter.

\subsection{The Issue of Heavy Panel Mismatch}

In the previous section, it is noted that there are three operation modes for smart converter, and panel mismatch will impact the operation mode. If panel mismatch condition deteriorates, smart converter with limited output voltage and current may not work in MPPT mode. The following part will explain why smart converter does not work in MPPT mode.

Fig. 2.11 (a) gives solar irradiance distribution on the PV array under heavy mismatch condition. In this case, string $\mathrm{A}$ and string $\mathrm{B}$ receive the same irradiance as the previous case study, but string $\mathrm{C}$ has heavier shading. In string $\mathrm{C}$, there are six panels $\left(\mathrm{C}_{3}-\mathrm{C}_{8}\right)$ receiving $95 \mathrm{~W} / \mathrm{m}^{2}$ irradiance, rather than $600 \mathrm{~W} / \mathrm{m}^{2}$ as shown in the previous case. Fig. 2.11 (b) shows the I-V curve of each converter in string C, and Fig. 2.11 (c) gives the I-V curves of three strings.

String A String B String C

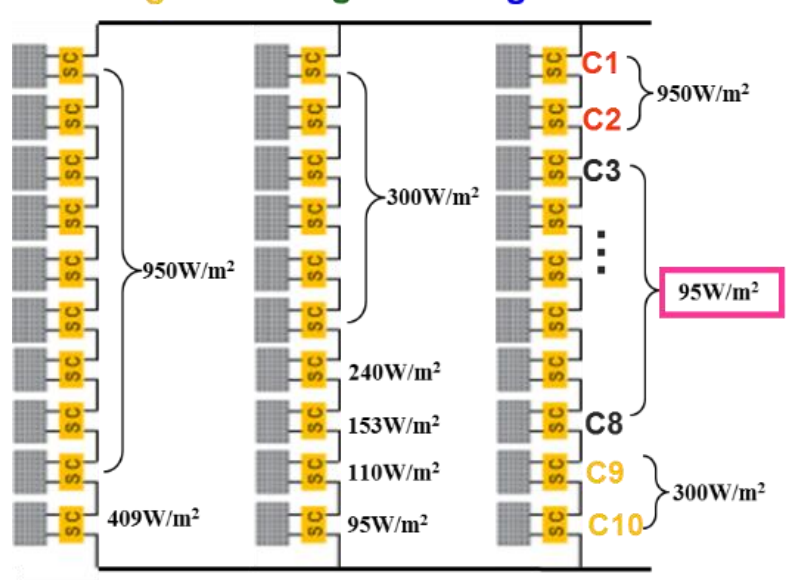

$10 \times$ Panels per string

(a) Solar irradiance on PV array

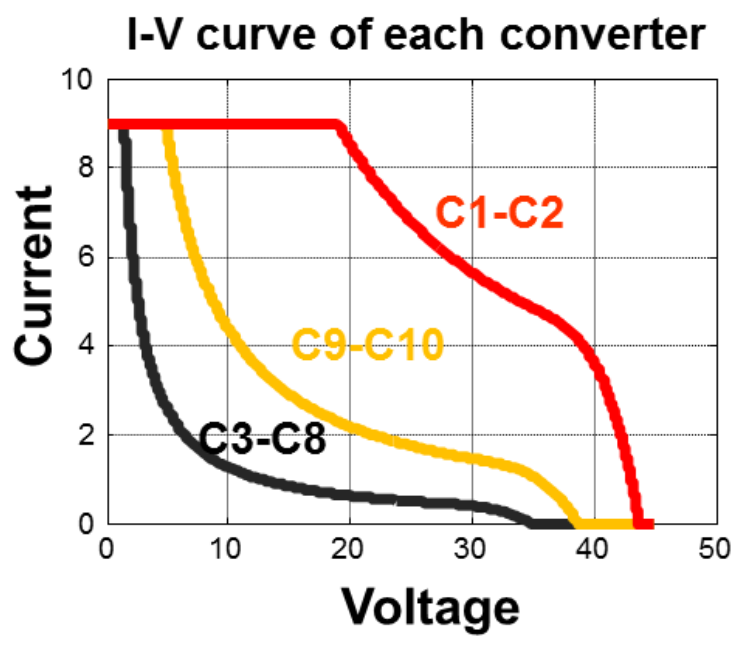

(b) I-V curve of each converter in string $\mathrm{C}$ 


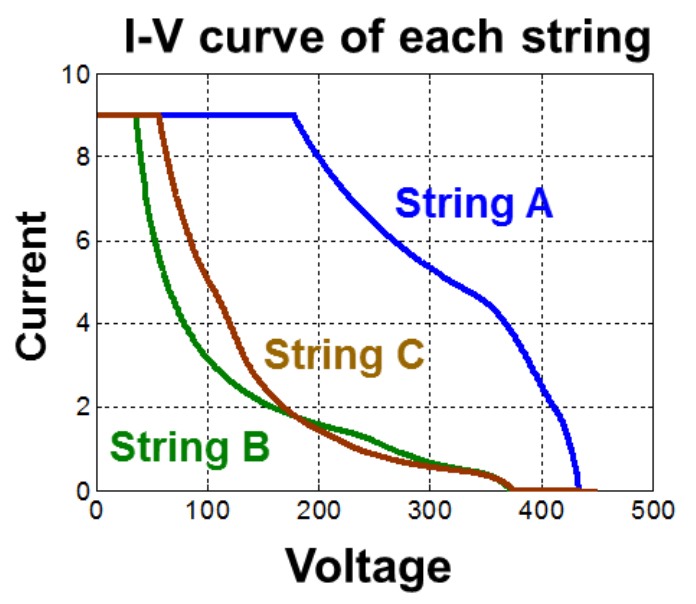

(c) I-V curve of each string

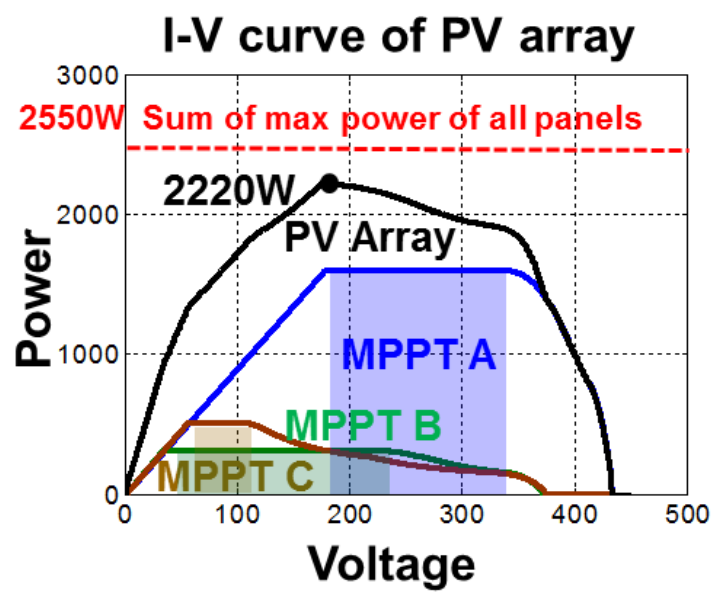

(d) P-V curve of PV array

Figure 2.11 Case study of heavy mismatch condition

Based on these curves, the P-V curves of each string can be plotted, and the P-V curve of PV array can also be derived in Fig. 2.11 (d). It shows that heavy mismatch in string $\mathrm{C}$ can narrow the common MPPT region of string $\mathrm{C}$ and move the flat area of power curve to the left side. When string $\mathrm{C}$ is connected to string $\mathrm{A}$ in parallel, there is no overlapping area between MPPT region of string $\mathrm{C}$ and string $\mathrm{A}$. Therefore, smart converter cannot deliver maximum power from PV array. In this heavy mismatch case, the total available power from PV array is $2550 \mathrm{~W}$, but the maximum system output power is only $2220 \mathrm{~W}$.

This issue is addressed in recent research [15] by using an alternative system configuration as shown in Fig. 2.12. According to mathematical derivation in [15], it is demonstrated that the alternative system configuration, named structure II in the figure above, can deliver maximum power from PV system under heavy mismatch condition. Fig.2.13 gives the output characteristics of alternative system configuration in the heavy mismatch condition. 

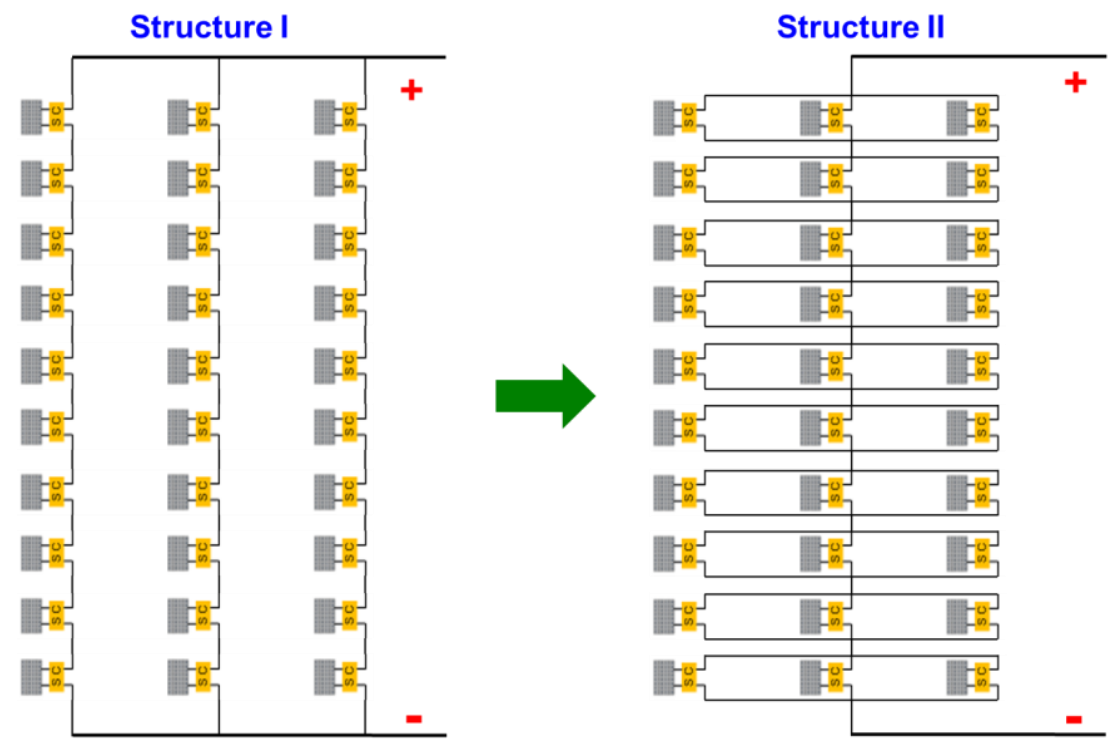

Figure 2.12 Alternative system configuration

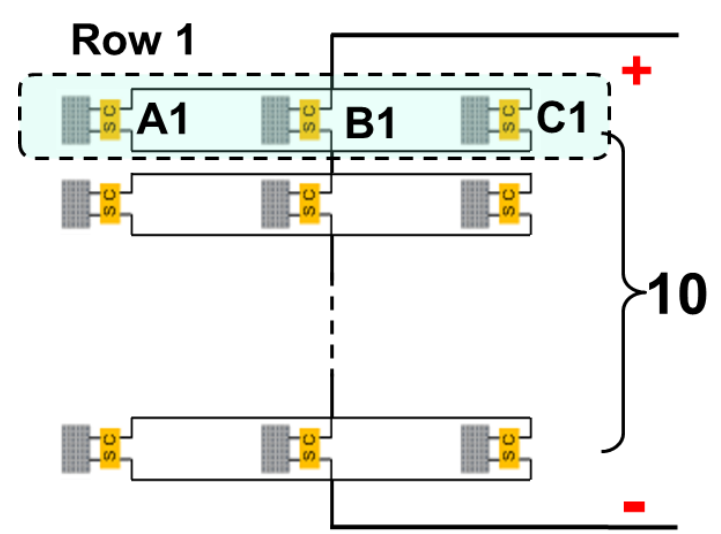

(a) Alternative system configuration

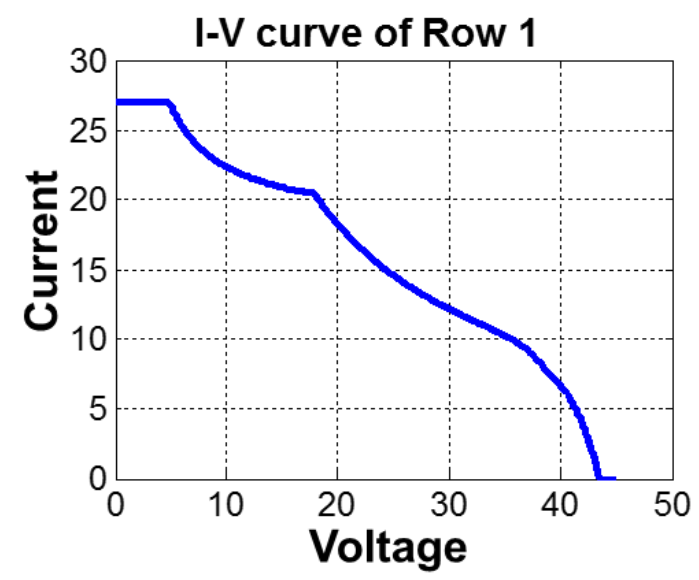

(c) I-V curve of Row 1

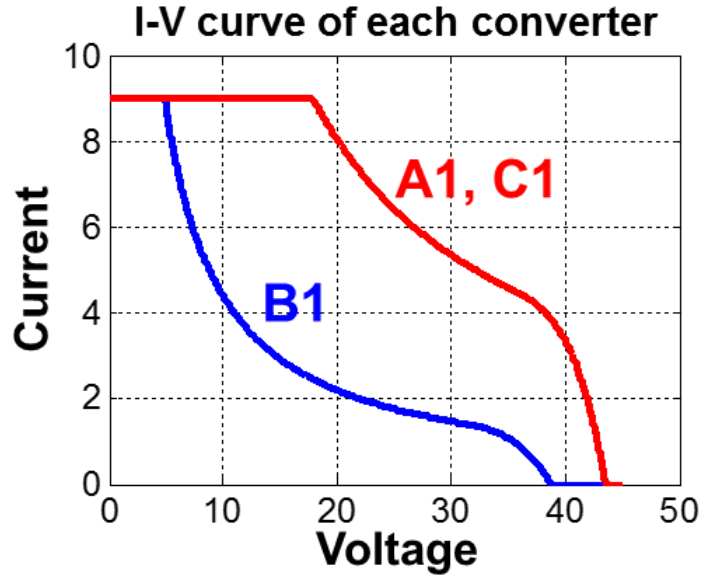

(b) I-V curve of each converter in Row 1

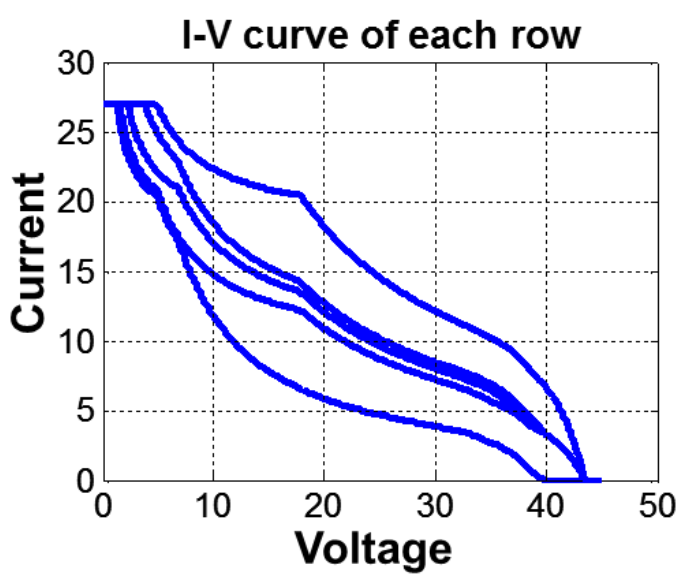

(d) I-V curve of each row 


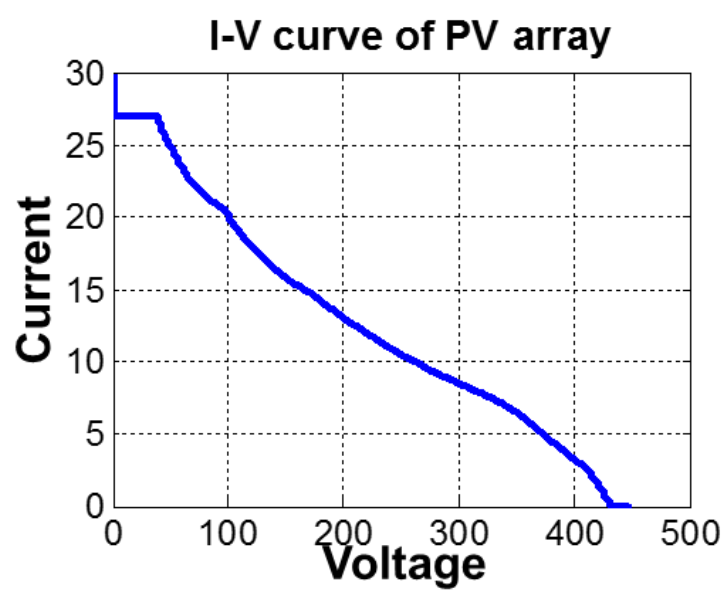

(e) I-V curve of PV array

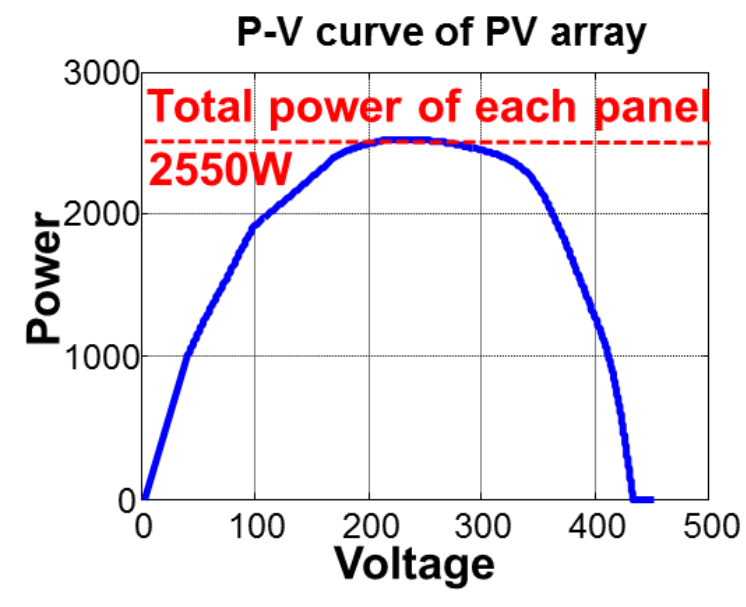

(f) P-V curve of PV array

Figure 2.13 Case study of alternative system configuration in heavy mismatch condition

Fig. 2.13 (a) shows that in the alternative system configuration, three converter is connected in parallel to form a row, and ten row in series connection forms a PV array. Fig. 2.13 (b) gives the I-V curve of each converter in Row 1 by stacking I-V curve of each converter along the voltage axis, and Fig. 2.13 (c) shows the I-V curve of Row 1. Similarly, using the same process, the I-V curves of other rows can be plotted as shown in Fig. 2.13 (d). Thus, the I-V curve and PV curve of PV array can be derived in Fig. 2.13(e) and Fig. 2.13 (f). Compared to previous system configuration, this alternative system configuration has better MPPT performance. In this case, the alternative PV system can deliver $2550 \mathrm{~W}$ power, which is the total available power of PV array.

The basic reason that why this alternative system has better MPPT performance is that there are only three converter in parallel and all rows share the same current. Even if the smart converter has limited output range, it is easy to form a common MPPT current region which can deliver maximum power from each row in heavy mismatch condition.

However, in the previous system configuration, each string formed by ten converters are connected in parallel. Even if there is common MPPT region in each string, it is hard to find a 
common MPPT voltage region to deliver maximum power from each string. The basic reason is that in heavy shaded string, the smart converter which deliver lower power needs to reduce its output voltage to increase its output current, and then this converter can connect in series to other smart converter which delivered high power. Thus, the common MPPT region of heavy shaded string, like string $\mathrm{C}$ in Fig. 2. 11, is located in the low voltage area; otherwise, the common MPPT region of light shaded string is located in the high voltage area as shown in Fig. 2.11. Therefore, there is no overlapping area for the common MPPT region of all the strings.

\subsection{The Issue of 2nd stage Central MPPT Converter}

It is noted that the smart converter PV system needs a $2^{\text {nd }}$ stage central MPPT converter to track the maximum power point of PV array. Fig. 2.14 shows the necessity of this $2^{\text {nd }}$ stage converter.
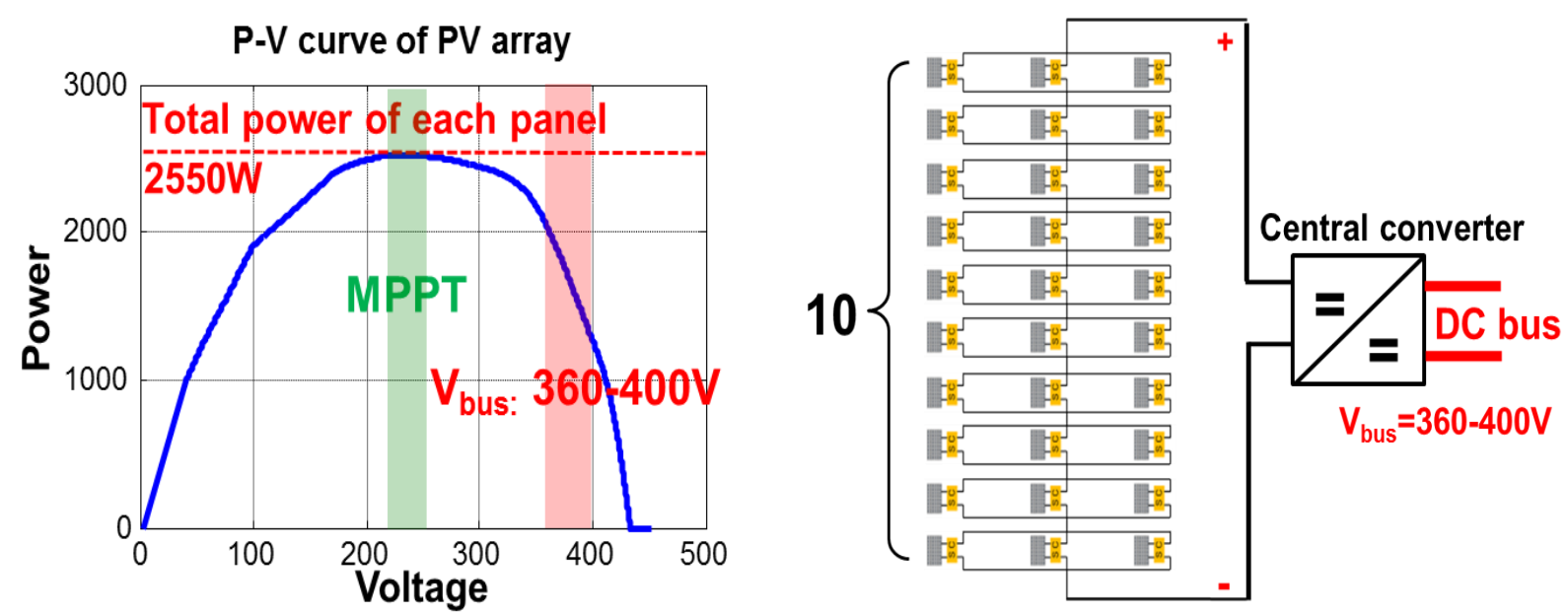

Figure 2.14 The $2^{\text {nd }}$ stage converter in smart converter PV system

As shown in the figure above, the PV array can only deliver maximum power in the green area, which is about $210 \mathrm{~V}-250 \mathrm{~V}$, but the DC bus voltage is $360-400 \mathrm{~V}$. Hence, a $2^{\text {nd }}$ stage boost converter is needed to interface PV array with DC bus. Even if the MPPT function of this $2^{\text {nd }}$ 
stage converter is easy to implement given that there is no multiple peak point on the P-V curve of PV array, it is still desired that this $2^{\text {nd }}$ stage converter can be eliminated to reduce cost and improve LCOE.

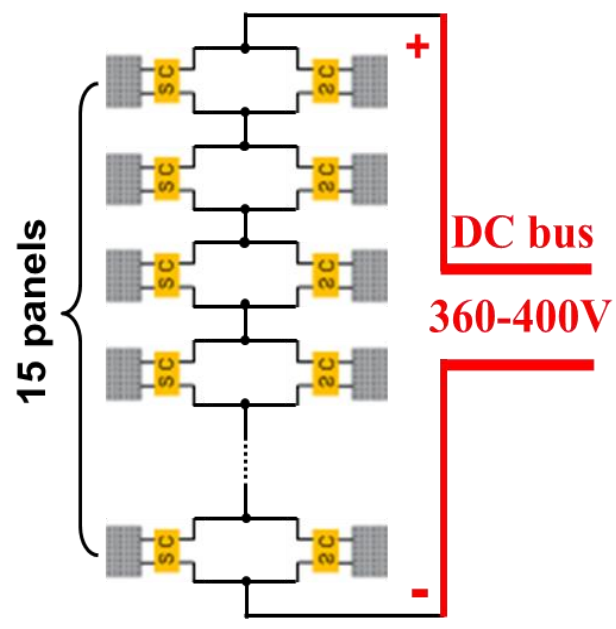

(a) Optimized configuration for smart converter PV system

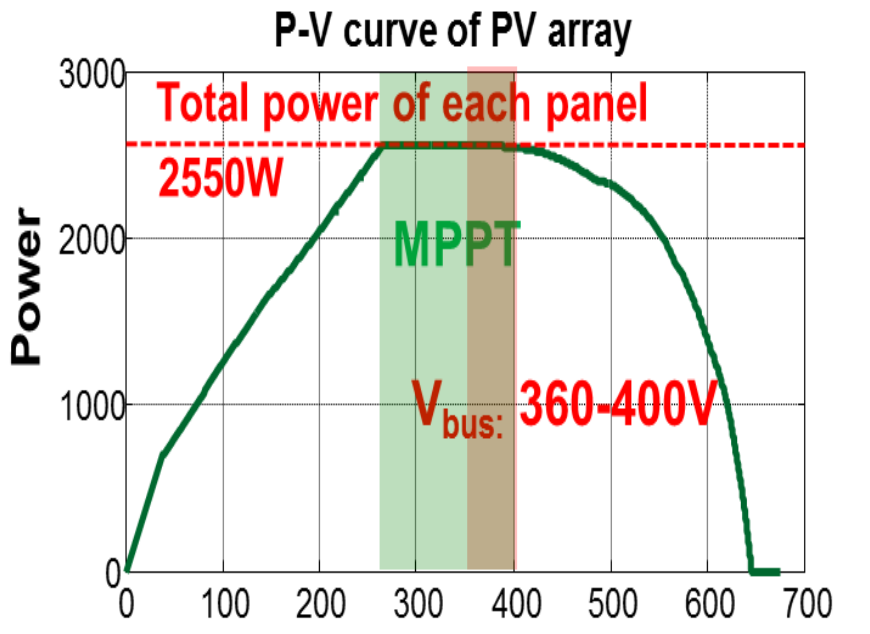

(b) P-V curve of optimized system configuration in heavy mismatch condition

Figure 2.15 Optimized system configuration for smart converter PV system

To address this issue, an optimized system configuration is given in Fig. 2. 15. The P-V curve of the optimized system configuration in Fig. 2.15 (b) shows that not only can this configuration deliver maximum power from PV array under heavy mismatch condition, but extend the common MPPT region to the DC bus voltage region, which means the PV array can connect to DC bus without $2^{\text {nd }}$ stage converter.

The optimized system configuration in Fig. 2.15 (a) can also be used in grid-tied PV system. In grid-tied PV system, normally the grid-tied inverter needs MPPT function to track the peak power point of PV array. By adopting this optimized configuration, the grid-tied inverter only needs DC-AC conversion under constant DC link voltage, which means the grid-tied inverter can be simplified and achieve high efficiency due to fixed voltage ratio. 


\subsection{Summary}

This chapter demonstrates the advantage of smart converter PV system over traditional centralized PV system with a typical case study. It is obvious that smart converter can recover the energy which is wasted in traditional PV system due to panel mismatch. However, the power generation efficiency can be impacted by heavy mismatch condition even if smart converter is applied to each panel. To address this issue, recent research presents an alternative system configuration. After modifying this alternative system configuration, an optimized system architecture is introduced at the end the this chapter to deliver maximum power from PV array in heavy mismatch condition, and connect PV array directly to DC bus without $2^{\text {nd }}$ stage MPPT converter. This optimized system architecture can be adopted in both DC and AC system. 


\section{Chapter 3. Proposed Multi-Phase Smart Converter for}

\section{PV System}

\subsection{The Concept of Multi-Phase Smart Converter}

In the traditional smart converter PV system, each panel has a dedicated MPPT converter as shown in Fig.3.1. Taking panel 1 as an example, the single phase smart converter senses panel output voltage $V_{P 1}$ and panel output current $I_{P 1}$, and uses a MPPT controller to track peak power point of panel 1 by perturbing $\mathrm{V}_{\mathrm{P} 1}$. All the single phase smart converters work simultaneously and keep tracking peak power points of panels without interruption.

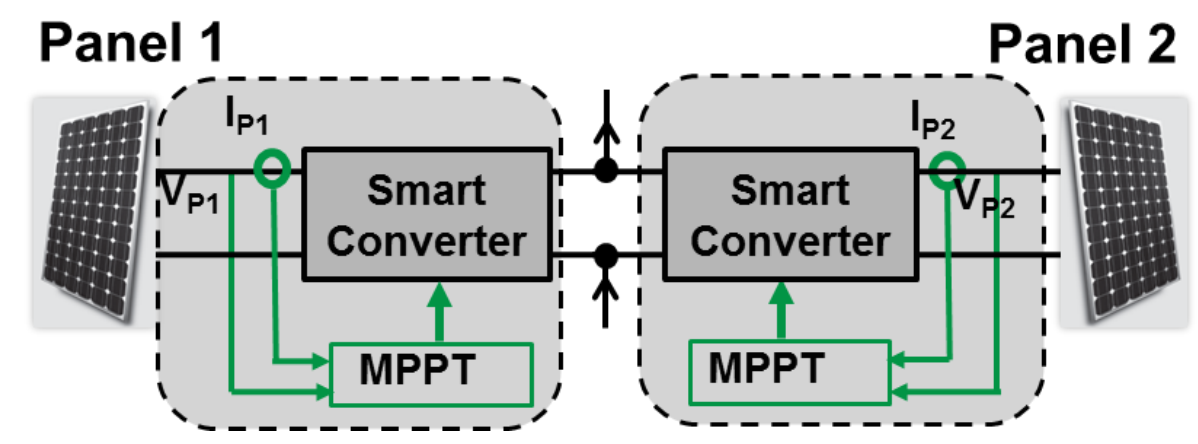

Figure 3.1 Traditional single phase smart converter

However, there is no need to use controller to track peak power point of panel all the time. The reason is that compared to the calculation speed of controller (MCU, DSP), the variance of solar irradiance is very slow. For example, during 0.1 second, the low cost MCU, TMS320F28027, can execute 6 million instructions, which are enough for MPPT algorithm to converge 10 times. Whereas, in the natural environment, the variance of solar irradiance during 0.1 second is very small. Therefore, most time the MPPT algorithm works in convergence mode, which means controller gives nearly constant input voltage reference to the smart converter. 
Based on this reason, the two single phase smart converter in Fig. 3.1 can be replaced by the two-phase smart converter with single controller as shown in Fig. 3.2. Taking panel 1 in Fig.3.2 as an example, when controller is tracking panel 1, controller gives perturbation on input voltage reference $V_{P 1}$. Meanwhile, controller outputs constant input voltage reference $V_{P 2}$, and then the voltage of panel 2 is fixed, which means the delivered power from panel 2 is constant. After the peak power point of panel 1 is tracked, the controller will turn to track panel 2 while fix the output voltage of panel 1 at its peak power point. When the peak power point of panel 2 is tracked, the controller will turn to track panel 1 again while fix $\mathrm{V}_{\mathrm{P} 2}$ at its peak point. This time sharing process repeats all the time to make sure all the panels can deliver its maximum power consistently.

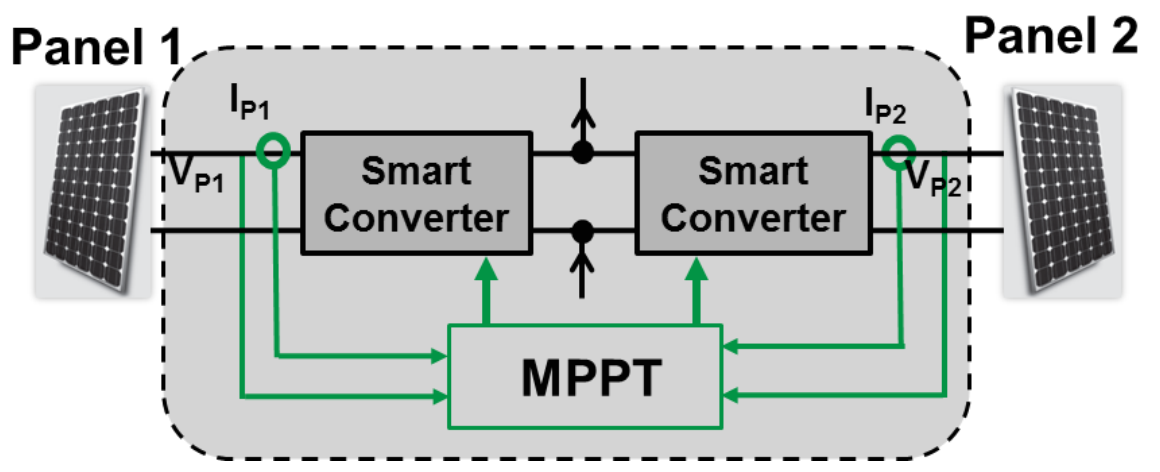

Figure 3.2 Proposed Two-phase smart converter with single controller

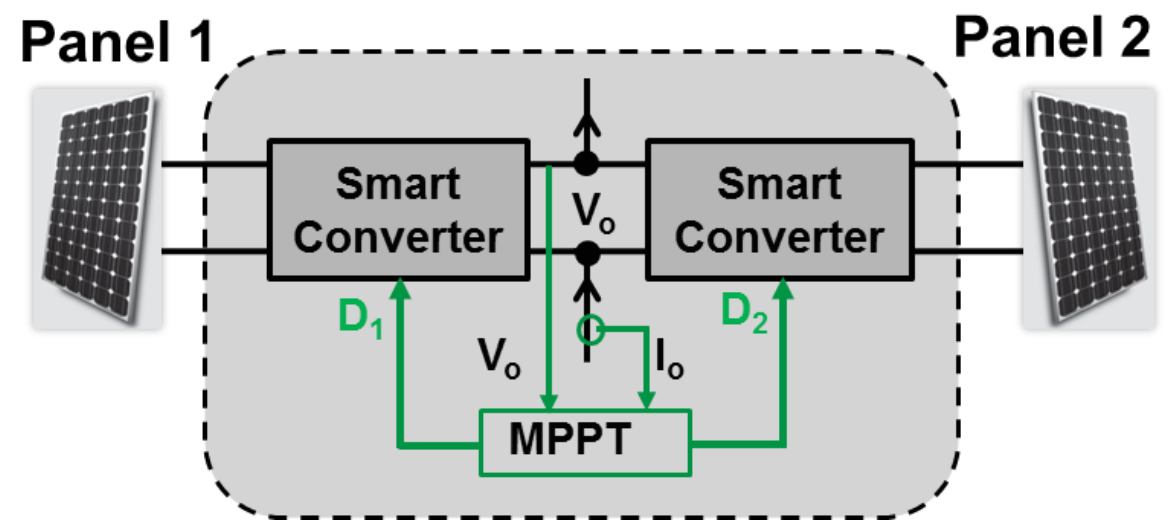

Figure 3.3 Optimized two-phase smart converter with single controller 
Nonetheless, both input voltage and input current of two converters need to be sensed. To further reduce cost, a solution for two phase smart converter with less sensors is proposed in Fig. 3.3. Taking panel 1 in Fig.3 (b) as an example, when controller is tracking panel 1, controller gives perturbation on $V_{P 1}$ by sensing $V_{o}$ and adjusting duty cycle $D_{1}$. Meanwhile, the voltage of panel 2 are fixed by adjusting duty cycle according to sensed $\mathrm{V}_{\mathrm{o}}$, which means panel 2 delivers constant power. Thus, assuming there is no power loss in the power conversion, if $\mathrm{V}_{\mathrm{P} 1}$ is perturbed toward higher power point, then the total power of two panels becomes higher; otherwise, if $\mathrm{V}_{\mathrm{P} 1}$ is perturbed toward lower power point, then the total power of two panels becomes lower. Using this method can track MPP of panel 1, and after that controller turns to track panel 2 while fix $V_{P 1}$ at its peak power point.

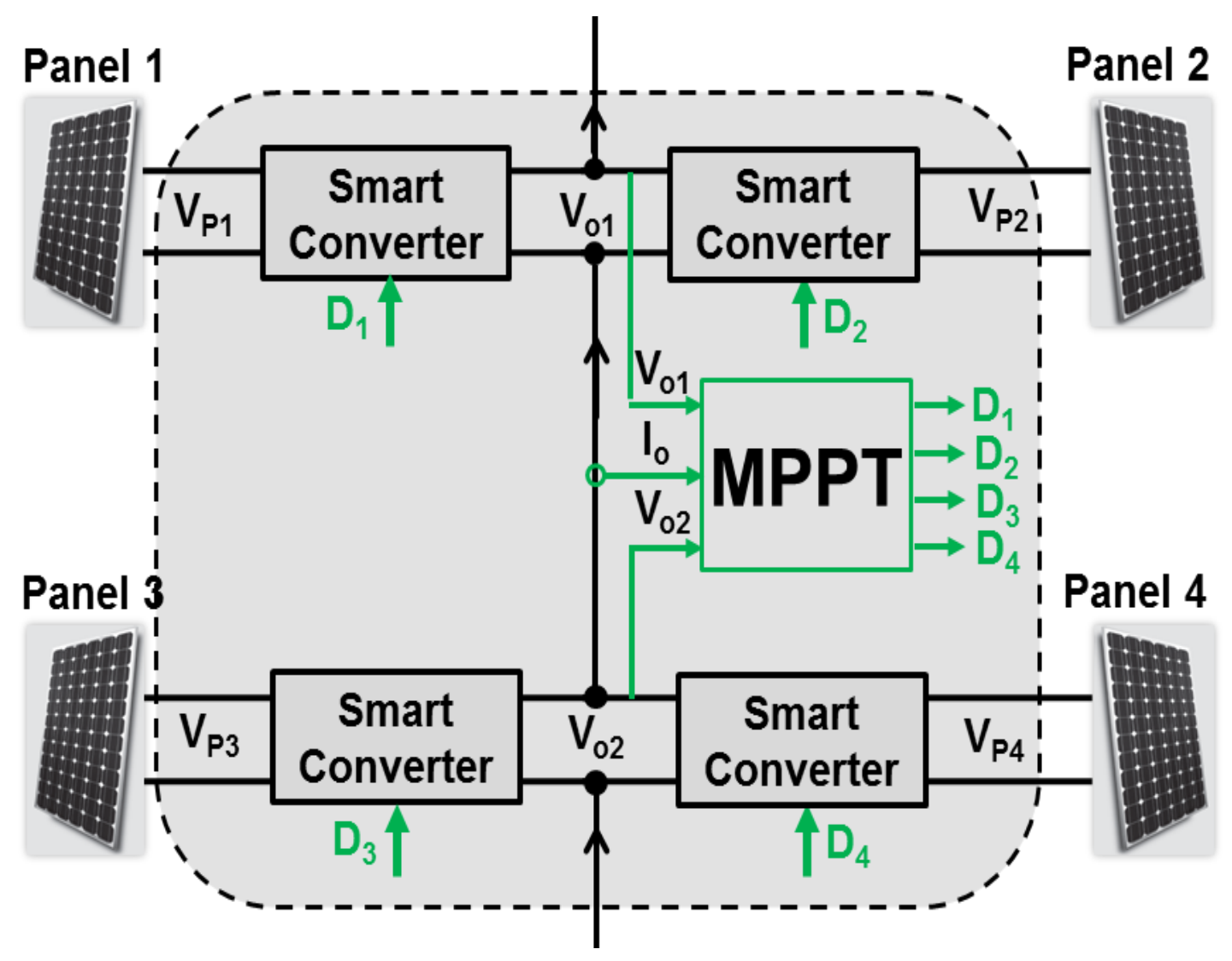

Figure 3.4 Proposed multi-phase smart converter with single controller 
For the cascaded smart converter system, applying the similar time sharing method can give rise to the proposed multi-phase smart converter as shown in Fig. 3.4. The proposed solution only senses $V_{\mathrm{o} 1}, \mathrm{~V}_{\mathrm{o} 2}$ and $\mathrm{I}_{\mathrm{o}}$, which respectively represents the output voltage of two top converters, the output voltage of two bottom converters, and total output current of two bottom converters. Hence, assuming there is no power loss in the power conversion, both total power of two top panels, and total power of two bottom panels can be measured. In order to achieve panel level MPPT, time sharing method is adopted to track MPP of four panels by using only one controller. Taking panel 1 in Fig.3.4 as an example, when controller is tracking panel 1, controller gives perturbation on $\mathrm{V}_{\mathrm{P} 1}$ by sensing $\mathrm{V}_{\mathrm{o} 1}$ and adjusting duty cycle $\mathrm{D}_{1}$. Meanwhile, the voltage of other three panels are fixed by adjusting duty cycle according to sensed $\mathrm{V}_{\mathrm{o1}}$ and $\mathrm{V}_{\mathrm{o} 2}$, which means the other three panels' power are constant. Thus, if $\mathrm{V}_{\mathrm{P} 1}$ is perturbed toward higher power point, then the total power of two top panels becomes higher; otherwise, if $\mathrm{V}_{\mathrm{Pl}}$ is perturbed toward lower power point, then the total power of two top panels becomes lower. Using this method can track MPP of panel 1, and after that controller moves to track other panel while fix $V_{P 1}$ at its peak power point.

It is worthy to note that this multi-phase structure for smart converter can be extended to many other architectures. One example is shown in the Fig. 3.5, which has multiple smart converters in parallel to form a row and multiple rows in series connection. The MPPT method for the architecture shown below is similar to the system architecture in Fig. 3.4. 


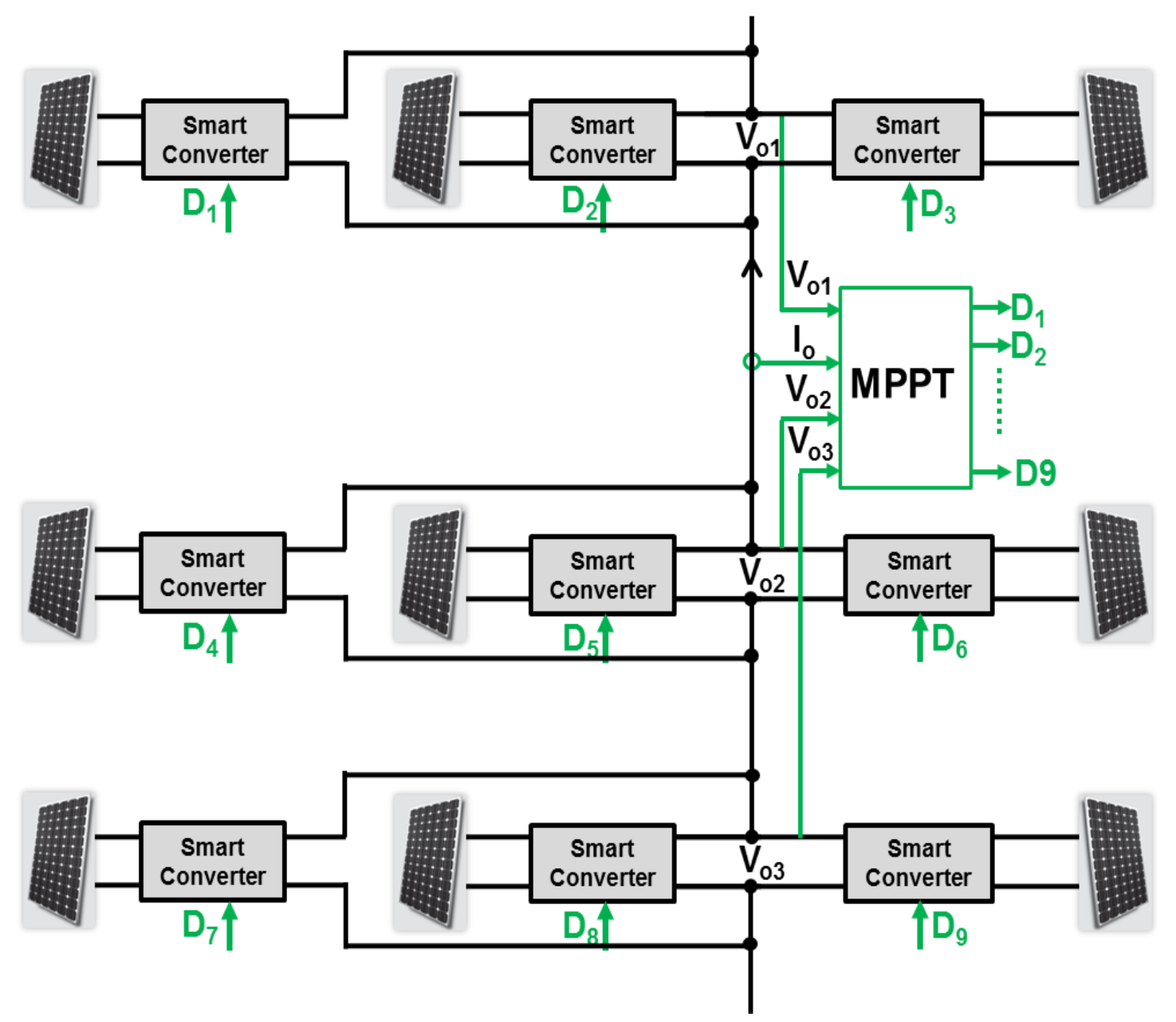

Figure 3.5 Extended architecture for proposed multi-phase smart converter

Recent research on distributed MPPT appeals that subpanel level peak power tracking can further improve energy production compared to panel level MPPT [16]. In [16], a unified output MPPT control structure is presented in order to reduce the cost and simplify the distributed MPPT system as shown in Fig. 3.6. 


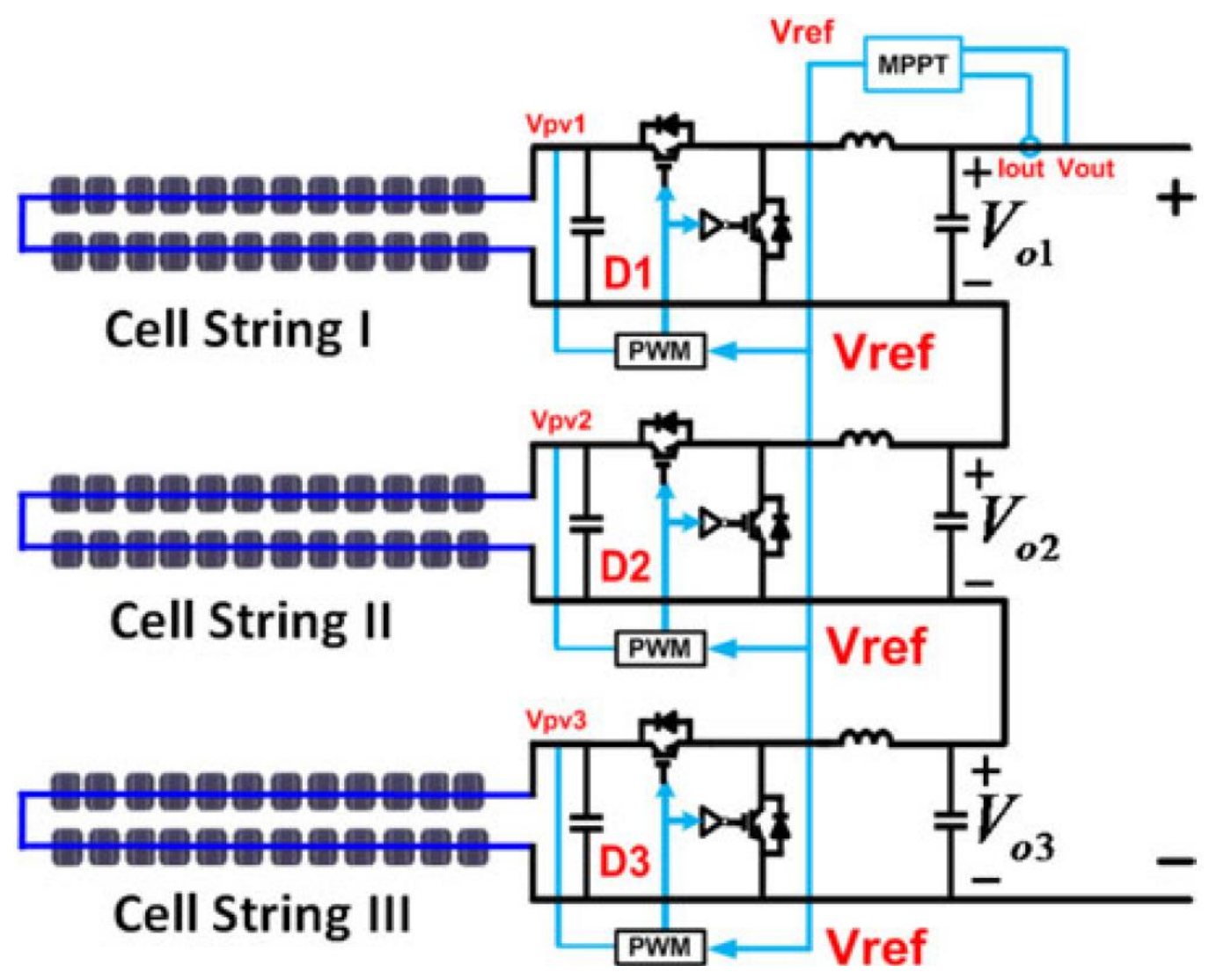

(a) Detailed structure

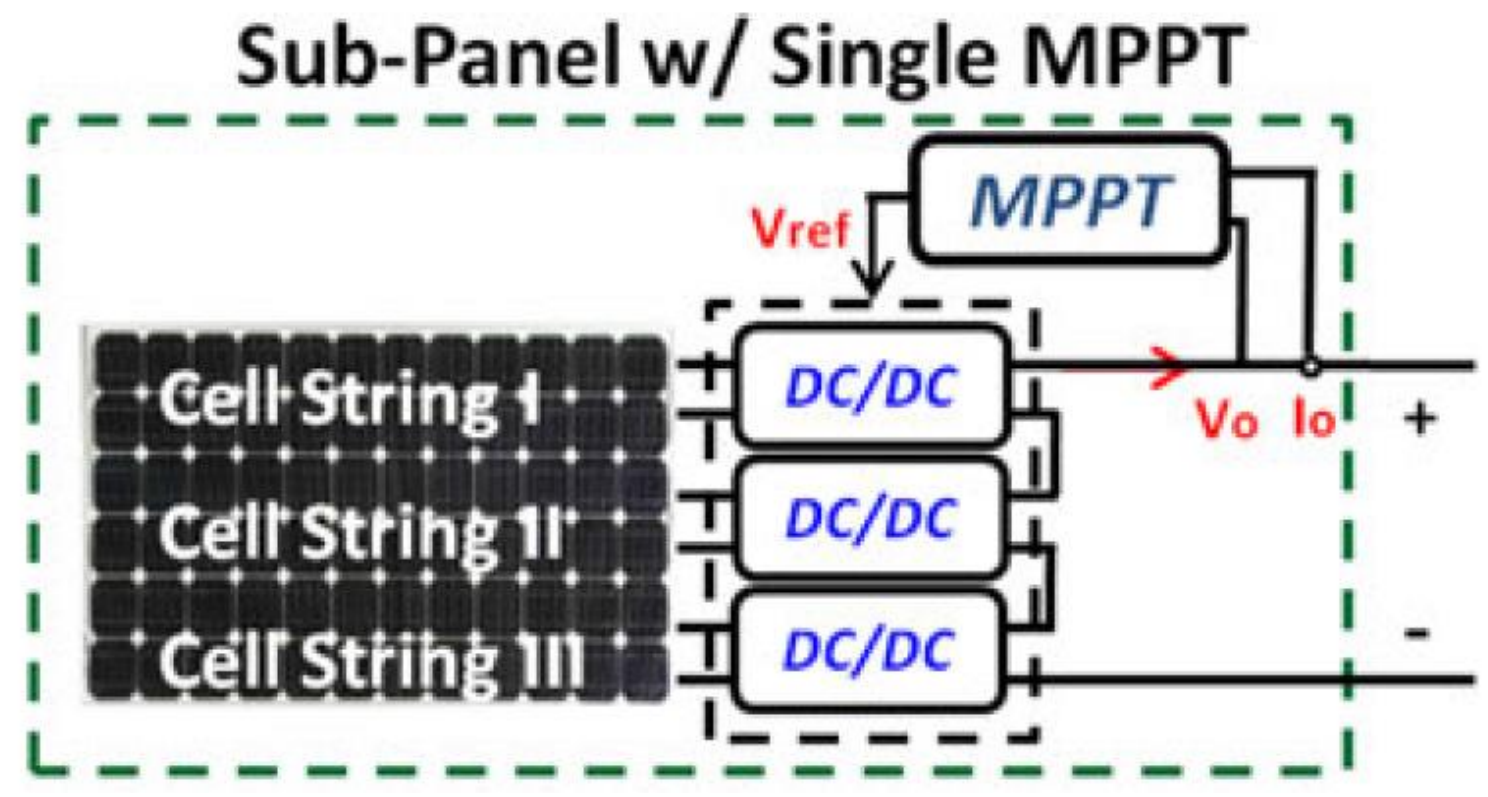

(b) Simplified structure

Figure 3.6 Unified output MPPT control structure for subpanel converter 
In this subpanel converter, all the cell strings share the same voltage reference. Analysis and derivation in [18] indicates that this MPPT control structure can effectively deliver maximum power when mismatch happens among cell strings. Based on this control strategy, a multi-phase subpanel MPPT converter is proposed in Fig. 3. 7. Taking panel 1 as an example, when controller is tracking panel 1 , controller gives perturbation on $\mathrm{V}_{\text {ref1 }}$. Meanwhile, the voltage reference of other three panels are fixed, which means the other three panels' power are constant. Thus, if $\mathrm{V}_{\text {ref1 }}$ is perturbed toward higher power point, then the total power of two top panels becomes higher; otherwise, if $\mathrm{V}_{\text {ref1 }}$ is perturbed toward lower power point, then the total power of two top panels becomes lower. Using this method can track MPP of panel 1, and after that controller moves to track other panel while fix $\mathrm{V}_{\text {ref1 }}$ at its peak power point.

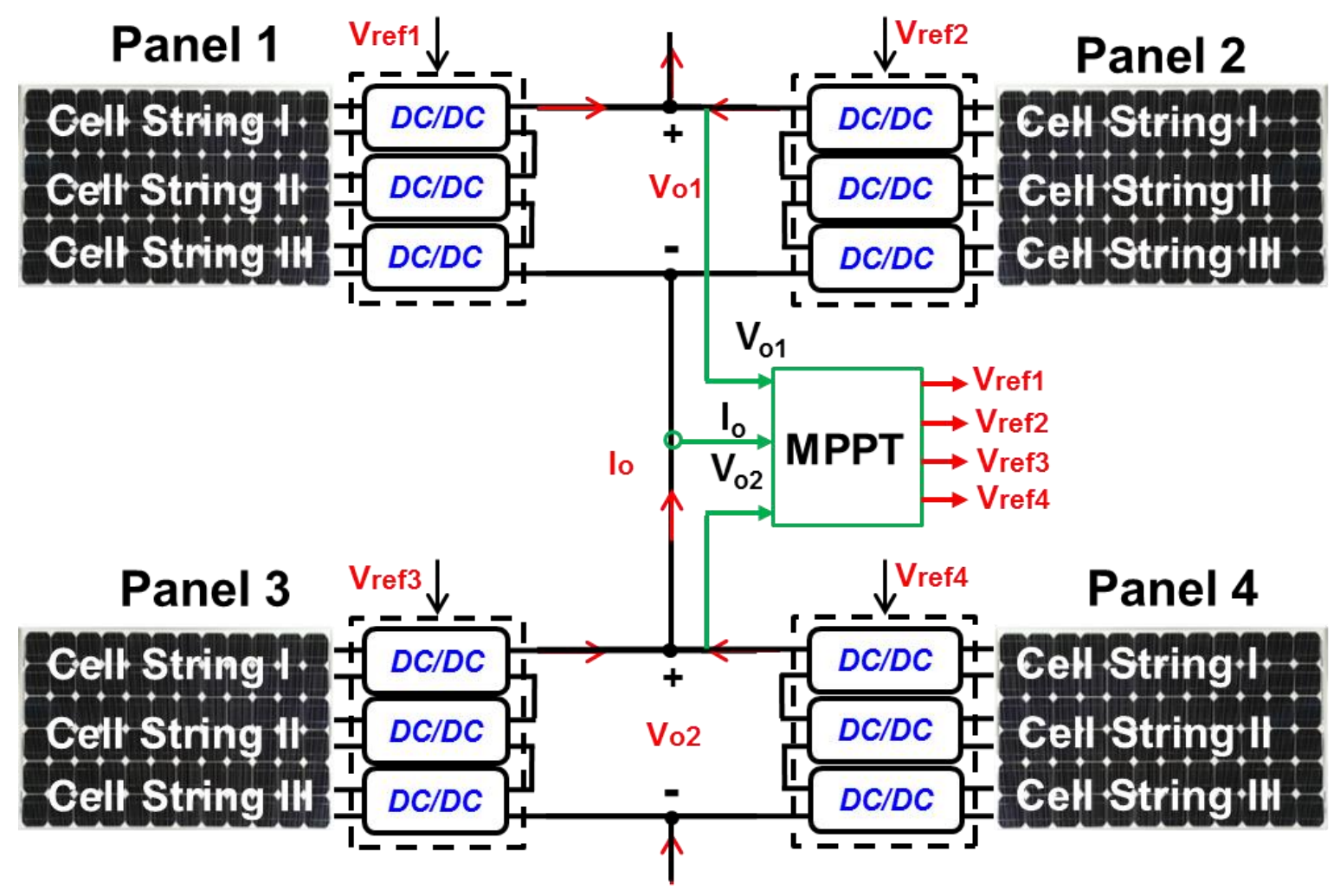

Figure 3.7 Proposed multi-phase subpanel converter with single controller 


\subsection{Implementation of Proposed Multi-Phase Smart Converter}

For the implementation of proposed solution, a four-phase buck converter is shown in Fig.

3.8. The converter output voltage and current are sensed as $\mathrm{V}_{\mathrm{o} 1}, \mathrm{~V}_{\mathrm{o} 2}$, and $\mathrm{I}_{\mathrm{o}}$. They are fed into MCU to calculate the total output power of four panels. Based on MPPT algorithm, MCU outputs the driving signals to switches to control the input voltage of each buck converter. Given that the output voltage of each buck converter is known, the input voltage of buck converter can be adjusted based on the following equations:

$$
\left\{\begin{array}{l}
V_{P 1}=V_{o 1} / D_{1} \\
V_{P 2}=V_{o 1} / D_{2} \\
V_{P 3}=V_{o 2} / D_{3} \\
V_{P 4}=V_{o 2} / D_{4}
\end{array}\right.
$$

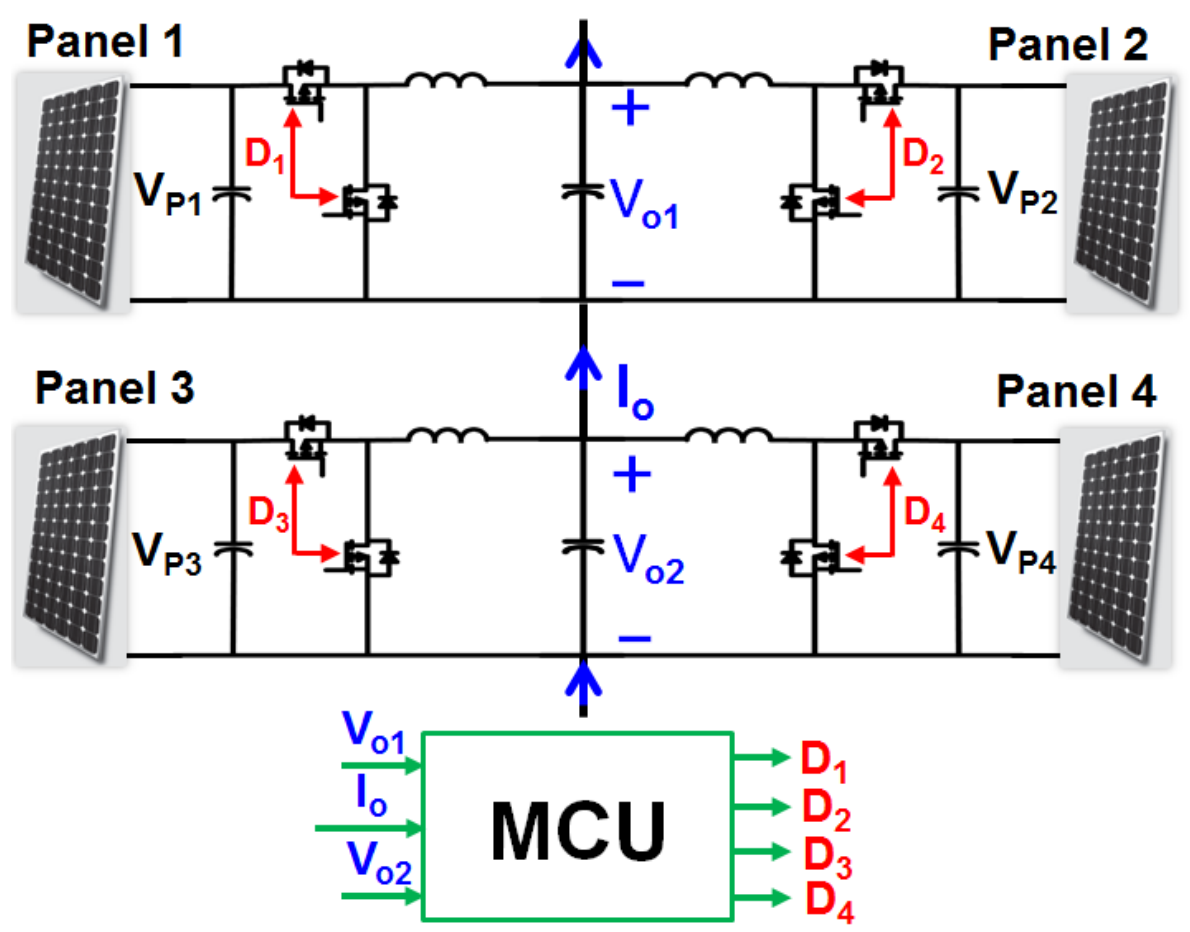

Figure 3.8 Power stage of four-phase buck converter. 
To implement panel level maximum power point tracking, time sharing method is adopted to use single MCU to control four panels. Fig. 3.9 gives the time sharing method, in which the controller each panel in turn. While panel 1 is tracked for MPPT, the voltage of panel $1, \mathrm{~V}_{\mathrm{P} 1}$ is perturbed, and the voltage of other panels are fixed. Fig. 3.10 shows the flowchart diagram of Perturbation \& Observation $(\mathrm{P} \& \mathrm{O})$ based MPPT algorithm during tracking panel 1 period.

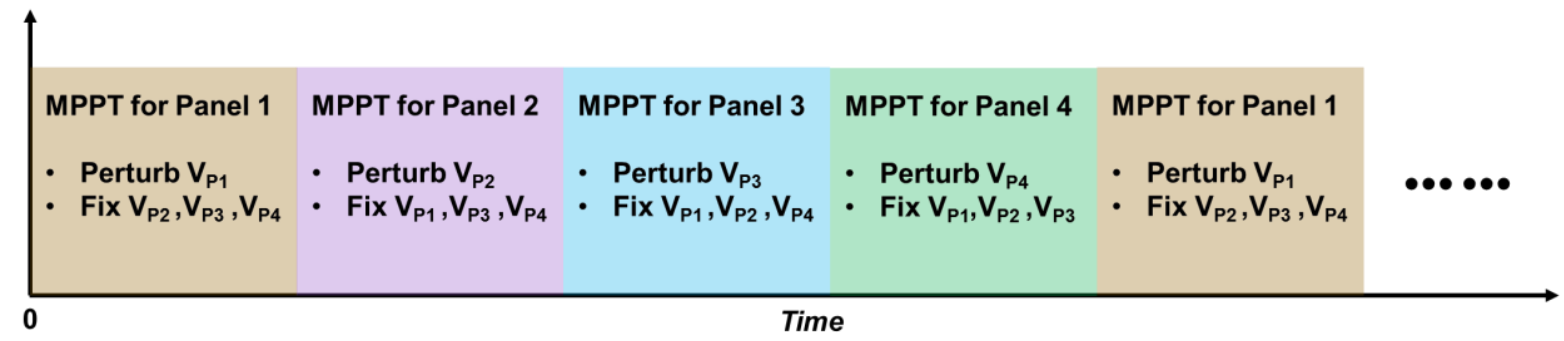

Figure 3.9 Time sharing of MPPT controller

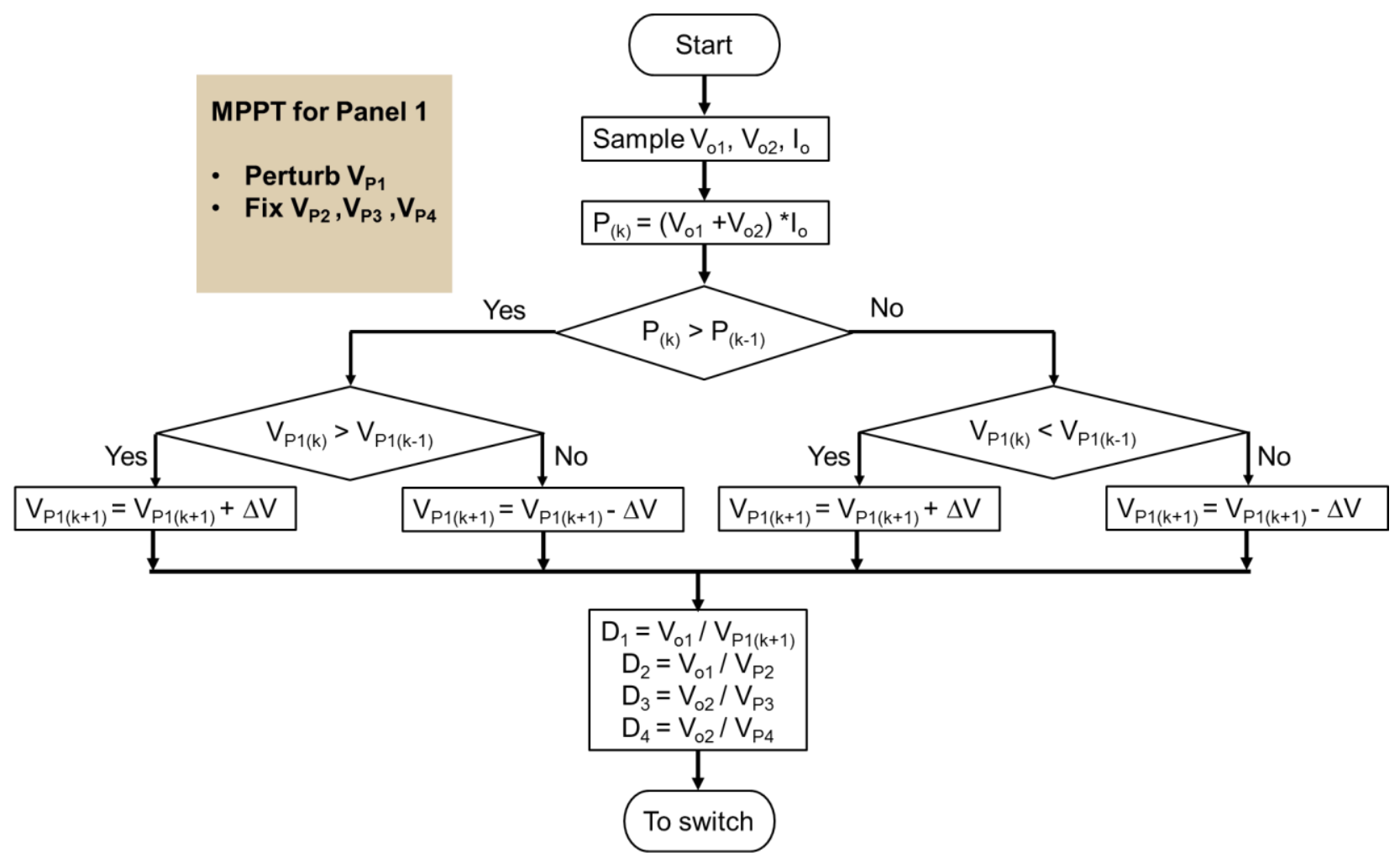

Figure 3.10 Flowchart diagram of MPPT algorithm during tracking panel 1 period 


\subsection{Simulation Verification of Multi-Phase Smart Converter}

\section{A. Average model of smart converter}

The simulation model for a single phase buck type smart converter is built in Matlab/Simulink, as shown in Fig. 3.11. According to the simplified model given in equation 2.4, PV panel behaves as a voltage controlled current source. To simulate the PV panel output characteristic, a model of PV panel is built based on I-V curve datasheet of PV panel. In this model, the output voltage of PV panel $\mathrm{V}_{\mathrm{pv}}$ is sensed and then sent to lookup table which stores the datasheet of I-V curve for PV panel. The lookup table sends the output current value of PV panel to controlled current source, so the model of PV panel has the same output characteristic as the real PV panel.

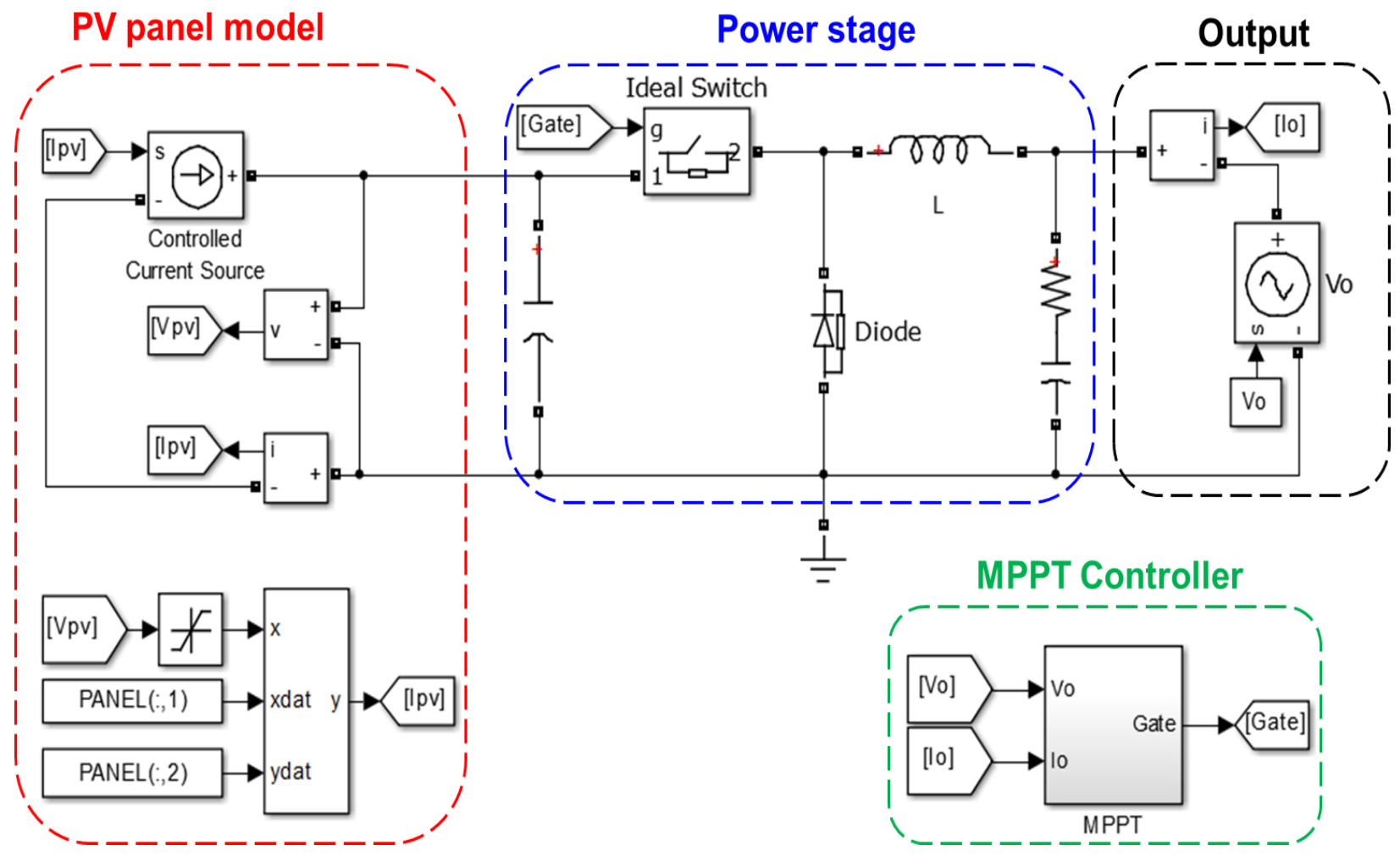

Figure 3.11 Simulation schematic of smart converter based on switching model 
Because the output side of smart converter PV system is connected with DC bus in dc nanogrid, to simplify the analysis, we assume that a single phase smart converter is connected with a constant voltage source $\mathrm{V}_{\mathrm{o}}$.

The converter output voltage $\mathrm{V}_{0}$, and output current $\mathrm{I}_{0}$, are sent to MPPT controller to output gate drive signal for the buck converter. The MPPT algorithm is based on Perturbation \& Observation method, and its flowchart is given in Fig. 3.10.

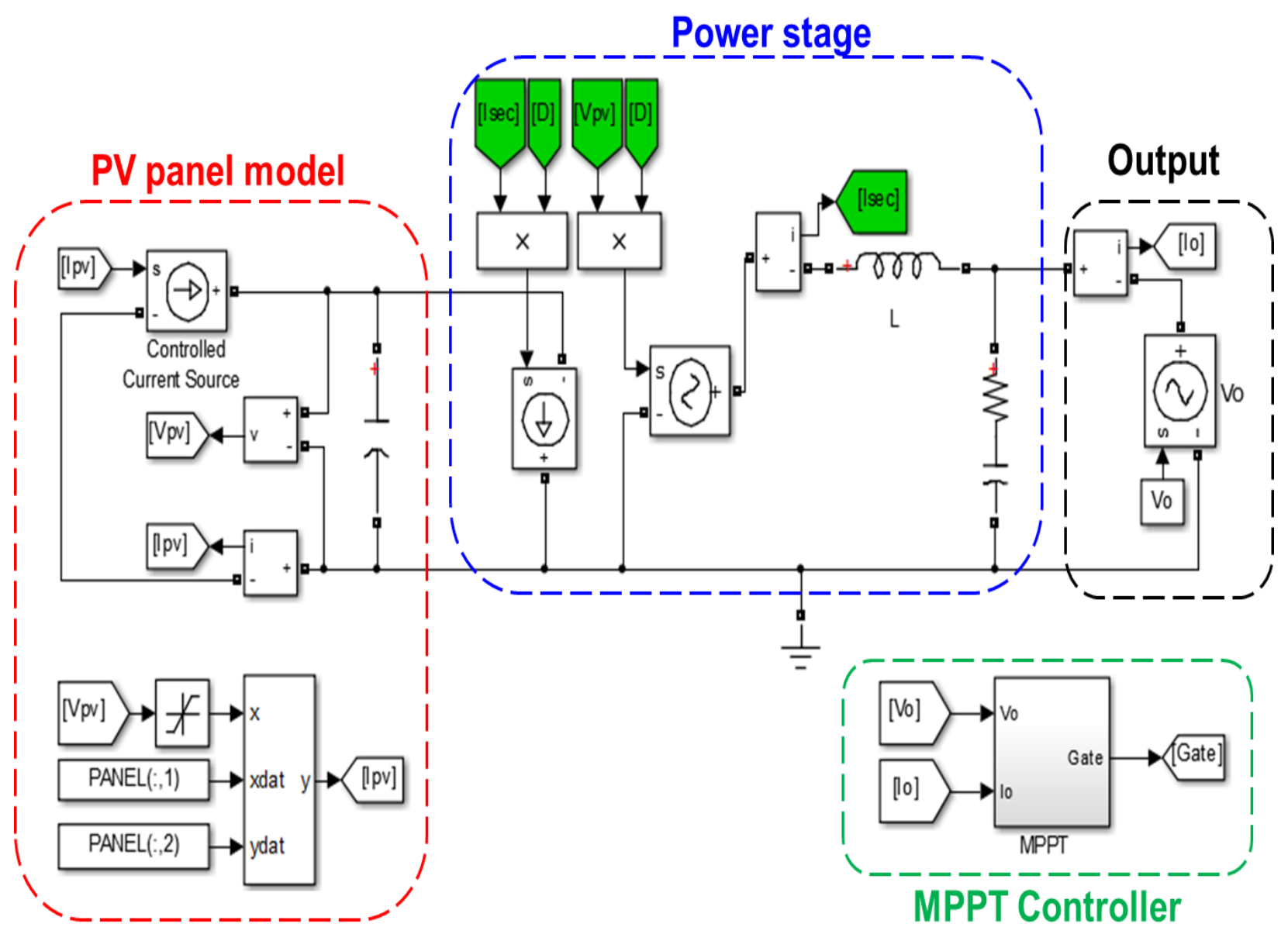

Figure 3.12 Simulation schematic of smart converter based on average model

The power stage shown in Fig. 3.11 is built with switching model. However, simulation for the power converter with switching model is very time consuming, especially for a system with 
multiple converter. To reduce the simulation time, a simulation model is built with average model as shown in Fig. 3. 12.

In the average model of buck type converter, a DC transformer is used to replace the switching network. For the DC transformer, the primary current is equal to the product of duty cycle $\mathrm{D}$ and secondary current $\mathrm{I}_{\mathrm{sec}}$, and the secondary voltage is equal to the product of duty cycle $\mathrm{D}$ and primary voltage $\mathrm{V}_{\mathrm{pv}}$.

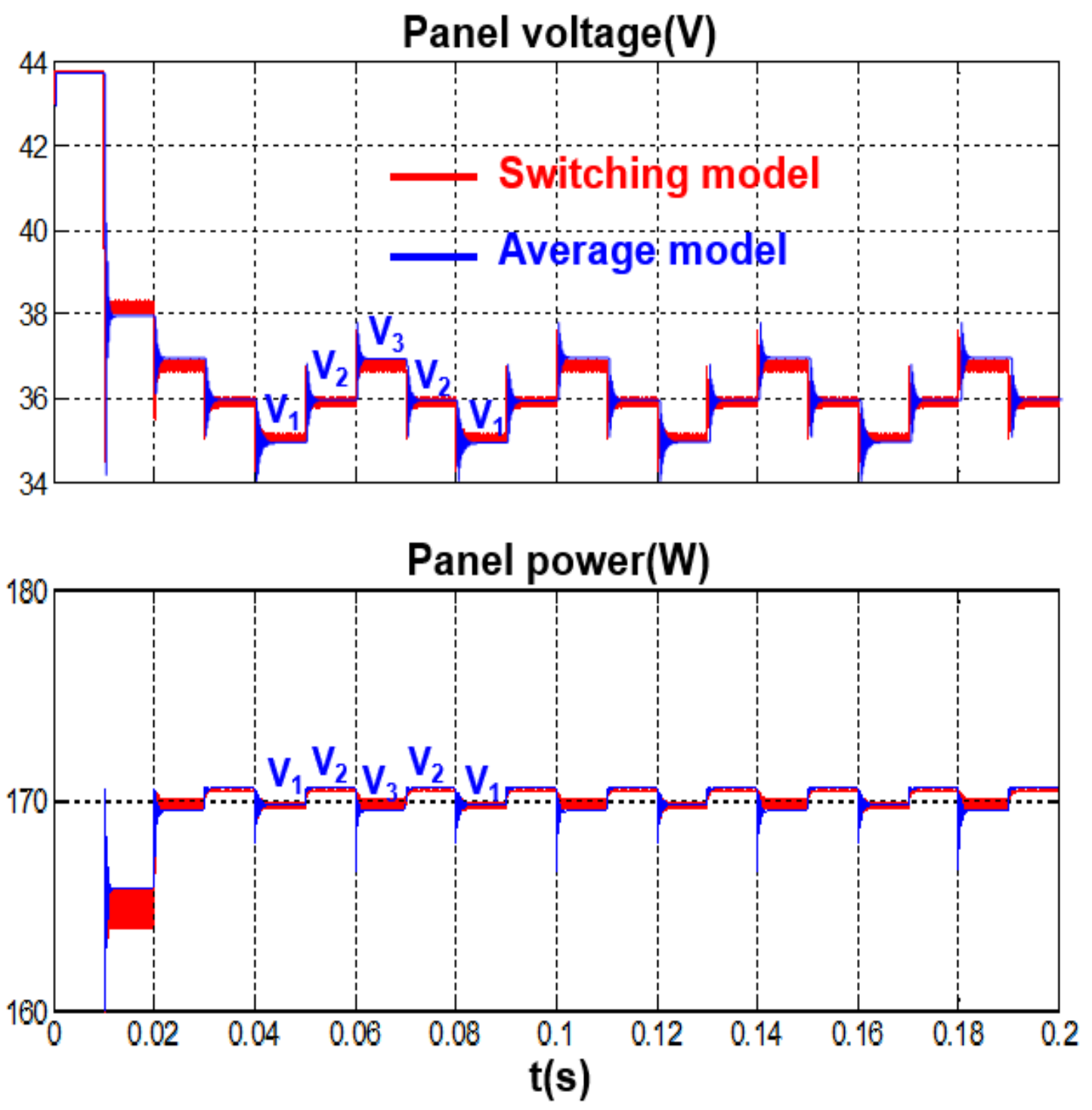

(a) Comparison of switching model and average model for smart converter 


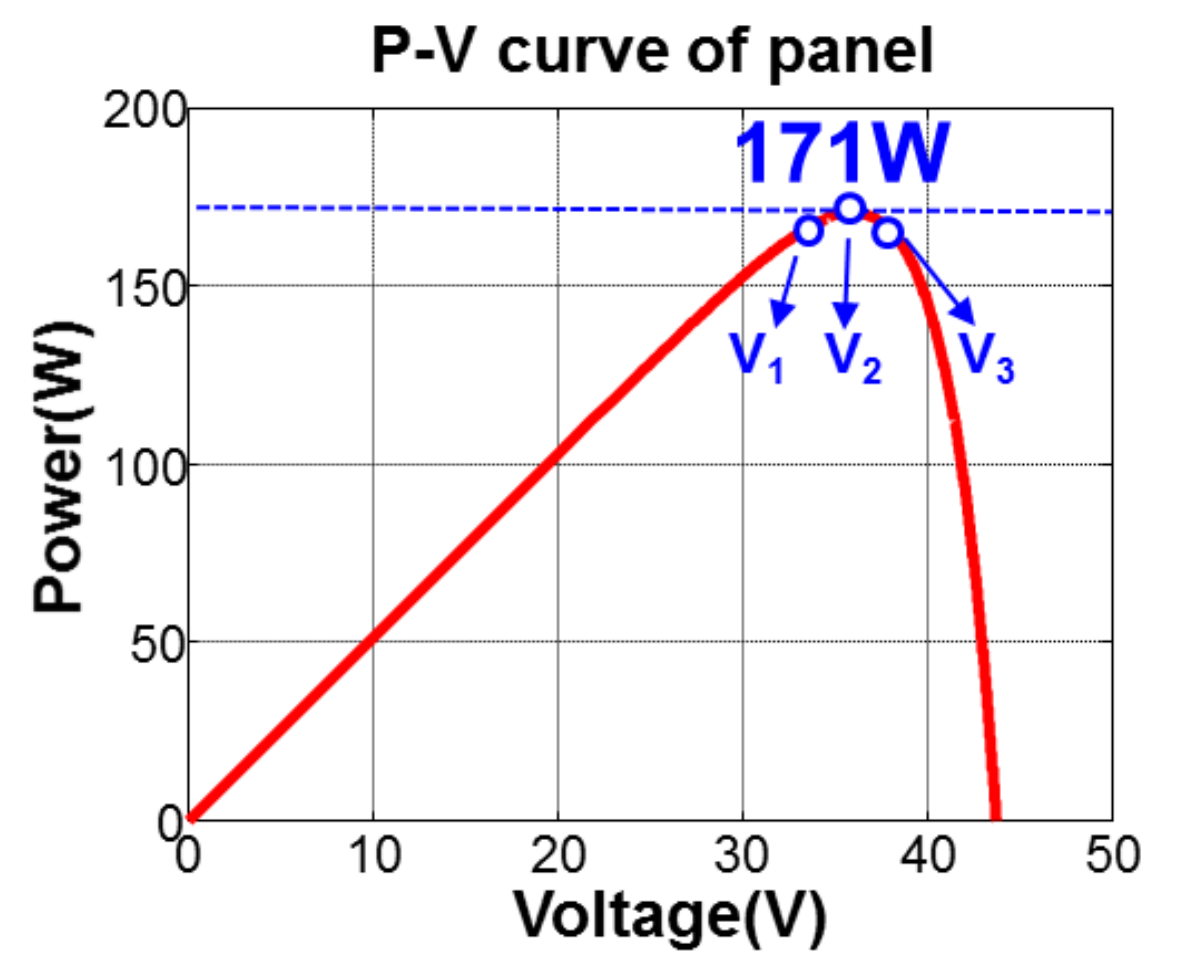

(b) P-V curve of PV panel

Figure 3.13 Simulation of smart converter with switching and average model

The comparison of simulation result for switching model and average model is given in Fig.

3. 13. This simulation shows the panel voltage is continuously reduced from the open circuit voltage during the MPPT process. After the operation point reaches the peak power point $\mathrm{V}_{2}$, the panel voltage keeps perturbing among $\mathrm{V}_{1}, \mathrm{~V}_{2}$, and $\mathrm{V}_{3}$, which means the panel can constantly deliver maximum power. According to the P-V curve of PV panel shown in Fig. 3. 13(b), it clearly demonstrates that the MPPT algorithm can deliver maximum power from PV panel. The waveforms of average model can match the switching model very well. Therefore, the smart converter with average model can be used to simulate the behavior of smart converter with switching model. 


\section{B. Simulation for multi-phase smart converter}

Based on the average model for single phase smart converter shown in Fig. 3.12, the simulation model for four-phase buck converter with average model is shown in Fig. 3.14(a). The equivalent switching model for the model below is shown in Fig. 3.8. In order to demonstrate the proposed MPPT solution can deliver peak power from PV panels with nonuniform solar irradiance, the four panels in this simulation have different irradiance level, as shown in Fig. 3.14(b). The parameters for the simulation are listed in Table 3.1.

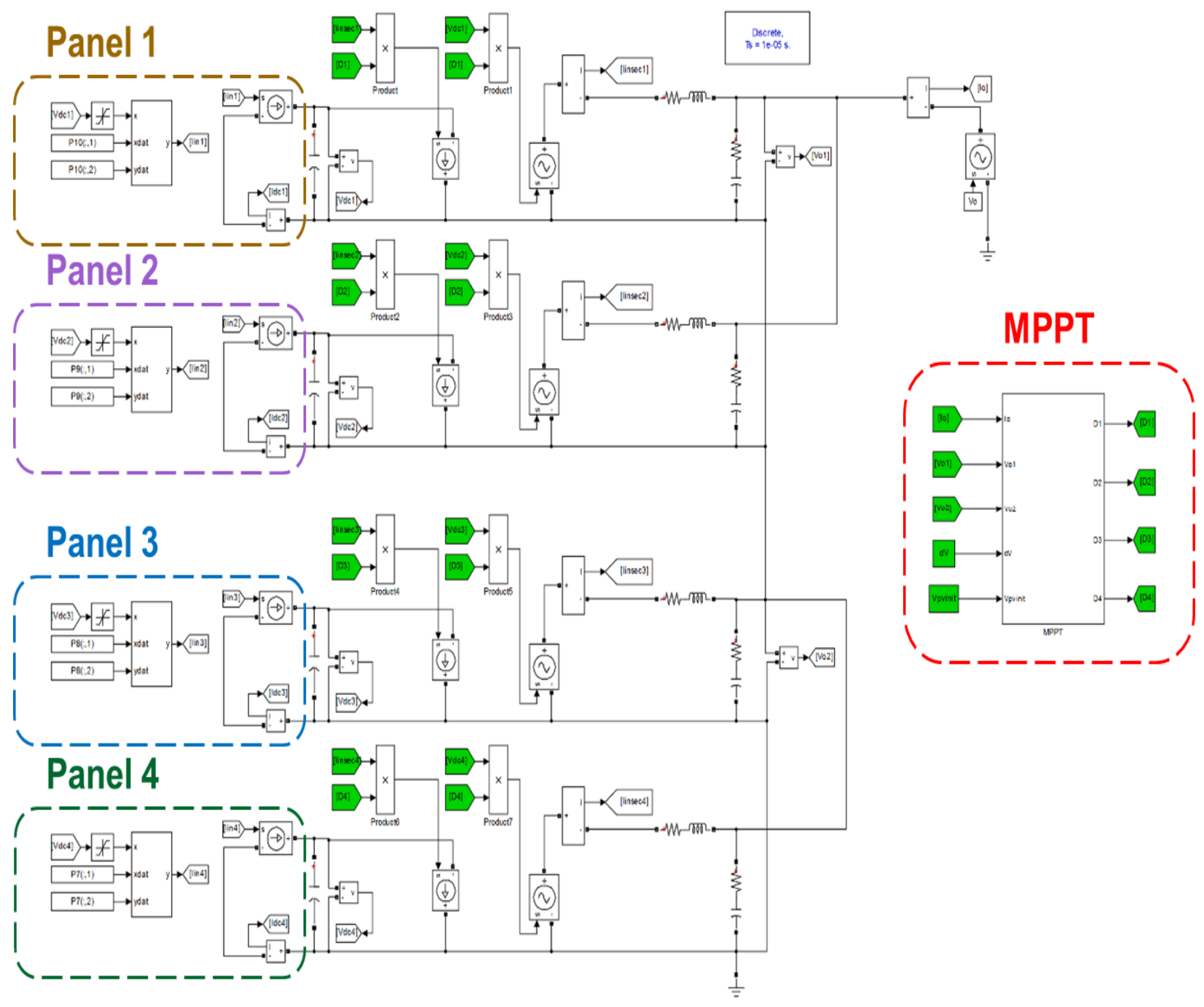

(a) Simulation model of four-phase buck converter 


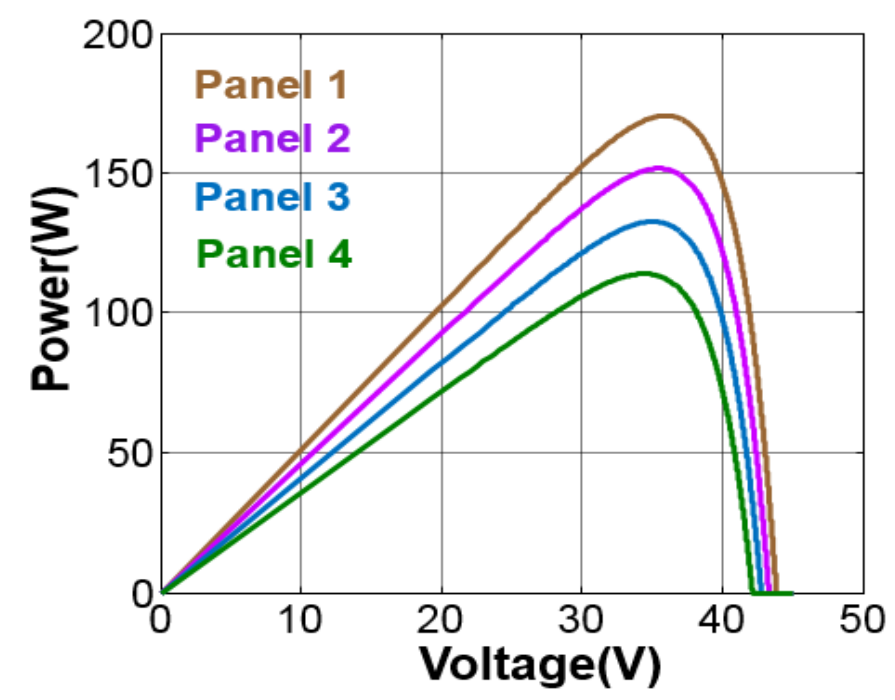

(b) P-V curves of four panels

Figure 3.14 Simulation of four-phase buck converter

Table 3.1 Simulation parameters for four-phase buck converter

\begin{tabular}{|c|c|c|}
\hline \multirow{5}{*}{ Solar irradiance } & Solar irradiance on panels & $\begin{array}{c}\text { Panel 1: } 1000 \mathrm{~W} / \mathrm{m}^{2}, \text { Panel 2: } 900 \mathrm{~W} / \mathrm{m}^{2} \\
\text { Panel 3: } 800 \mathrm{~W} / \mathrm{m}^{2}, \text { Panel 4: } 700 \mathrm{~W} / \mathrm{m}^{2}\end{array}$ \\
\cline { 2 - 3 } & Maximum power of panels & $\begin{array}{c}\text { Panel 1: } 171 \mathrm{~W}, \text { Panel 2: } 152 \mathrm{~W} \\
\text { Panel 3: } 132 \mathrm{~W}, \text { Panel 4: } 113 \mathrm{~W} \\
\text { Total peak power: } 568 \mathrm{~W}\end{array}$ \\
\hline \multirow{5}{*}{ MPPT } & Initial panel voltage & $40 \mathrm{~V}$ \\
\cline { 2 - 3 } & Voltage step size & $0.5 \mathrm{~V}$ \\
\cline { 2 - 3 } & Sampling period & $5 \mathrm{~ms}$ \\
\cline { 2 - 3 } & MPPT period on each panel & $200 \mathrm{~ms}$ \\
\hline \multirow{5}{*}{ Power stage } & Inductor & $10 \mathrm{uH}$ \\
\cline { 2 - 3 } & Input capacitor & $47 \mathrm{uF}$ \\
\cline { 2 - 3 } & Output capacitor & $5 \mathrm{uF}$ \\
\hline
\end{tabular}



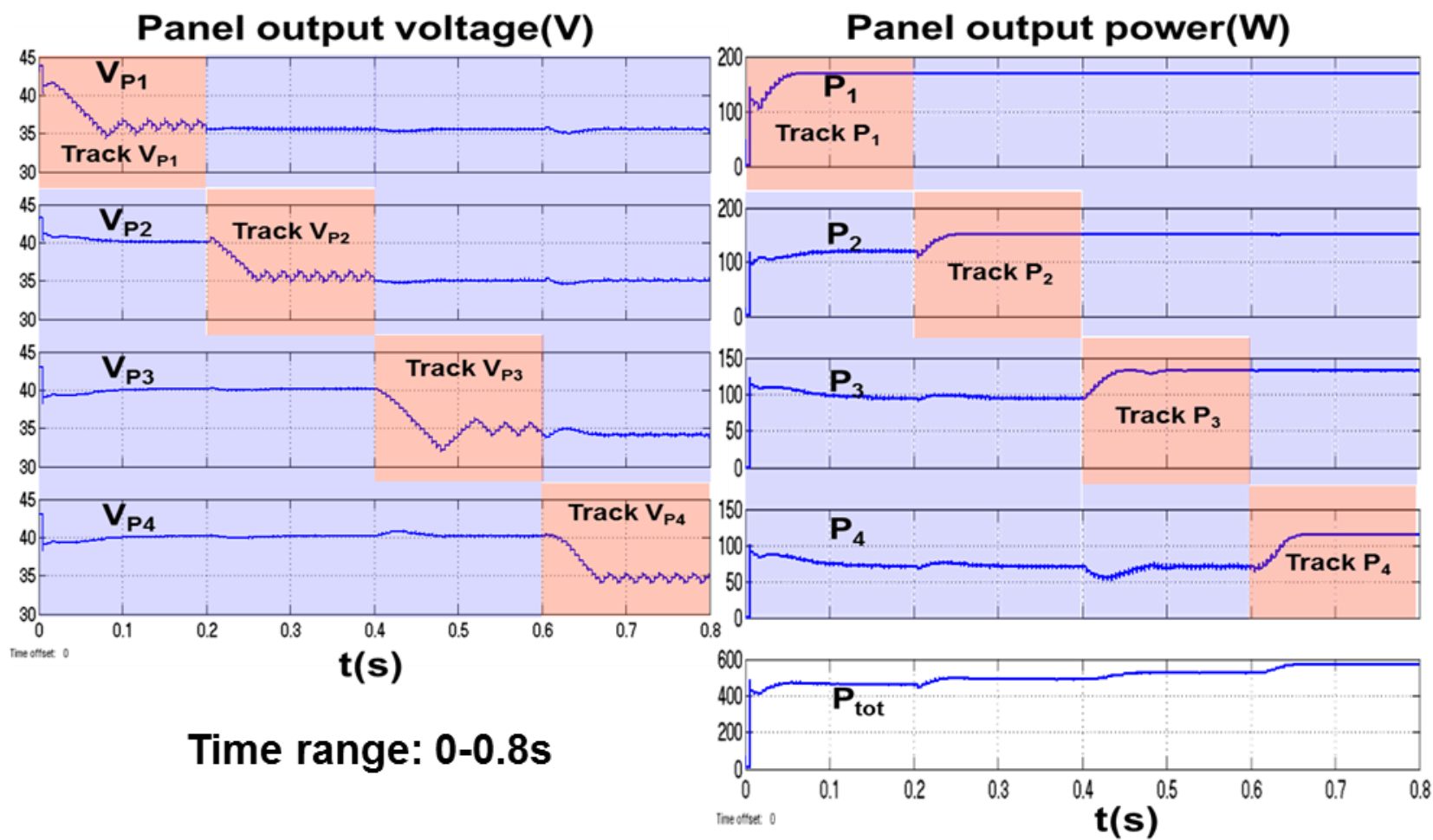

(a) Startup waveforms of panel voltage and panel power
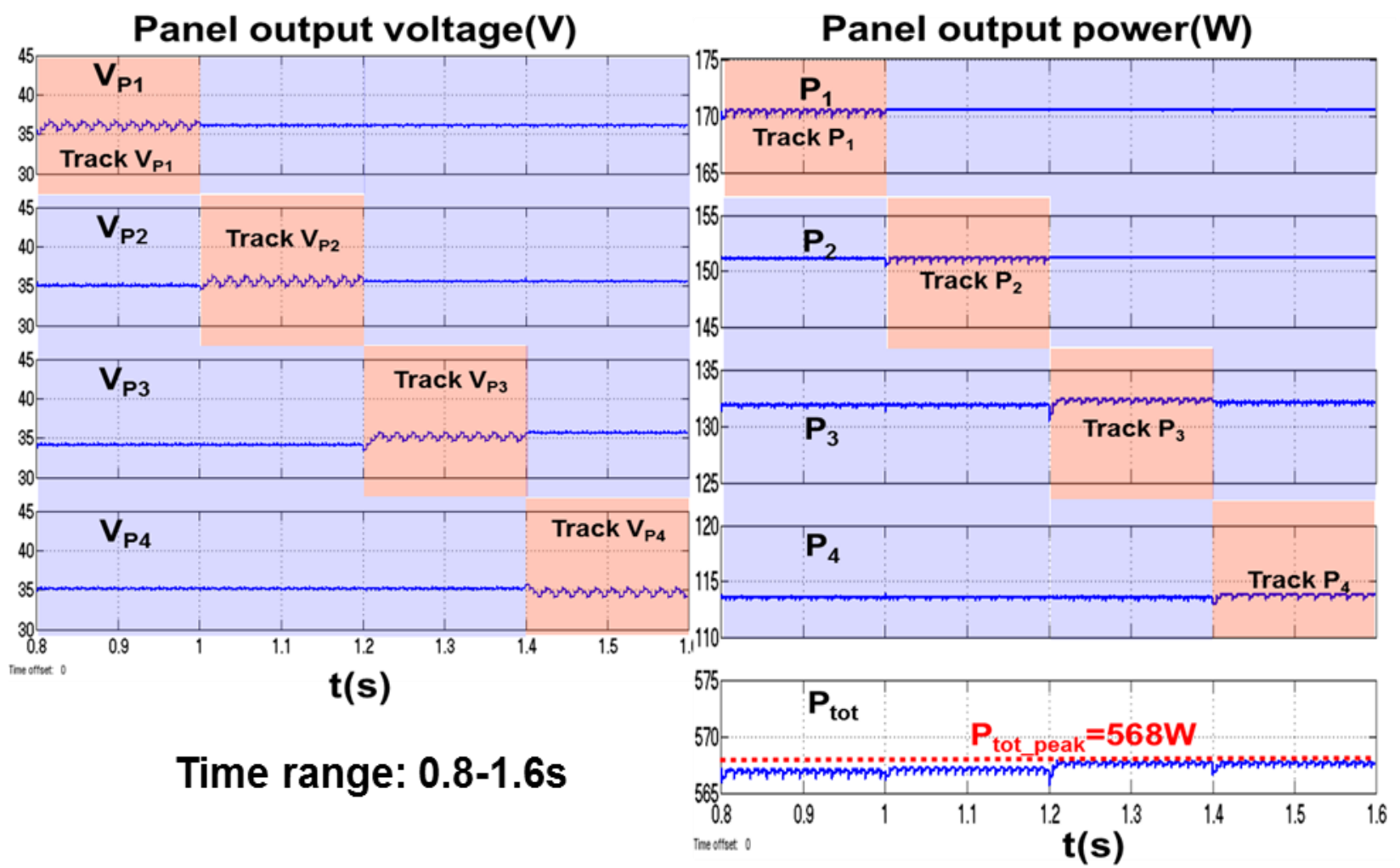

(b) Steady state waveforms of panel voltage and panel power 


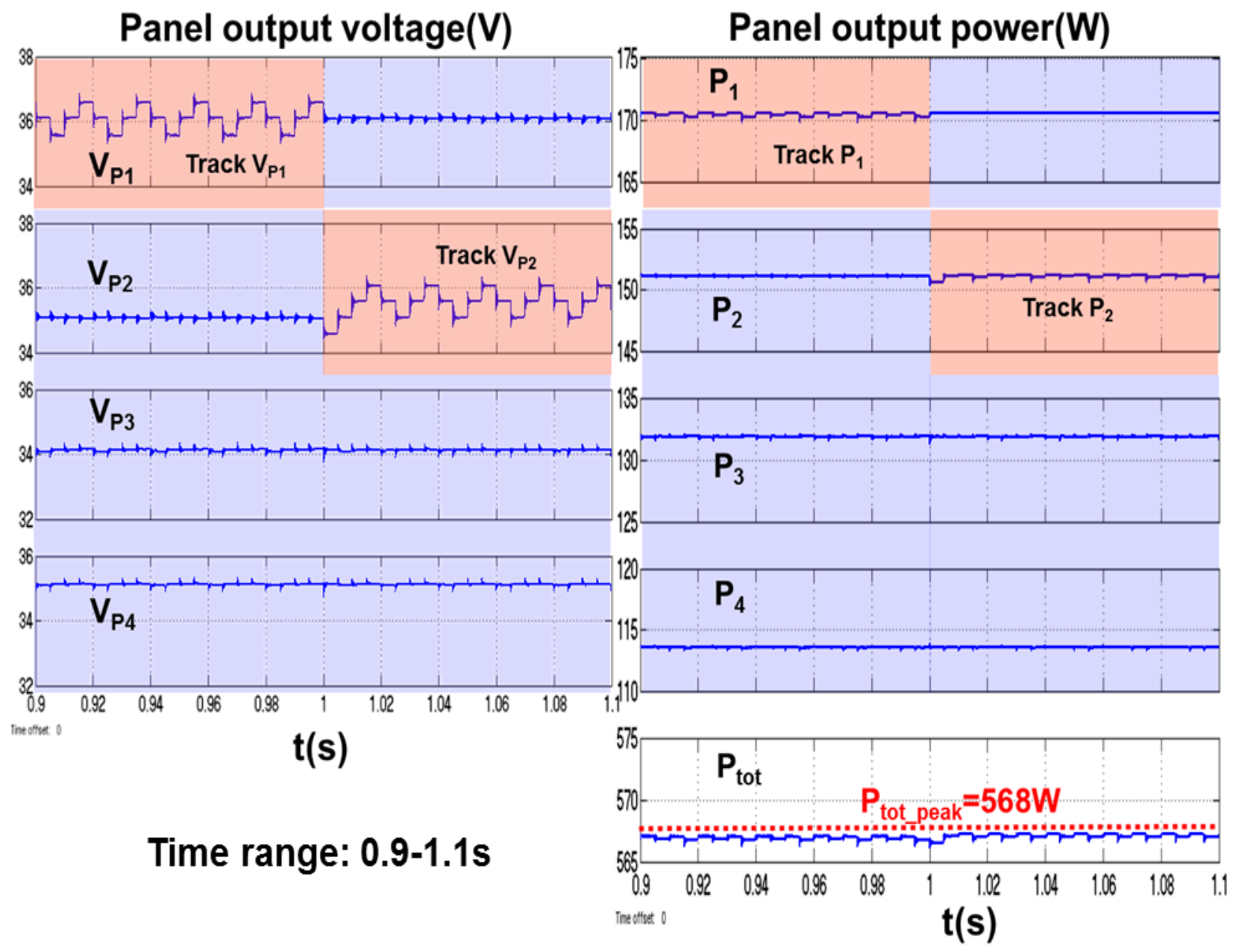

(c) Steady state waveforms during tracking panel 1 and panel 2 period

Figure 3.15 Simulation results of four-phase buck converter

Fig. 3.15(a) shows the startup waveforms of panel voltage and panel power. During the first time interval $0-0.2 \mathrm{~s}$, the controller is tracking the peak power point of panel 1 and fixing other three panels' voltage at initial voltage $40 \mathrm{~V}$. Hence, the output power of other three panels are basically constant but the output power of panel 1increased to its peak value.

During the second interval $0.2-0.4 \mathrm{~s}$, the controller is tracking the peak power point of panel 2. Meanwhile, the voltage of panel 1 is fixed at its peak power point, but the voltage of panel 3 and panel 4 is still fixed at initial voltage $40 \mathrm{~V}$. Therefore, panel 1 continues to deliver its peak 
power, panel 2 gradually increases its output power to the peak value, and the other two panels still output the same power as they do during the first time interval.

Using the same method, the controller can track the peak power point of panel 3 and panel 4 in the third time interval and the fourth time interval respectively.

Fig. 3.15(b) shows the steady state waveforms from 0.8-1.6s. During the first time interval, the controller is track panel 1 , so the voltage of panel 1 is perturbing around the peak power point while the voltage of other three panels is fixed at the peak power point. In the second time interval, the voltage of panel 2 is perturbing around its peak point, but the voltage of other three panels is fixed at its peak power point.

Using the same method, the controller can perturb the voltage of other two panels around its peak during the next two time intervals. Therefore, in the steady state, all the panels work in two modes: one is perturbing around its peak point, and the other one is fixed at its peak power point. Fig. 3.15(c) shows the zoomed waveform during 0.9-1.1s, which clearly indicates in the steady state the voltage of tracked panel is perturbed around its peak power point and the voltage of untracked panel is fixed at its optimal operation point.

\section{Simulation for multi-phase smart converter with changing irradiance}

In the above section, the model is simulated under constant solar irradiance condition. However, in the real condition, the solar irradiance can be affected by the solar positions, clouds, etc. Fig.3.16 gives the real measurement data of solar irradiance which shows the maximum rate of irradiance change in different season. According to the data, the highest change rate of

irradiance is $50 \mathrm{~W} / \mathrm{m}^{2} / \mathrm{s}$, which means the sunlight can drops from the standard value $1000 \mathrm{~W} / \mathrm{m}^{2}$ to half standard value within 10 seconds. 
Real measurement data@Jan 5, 2013, CA

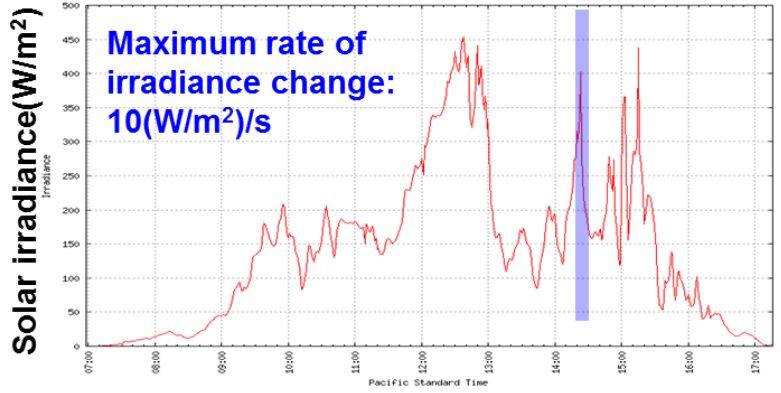

Real measurement data@July 4, 2013, CA

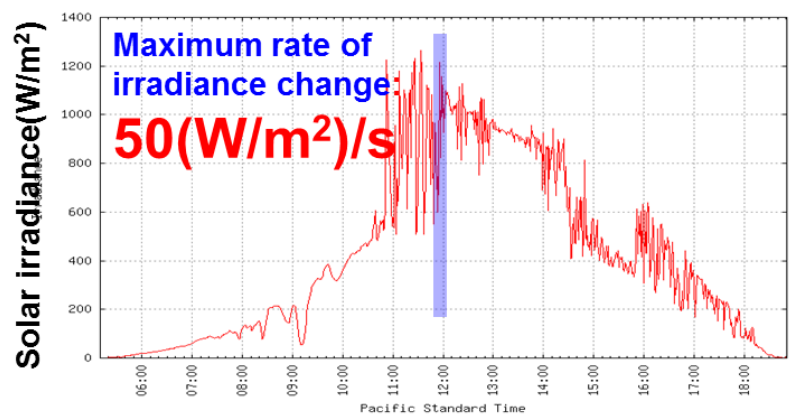

Real measurement data@April 5, 2013, CA

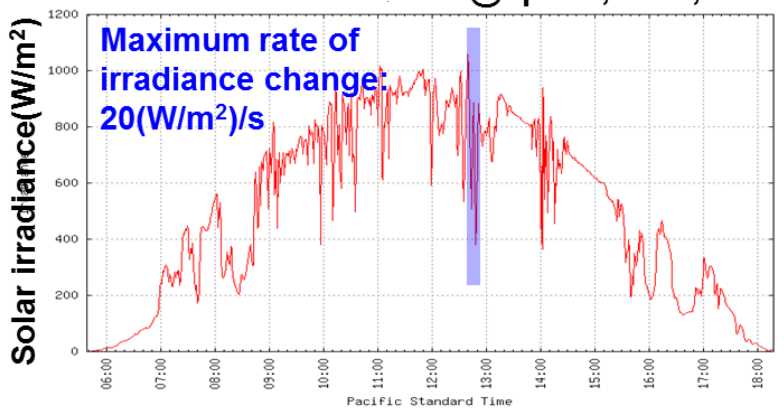

Real measurement data@October 5, 2013, CA

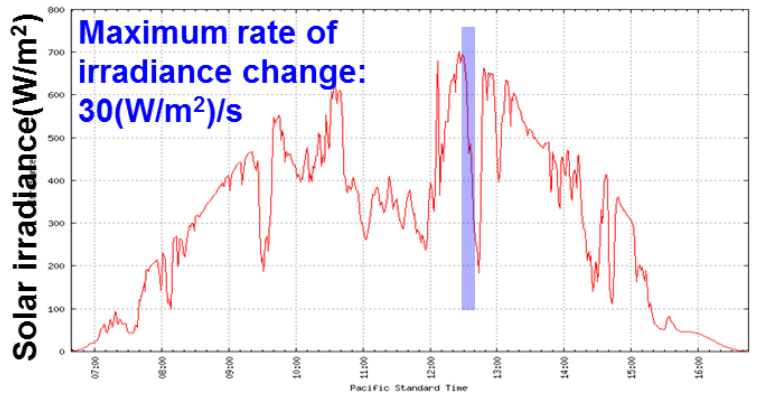

Figure 3.16 Data of variant solar irradiance
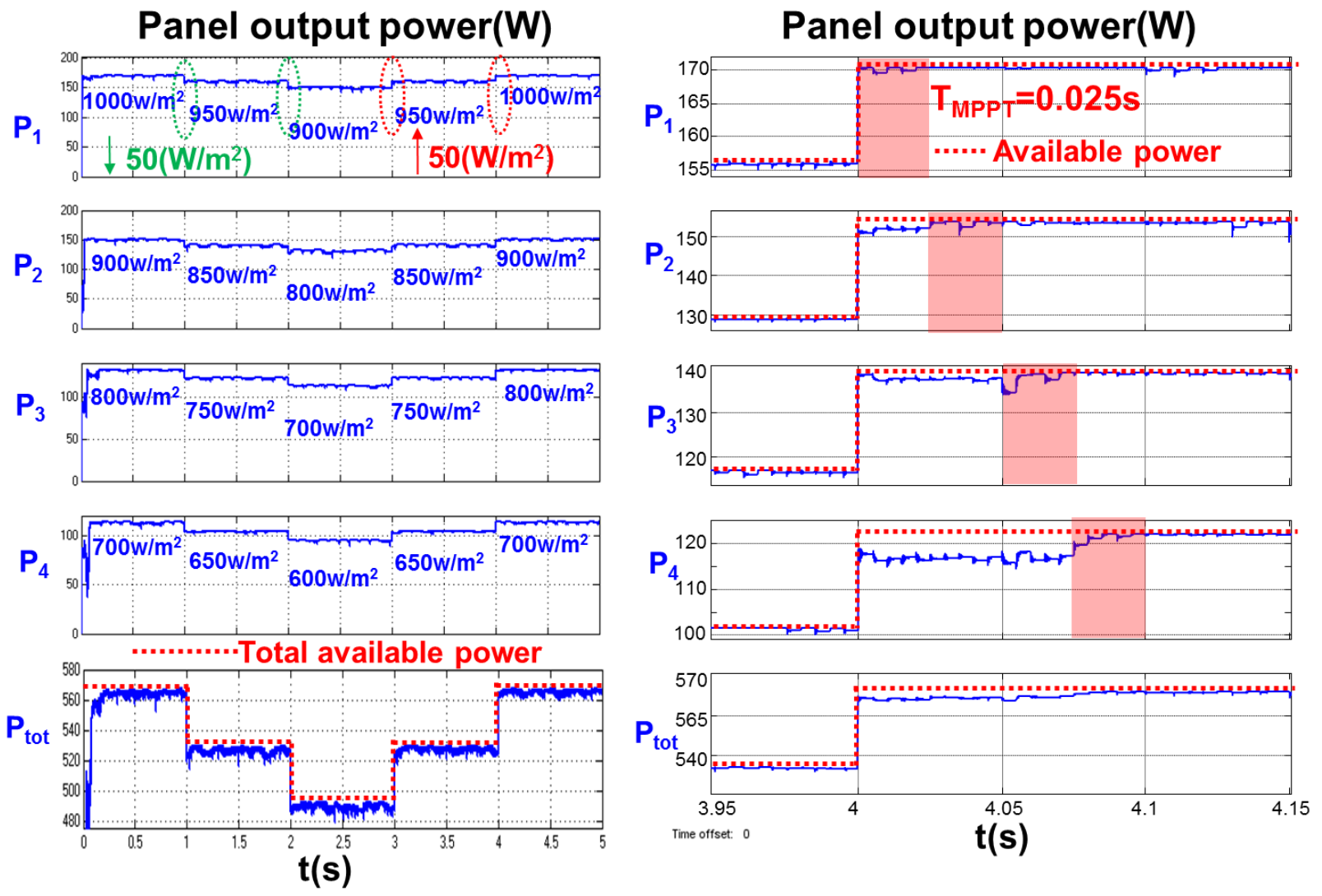

Figure 3.17 Simulation with variant solar irradiance 
To investigate the impact of variant irradiance on MPPT performance, Fig. 3.17 shows the simulation results for four-phase smart converter under solar irradiance with maximum changing rate $50 \mathrm{~W} / \mathrm{m}^{2} / \mathrm{s}$. To enable fast response to overcome the impact of variant irradiance, the MPPT period is set to $25 \mathrm{~ms}$ in this simulation.

As shown in Fig. 3.17, the solar irradiance on each panel increases $50 \mathrm{~W} / \mathrm{m}^{2}$ at $\mathrm{t}=1 \mathrm{~s}$ and $\mathrm{t}=2 \mathrm{~s}$, and then decreases $50 \mathrm{~W} / \mathrm{m}^{2}$ at $\mathrm{t}=3 \mathrm{~s}$ and $\mathrm{t}=4 \mathrm{~s}$. The red dash line shows the total available power, which is very close to simulated output power of four panels. The right hand side of Fig.3.17 gives the zoomed waveforms from 3.95 to 4.15 s. It shows that after the solar irradiance changes, panel 1 can reach its new optimal operation point after one MPPT period, 25ms, and panel 2 can reach its new peak point after two MPPT period, 50ms.

Similarly, panel 3 and panel 4 can also reach the new optimal point after $75 \mathrm{~ms}$ and $100 \mathrm{~ms}$ respectively. According to the waveform of total output power, the maximum difference between the simulation output power and total available power is less than $10 \mathrm{~W}$, and the simulation output power can reach the total available power after $100 \mathrm{~ms}$.

Therefore, the proposed multi-phase smart converter can quickly track the maximum power point under changing irradiance condition. Actually, the MPPT performance can be even better if continuing to optimize the MPPT parameters, such as voltage step size and sampling period.

\section{Simulation of $5 K W P V$ system with multi-phase smart converter}

Based on the system architecture shown in Fig. 2.15(a), a 5kW PV system is built with 28 PV panels, which are interfaced with DC bus by seven four-phase smart converter as shown in Fig. 3.18(a). The solar irradiance distribution is same as Fig. 2.8(a), and the simulation waveform of system output power is given in Fig.3.18 (b). 


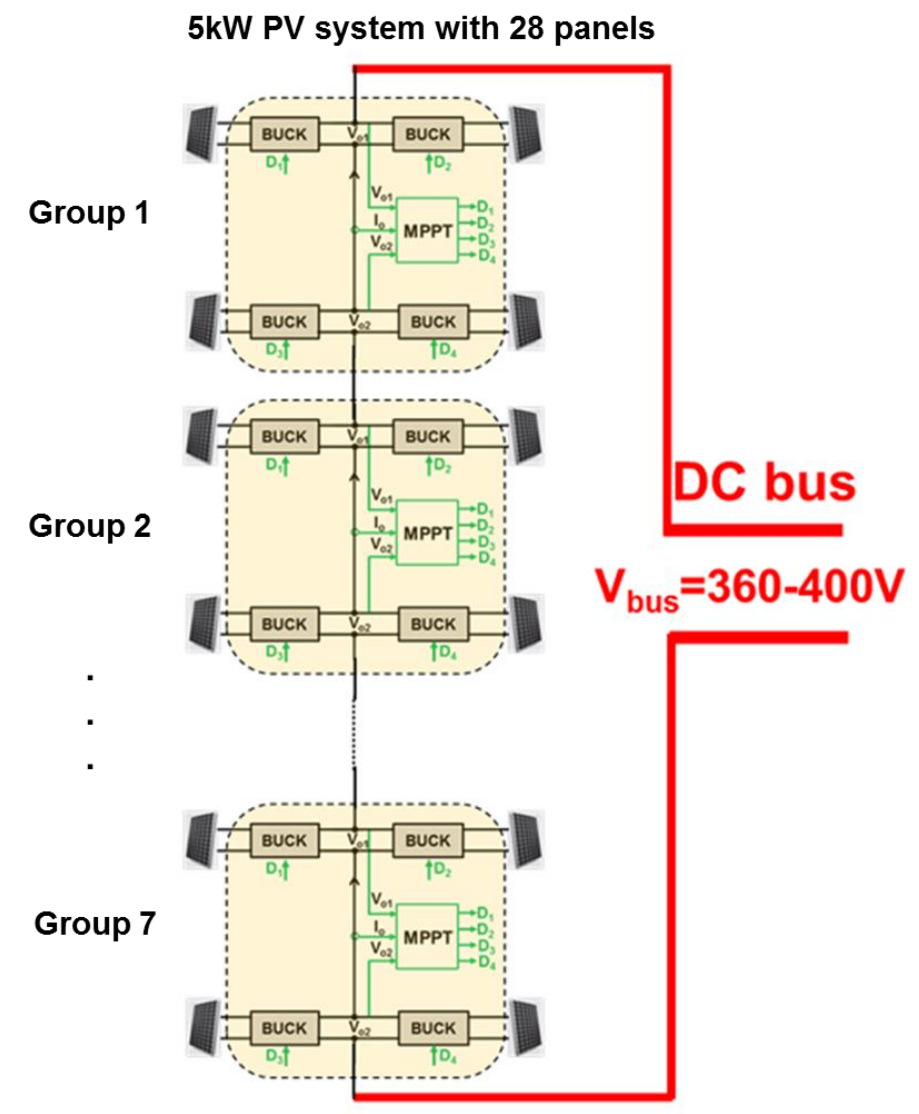

(a) System architecture for 5kW PV system

\section{$\mathbf{P}_{\text {Group1 }}(\mathbf{W})$}

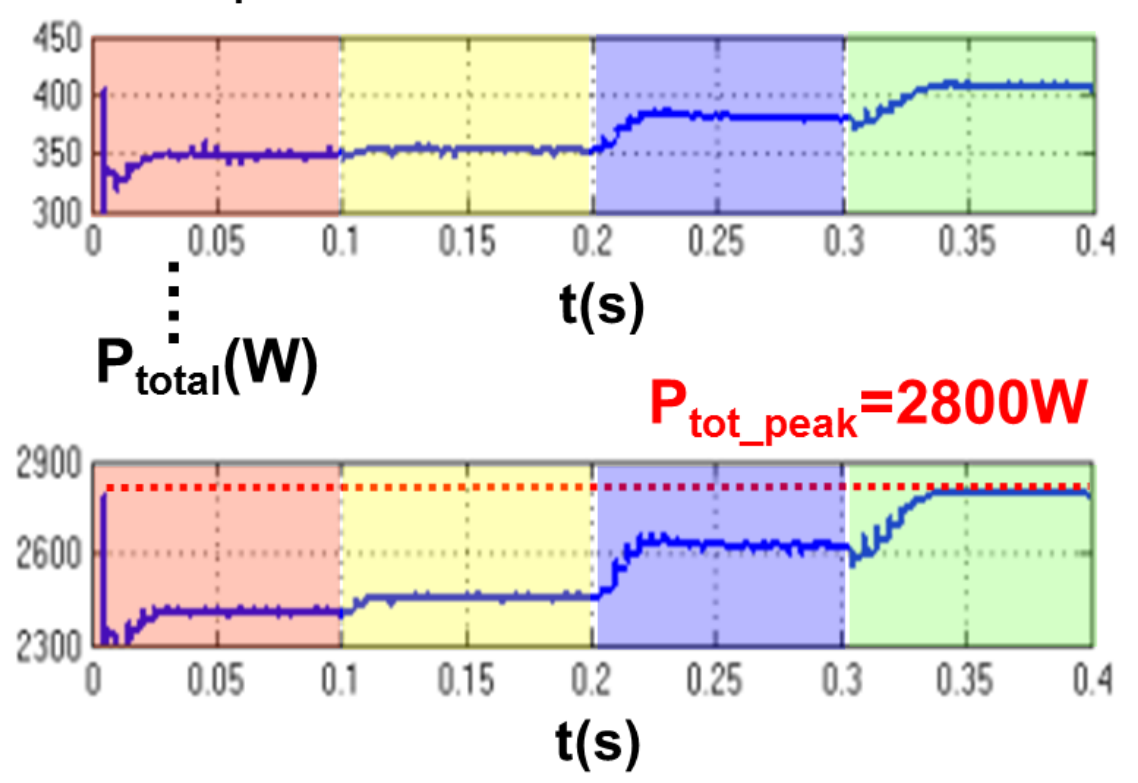

(b) Simulation waveforms of system output power

Figure 3.18 Simulation of 5kW PV system 
Similar to the waveform for output power of group 1, the system output power gradually builds up. After four MPPT periods that are noted as colored region in the figure below, which mean all the panels in the system has been tracked, the system output power reaches the total available power, $2800 \mathrm{~W}$.

This simulation shows that multi-phase smart converter PV system can connect to DC bus without $2^{\text {nd }}$ stage central converter. Moreover, compared to the traditional smart converter PV system, the proposed solution can largely reduce MPPT controllers, current and voltage sensors. Table 3.2 gives the comparison results.

Table 3.2 Comparison between traditional and proposed smart converter.

\begin{tabular}{|c|c|c|}
\hline \multirow{2}{*}{$\begin{array}{c}\text { The number of } \\
\text { component }\end{array}$} & 5kW PV system with 28 PV panels \\
\cline { 2 - 3 } & smart converter & Proposed four-phase \\
\hline Converter & 28 & smart converter \\
\hline MPPT controller & 28 & 7 \\
\hline Current sensor & 28 & 7 \\
\hline Voltage sensor & 28 & 14 \\
\hline
\end{tabular}




\section{E. Simulation of extended structure for multi-phase smart converter}

The simulations above demonstrate that four-phase smart converter is doable. In this section, the simulation shows the multi-phase smart converter can handle multiple phase in both parallel and series connection. For example, Fig. 3.19 gives a nine-phase smart converter with 3 rows and 3 panels per row. The solar irradiance on each panel is listed in the figure, which varies from $1000 \mathrm{~W} / \mathrm{m}^{2}$ to $400 \mathrm{~W} / \mathrm{m}^{2}$. Fig 3.20 shows the output power of each panel. The peak power point of each panel is tracked in turn, and then the total output power is built up gradually, which is similar to the simulation results of four-phase smart converter.

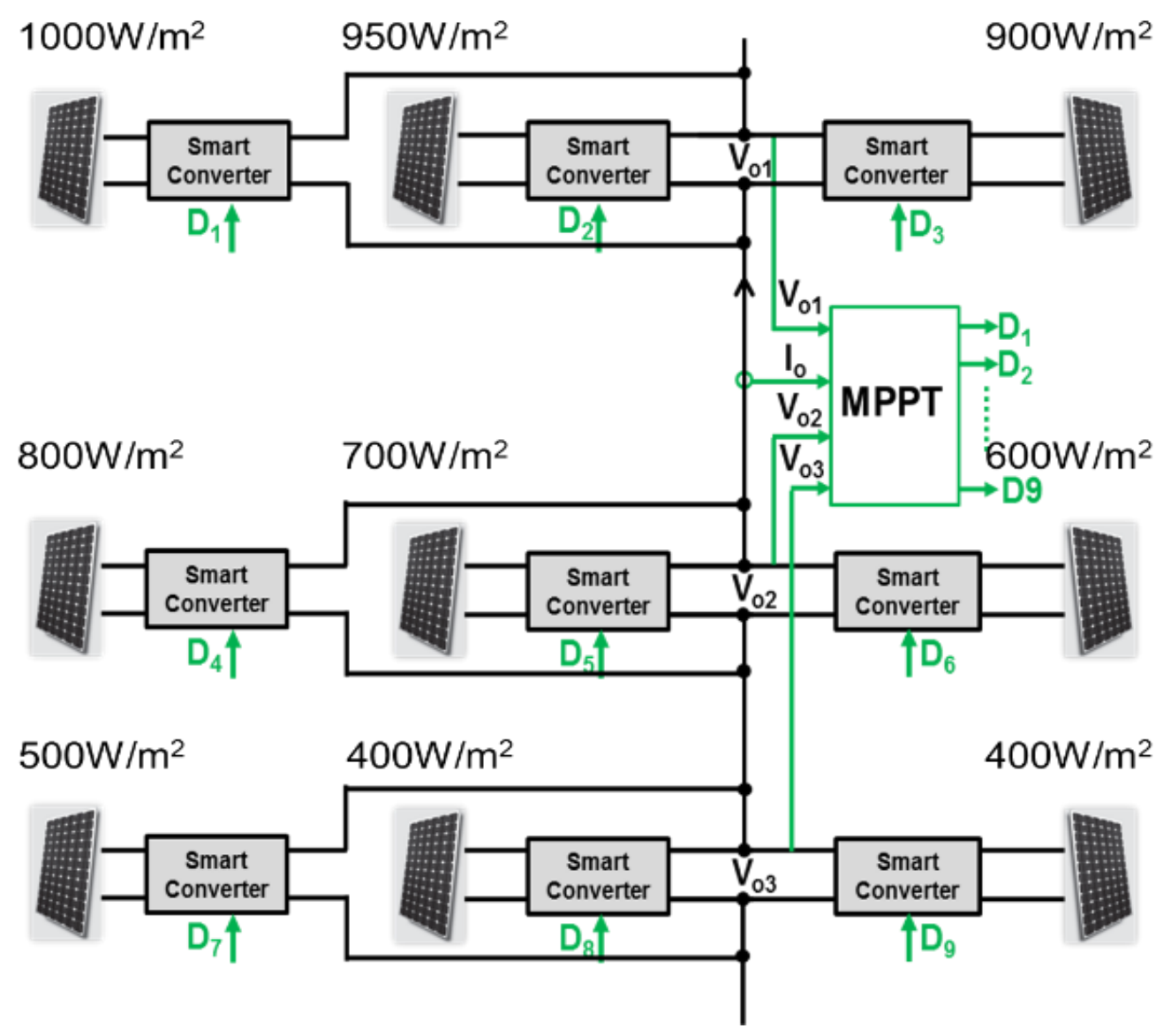

Figure 3.19 Solar irradiance distribution for extended architecture 

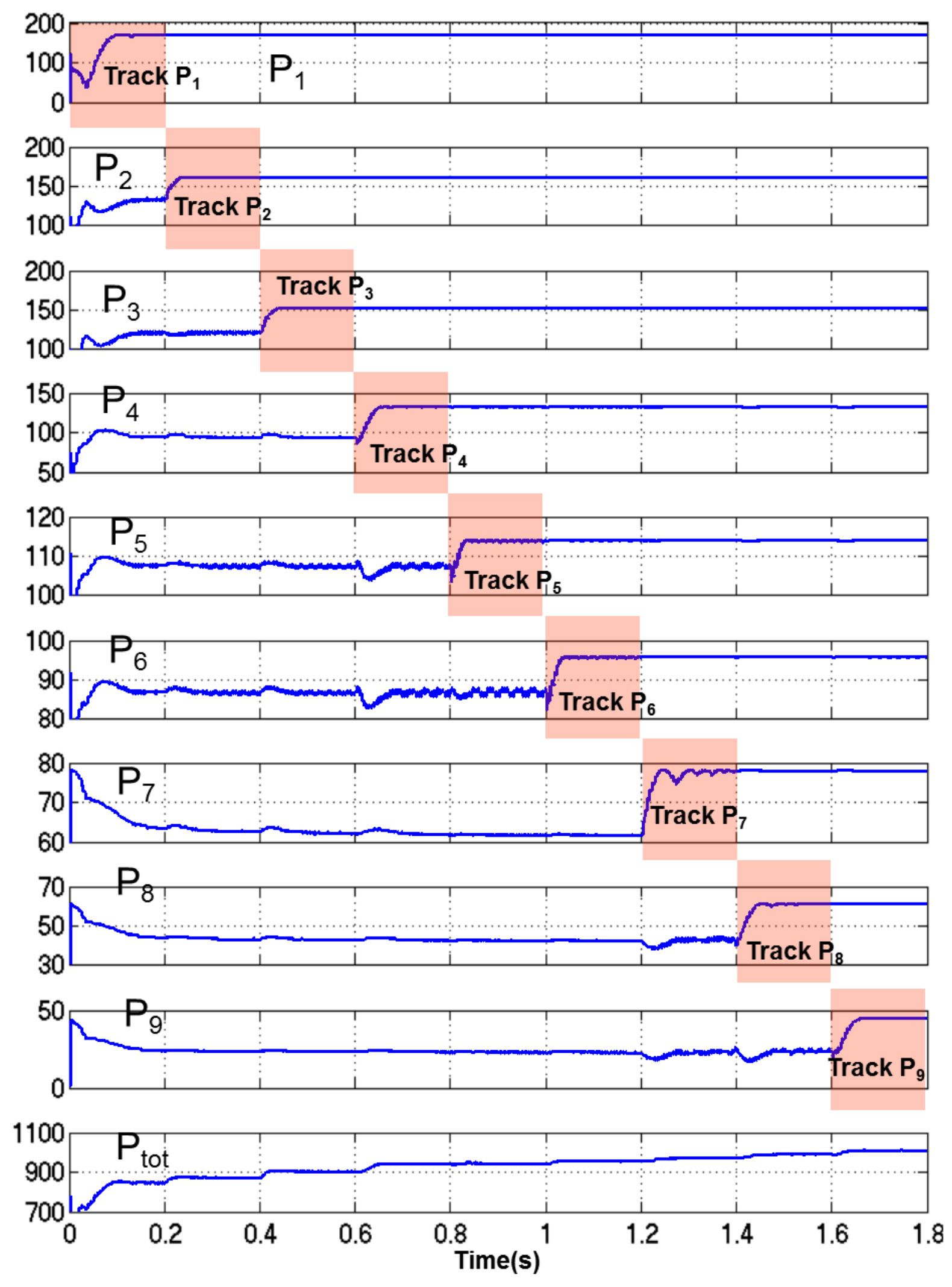

Figure 3.20 Output power of each panel in extended architecture 


\subsection{Experimental Verification of Multi-Phase Smart Converter}

The chapter II mainly introduces how to optimize the PV system architecture based on the case study for a $5 \mathrm{~kW}$ rooftop PV system, so the future goal of experimental verification is to build a 5kW PV system with four-phase buck converter as shown in Fig.3.18(a). Although the scope of this thesis only includes the hardware test of one four-phase buck converter, this converter is designed based on consideration for operation in system level.

\section{A. Converter design}

\section{(1) Converter output current limit}

It is noted in [15] that the output current limit can impact the output characteristic of PV system. To design the output current limit of single phase buck converter, the system behavior must be analyzed first. Fig.3.21 shows how the output current limit impacts the P-V curve of PV array with the shading case shown in Fig.2.11 (a). Because the DC bus voltage is basically fixed in the $360-400 \mathrm{~V}$ region, the red curve in the figure below is preferred because both two curves output the same power at DC bus voltage region but green curve has lower current limit which lowers the requirement on device rating.

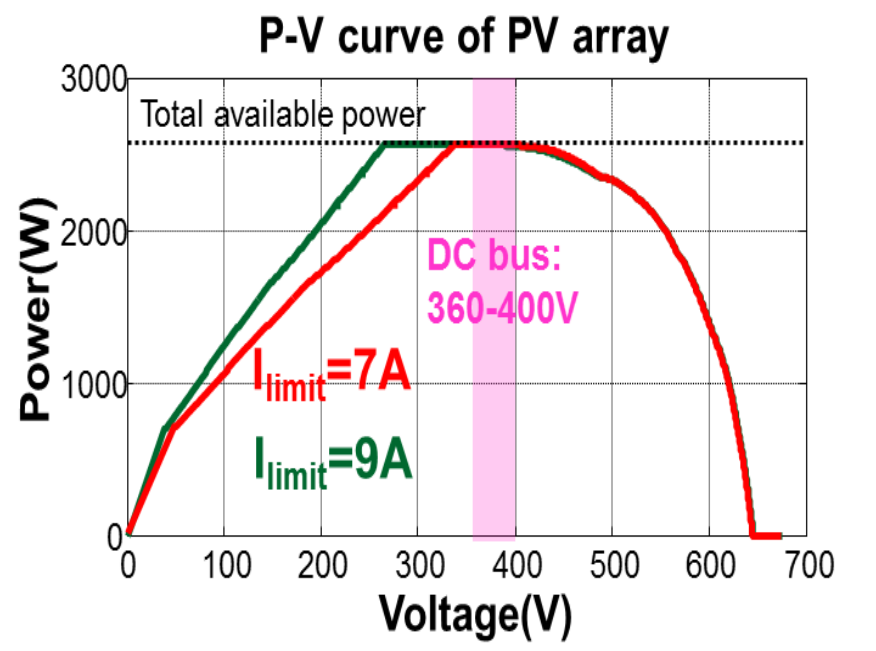

Figure 3.21 Impact of output current limit on P-V curve for PV array 
The rating power of PV system in Fig.2.11 (a) is 5kW, but its total available power in this shading case is lower than $3 \mathrm{~kW}$. Hence, it is reasonable to consider this shading case as a quite heavy shading condition, which means setting $\mathrm{I}_{\text {limit }}$ to $7 \mathrm{~A}$ can deal with most shading cases.

If there is no mismatch on the PV array and all the panels receive standard irradiance level $\left(1000 \mathrm{~W} / \mathrm{m}^{2}\right)$, the output power of each converter, $\mathrm{P}_{\mathrm{o}}$, is equal and thus the output voltage of each converter, $\mathrm{V}_{\mathrm{o}}$, is equal. Fig.3.22 indicates that $\mathrm{I}_{\text {limit }}$ should be higher than 6.6A.

Therefore, $\mathrm{I}_{\text {limit }}$ is set to $7 \mathrm{~A}$, because this value can deal with non-shading case and most shading case to ensure MPPT performance.

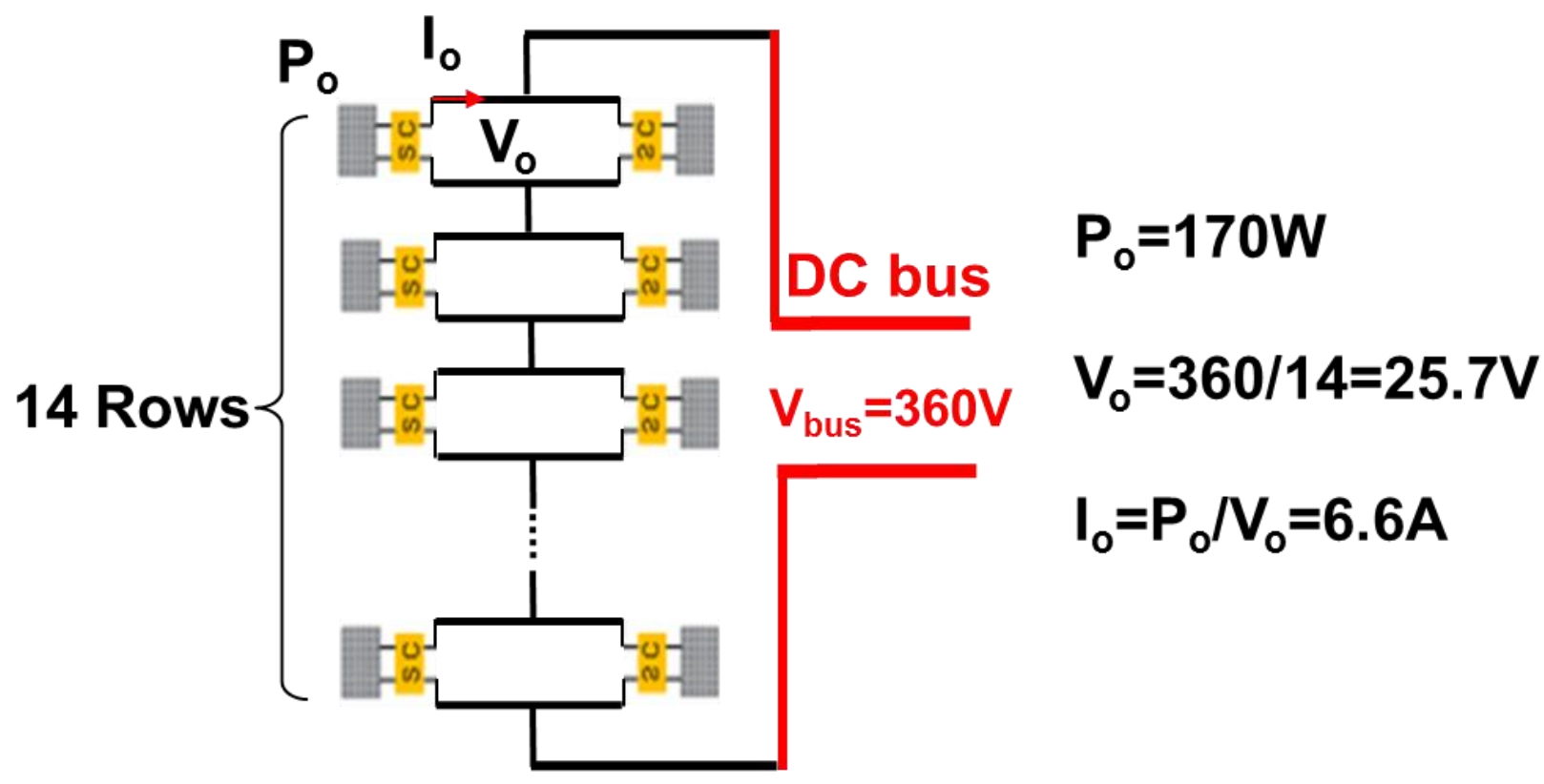

Figure 3.22 The output voltage and current of buck converter in non-shading case

\section{(2) Converter output voltage limit}

According to Table 2.1, the open circuit voltage of PV panel is $43.8 \mathrm{~V}$, and then output voltage limit of the single phase buck converter is $43.8 \mathrm{~V}$. 


\section{(3) Switching frequency}

The design of switching frequency referred to the typical commercial product of traditional smart converter and is chosen to $200 \mathrm{kHz}$, which compromises on converter efficiency and converter size.

\section{(4) Inductor value design}

For the cascaded smart converter PV system, each smart converter has different duty cycle if panel mismatch happens. The converter delivers low power must decrease its output voltage so it can connect in series to other converters delivering high power. Therefore, the basic operation principle for cascaded smart converter is that the converter transferring high power has large duty cycle and the converter transferring low power has small duty cycle. In the real PV application, the partial shaded panel is minority and most of PV panels receive the normal irradiance. Therefore, in the PV system shown in Fig.3.18 (a), most converter operate with large duty cycle.

Based on this principle, the inductor value can be designed to a low value, because the inductor current ripple is relatively low in the large duty cycle region even if a small inductor is used. As noted before, the maximum output current of single phase buck converter is $7 \mathrm{~A}$, and then the maximum inductor current ripple is set to 7A. Equation (3.2) and (3.3) show how to select inductor value based on the maximum inductor current ripple. In these equations, $V_{i n}, D$, and $f_{s}$ stand for input voltage for buck converter, duty cycle, and switching frequency respectively.

According to Fig. 3.23, using an inductor with $6.3 \mathrm{uH}$ can make the current ripple smaller than 4A for the most converters in the PV system. The current ripple ratio is smaller than $60 \%$. 


$$
\begin{gathered}
\Delta I_{L}=V_{\text {in }} \cdot D \cdot(1-D) /\left(L \cdot f_{s}\right) \leq 100 \% \cdot I_{o}=7 \mathrm{~A} \\
\Rightarrow \quad L \geq V_{\text {in }} \cdot D \cdot(1-D) /\left(7 \cdot f_{s}\right) \\
\left\{\begin{array}{c}
V_{i n} \cdot D \cdot(1-D) /\left(7 \cdot f_{s}\right) \leq V_{\text {in }} \cdot 0.25 /\left(7 \cdot f_{s}\right) \leq L \\
V_{\text {in }}=30 \sim 35 \mathrm{~V}, f_{s}=200 \mathrm{kHz}
\end{array} \Rightarrow L \geq 6.3 \mu \mathrm{H}\right.
\end{gathered}
$$
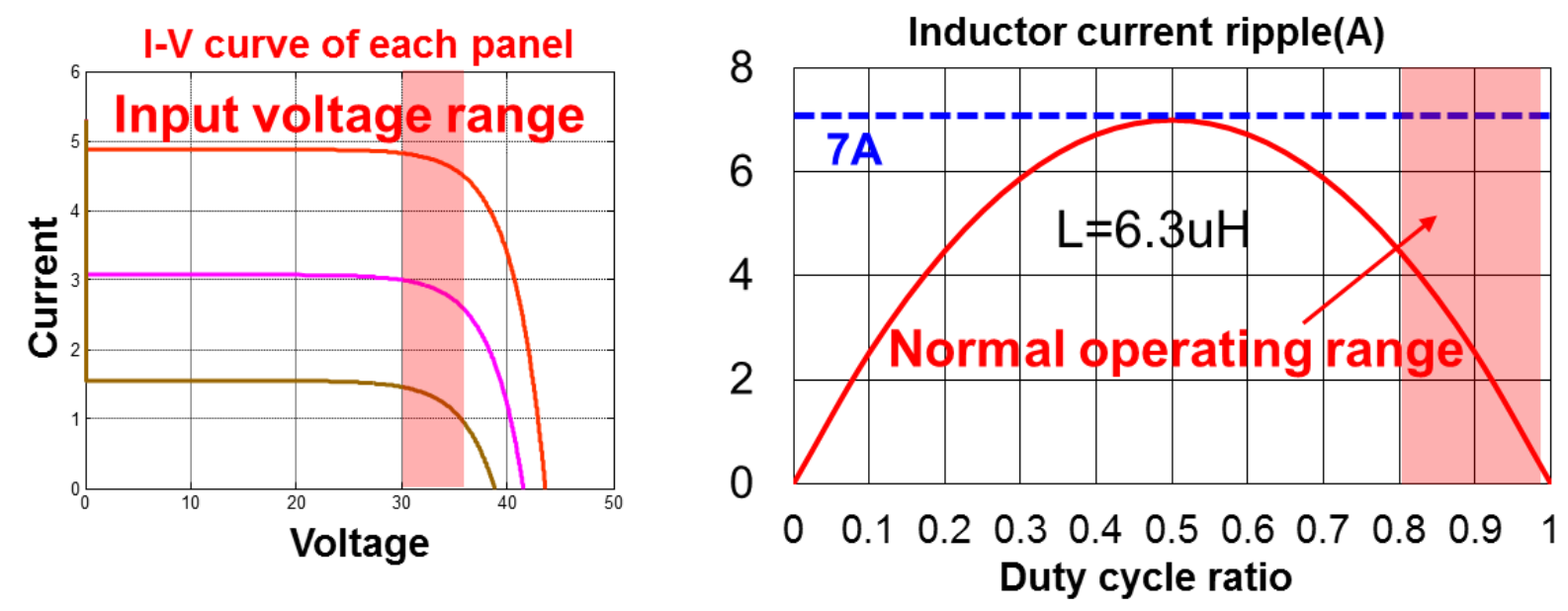

Figure 3.23 Normal operation condition of single phase buck converter

\section{(5) Top switch selection}

The voltage rating and current rating for device is determined by the output voltage limit and current limit of buck converter. Table 3.3 shows the requirement of power rating for the device.

Table 3.3Voltage and current rating for device selection

\begin{tabular}{|c|l|}
\hline Converter maximum output voltage: 43V & Voltage rating for device: $80 \mathrm{~V}$ \\
\hline Converter maximum output current: 7A & Current rating for device: 15A \\
Inductor maximum current ripple: 7A & \\
\hline
\end{tabular}

According to the analysis in the previous section, buck converter works in large duty cycle condition most of the time. Thus low $\mathrm{R}_{\mathrm{dson}}$ for top switch is desired to improved converter efficiency. Table 3.4 gives the comparison of different device that achieve the requirements 
listed in Table 3.3. Finally the first two device in the table, BSC057N08NS3G and BSC047N08NS3G, are selected because of their low $R_{d s o n}$ and low $Q_{g d} R_{d s o n}$.

Table 3.4 Comparison of 80V device candidates for top switch

\begin{tabular}{|c|c|c|c|c|c|}
\hline Part number & $\mathrm{V}_{\mathrm{ds}}(\mathrm{V})$ & $\mathrm{I}_{\mathrm{d}}(\mathrm{A})$ & $\mathrm{Q}_{\mathrm{gd}}(\mathrm{nC})$ & $\mathrm{R}_{\mathrm{dson}}(\mathrm{m} \Omega) @ 10 \mathrm{v}, 75^{\circ} \mathrm{C}$ & $\mathrm{Q}_{\mathrm{gd} * \mathrm{R}_{\mathrm{dson}}}$ \\
\hline BSC057N08NS3 G & 80 & 100 & 8 & 5.7 & 45.6 \\
\hline BSC047N08NS3 G & 80 & 100 & 10 & 4.7 & 47 \\
\hline BSC123N08NS3 G & 80 & 55 & 4 & 12.3 & 49.2 \\
\hline IPP139N08N3 G-ND & 80 & 45 & 4 & 13.6 & 54.4 \\
\hline FDMS86300 & 80 & 19 & 14 & 5.5 & 77 \\
\hline
\end{tabular}

(6) Bottom switch selection

Given that buck converter normally operates in large duty cycle condition, the turn-on period for bottom switch is smaller than its turn-off period. Therefore, for bottom switch low diode reverse-recovery loss is more preferred than low $R_{d s o n}$. Table 3.5 gives the comparison of $80 \mathrm{~V}$ device candidates for bottom switch. Finally the first device in the table, BSC123N08NS3G is selected due to its low $\mathrm{Q}_{\mathrm{rr}}$ and low $\mathrm{Q}_{\mathrm{g}}$ which give rise to low diode reverse-recovery loss and low driving loss. 
Table 3.5 Comparison of $80 \mathrm{~V}$ device candidates for bottom switch

\begin{tabular}{|c|c|c|c|c|c|c|}
\hline Part number & $\mathrm{V}_{\mathrm{ds}}(\mathrm{V})$ & $\mathrm{I}_{\mathrm{d}}(\mathrm{A})$ & $\mathrm{Q}_{\mathrm{rr}}(\mathrm{nC})$ & $\mathrm{Q}_{\mathrm{g}}(\mathrm{nC})$ & $\begin{array}{c}\mathrm{R}_{\mathrm{dson}}(\mathrm{m} \Omega) \\
@ 10 \mathrm{v}, \\
75^{\circ} \mathrm{C}\end{array}$ & $\mathrm{Q}_{\mathrm{g}} * \mathrm{R}_{\mathrm{dson}}$ \\
\hline BSC123N08NS3 G & 80 & 55 & $\begin{array}{c}54 \\
\left(\mathrm{~V}_{\mathrm{R}}=40 \mathrm{~V}, \mathrm{I}_{\mathrm{F}}=20 \mathrm{~A},\right. \\
\left.\mathrm{d} i_{\mathrm{F}} / \mathrm{d} t=100 \mathrm{~A} / \mathrm{us}\right)\end{array}$ & $\begin{array}{c}19 \\
\left(\mathrm{~V}_{\mathrm{DD}}=40 \mathrm{~V}, \mathrm{I}_{\mathrm{D}}=20 \mathrm{~A},\right. \\
\left.\mathrm{V}_{\mathrm{GS}}=0-10 \mathrm{~V}\right)\end{array}$ & 12.3 & 233.7 \\
\hline BSC057N08NS3 G & 80 & 100 & $\begin{array}{c}77 \\
\left(\mathrm{~V}_{\mathrm{R}}=40 \mathrm{~V}, \mathrm{I}_{\mathrm{F}}=25 \mathrm{~A},\right. \\
\left.\mathrm{d} i_{\mathrm{F}} / \mathrm{d} t=100 \mathrm{~A} / \mathrm{us}\right)\end{array}$ & $\begin{array}{c}42 \\
\left(\mathrm{~V}_{\mathrm{DD}}=40 \mathrm{~V}, \mathrm{I}_{\mathrm{D}}=25 \mathrm{~A},\right. \\
\left.\mathrm{V}_{\mathrm{GS}}=0-10 \mathrm{~V}\right)\end{array}$ & 5.7 & 239.4 \\
\hline $\begin{array}{c}\text { FDMS039N08BCT- } \\
\text { ND }\end{array}$ & 80 & 50 & $\begin{array}{c}80 \\
\left(\mathrm{~V}_{\mathrm{R}}=40 \mathrm{~V}, \mathrm{I}_{\mathrm{F}}=50 \mathrm{~A},\right. \\
\left.\mathrm{d} i_{\mathrm{F}} / \mathrm{d} t=100 \mathrm{~A} / \mathrm{us}\right)\end{array}$ & $\begin{array}{c}77 \\
\left(\mathrm{~V}_{\mathrm{DD}}=40 \mathrm{~V}, \mathrm{I}_{\mathrm{D}}=50 \mathrm{~A},\right. \\
\left.\mathrm{V}_{\mathrm{GS}}=0-10 \mathrm{~V}\right)\end{array}$ & 3.2 & 246.4 \\
\hline $\begin{array}{c}\text { IPP139N08N3 G- } \\
\text { ND }\end{array}$ & 80 & 45 & $\begin{array}{c}74 \\
\left(\mathrm{~V}_{\mathrm{R}}=40 \mathrm{~V}, \mathrm{I}_{\mathrm{F}}=45 \mathrm{~A},\right. \\
\left.\mathrm{d} i_{\mathrm{F}} / \mathrm{d} t=100 \mathrm{~A} / \mathrm{us}\right)\end{array}$ & $\begin{array}{c}1 \mathrm{~V}_{\mathrm{DD}}=40 \mathrm{~V}, \mathrm{I}_{\mathrm{D}}=45 \mathrm{~A}, \\
\left.\mathrm{~V}_{\mathrm{GS}}=0-10 \mathrm{~V}\right)\end{array}$ & 13.6 & 258.4 \\
\hline FDMS86300 & 80 & 19 & $\begin{array}{c}103 \\
\left(\mathrm{I}_{\mathrm{F}}=19 \mathrm{~A},\right. \\
\left.\mathrm{d} i_{\mathrm{F}} / \mathrm{d} t=300 \mathrm{~A} / \mathrm{us}\right)\end{array}$ & $\begin{array}{c}72 \\
\left(\mathrm{~V}_{\mathrm{DD}}=40 \mathrm{~V}, \mathrm{I}_{\mathrm{D}}=19 \mathrm{~A},\right. \\
\left.\mathrm{V}_{\mathrm{GS}}=0-10 \mathrm{~V}\right)\end{array}$ & 5.5 & 396.0 \\
\hline
\end{tabular}

\section{(7) Controller selection}

According to the MPPT control strategy of proposed four-phase buck converter, the controller needs to sense one current and two voltage, and output driving signal to four-phase buck converter. Therefore, the controller needs at least three ADC channels and four PWM channels. Table 3.6 gives the parameter of selected controller, TMS320F28027, which can achieve the requirement and have low cost.

Table 3.6 Parameters of selected controller

\begin{tabular}{|c|c|c|}
\hline & ADC channels & PWM channels \\
\hline Requirement for controller & 3 & 4 \\
\hline Selected controller:TMS320F28027 & 7 & 8 \\
\hline
\end{tabular}


(8) Schematic design

Fig.3.24 shows the schematic of hardware implementation. Digital isolator, ADUM1100, is used to send driving signal to the two top buck converters. The isolated dc/dc converter, UST12/250D48, is connected to PV panel and output 12V to driver LM5101A, and LDO LT1763. LDO outputs 3.3V to MCU and digital isolator.

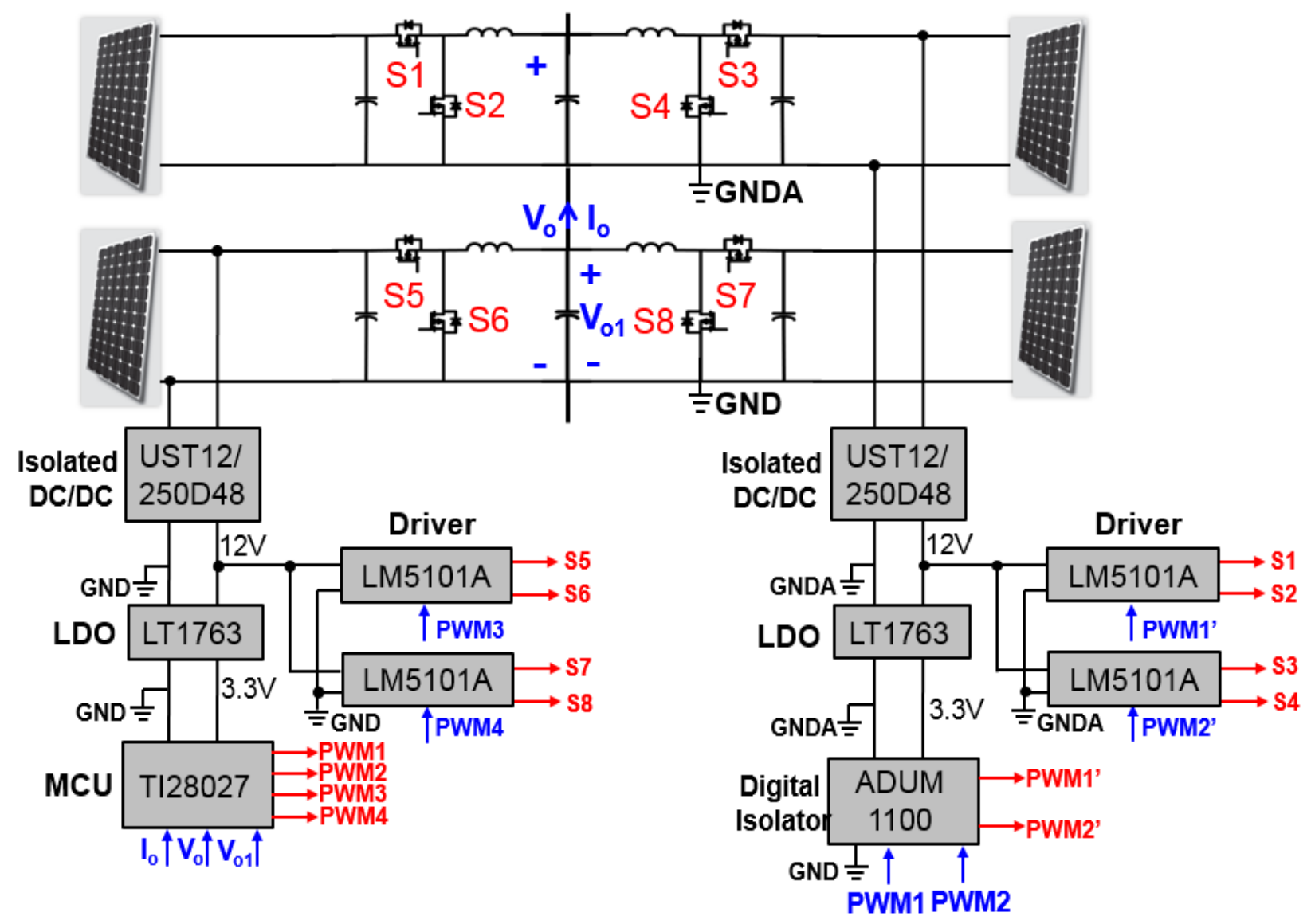

Figure 3.24 Simplified schematic of hardware implementation 


\section{B. Hardware test}

The experiment hardware is shown in the following Fig. 3.25. A four-phase buck converter is constructed. E4361 Agilent Solar Simulators are used to simulate four PV panels. This low power experiment is for concept verification before applying to $5 \mathrm{~kW}$ smart converter PV system.

\section{Input: Agilent E4360 Solar simulator}

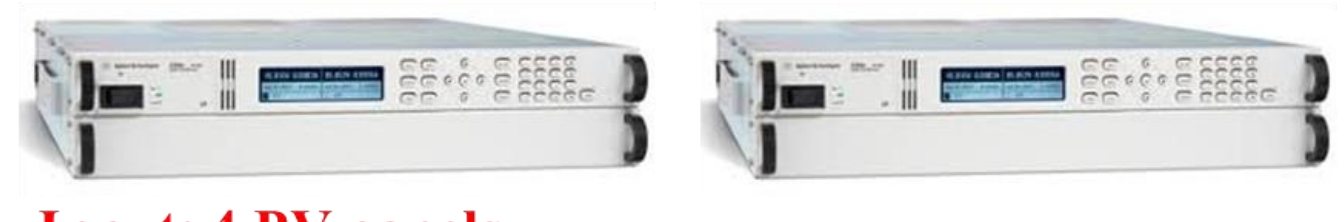

\section{Input: 4 PV panels}

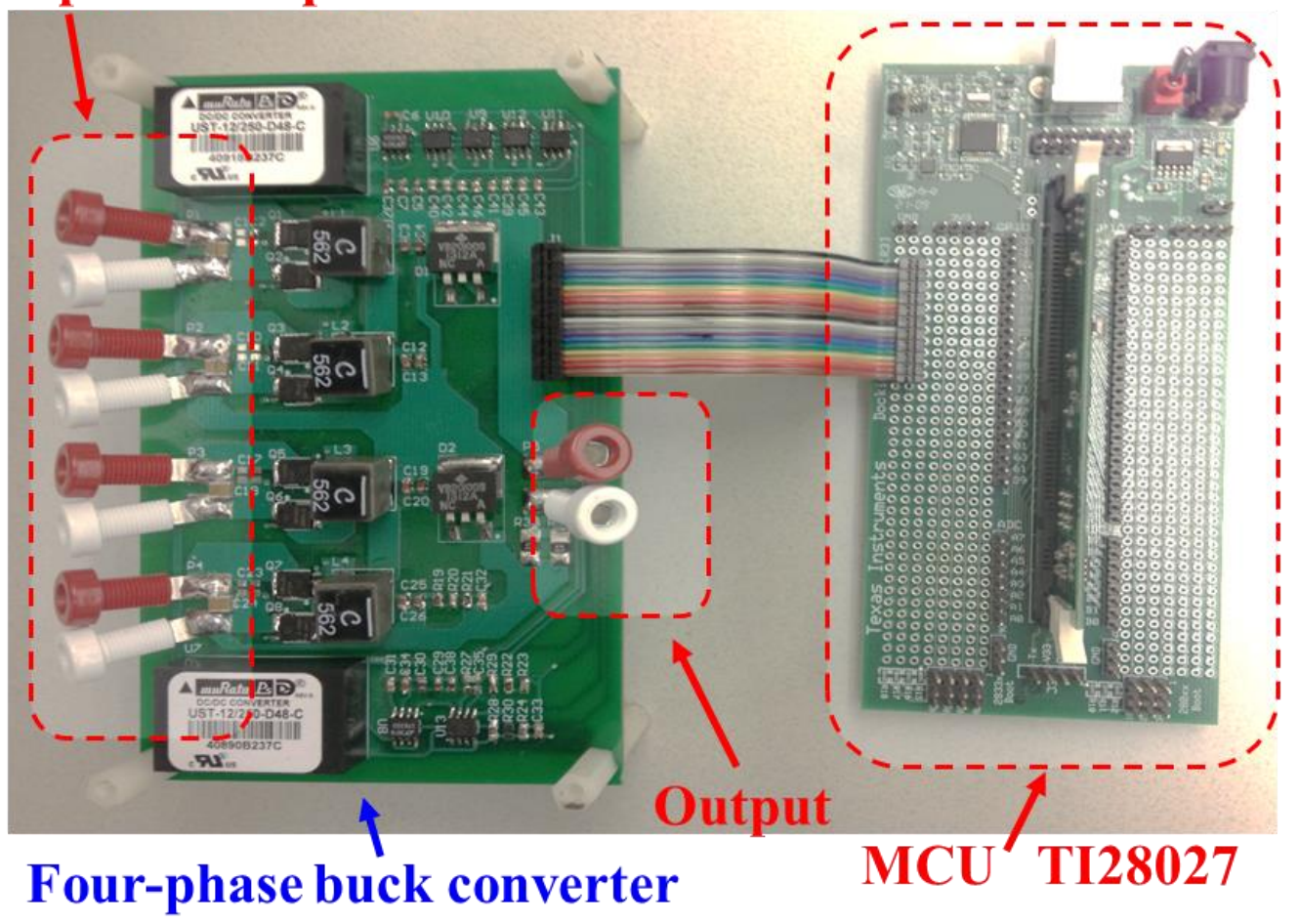

Figure 3.25 Experiment hardware of four-phase buck converter

To verify the effectiveness of proposed four-phase buck converter can deliver maximum power from four panels even if panel mismatch happens, the output of four solar simulators have different I-V curve as shown in Fig. 3.26(a). 


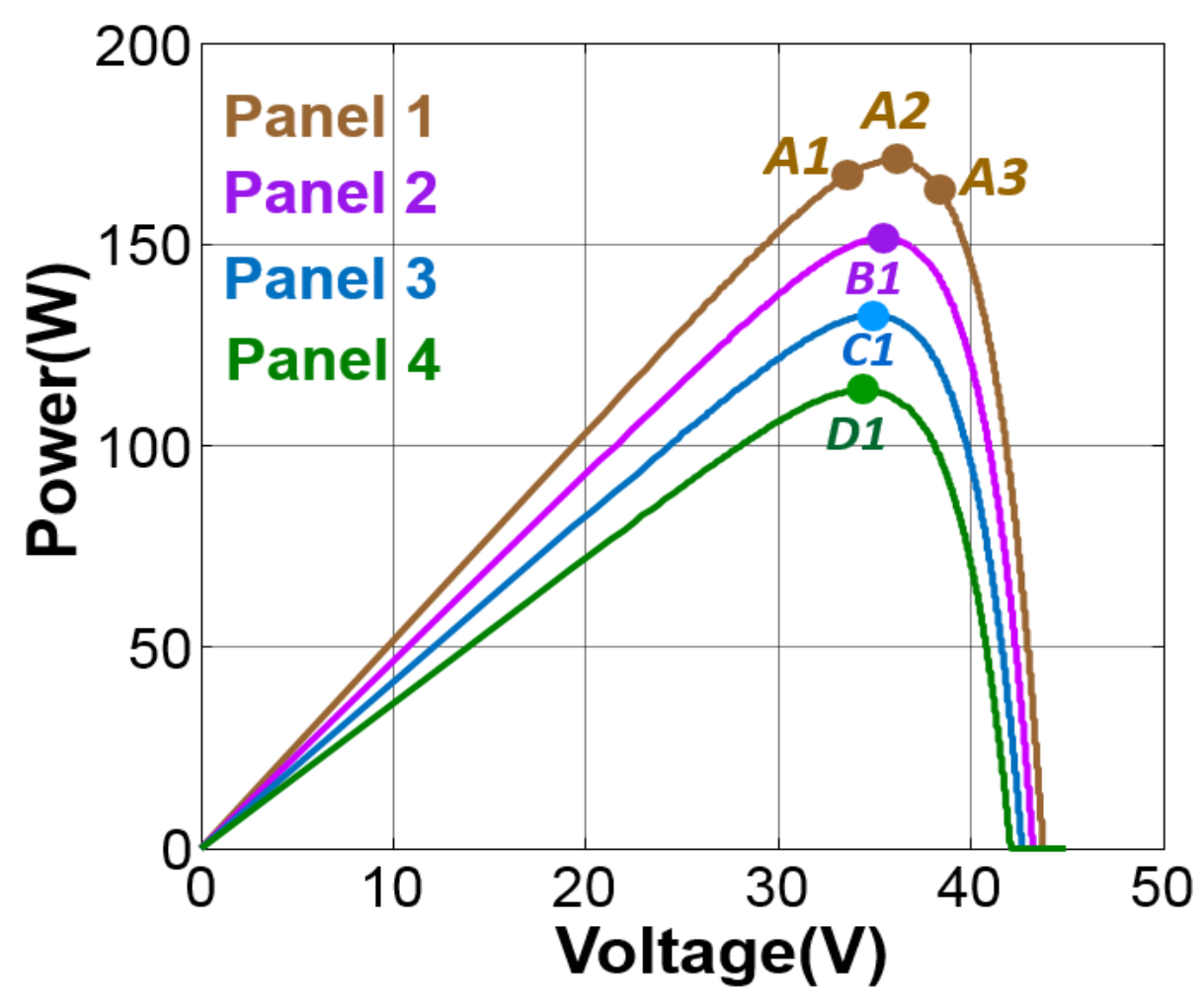

(a) I-V curves of four panels

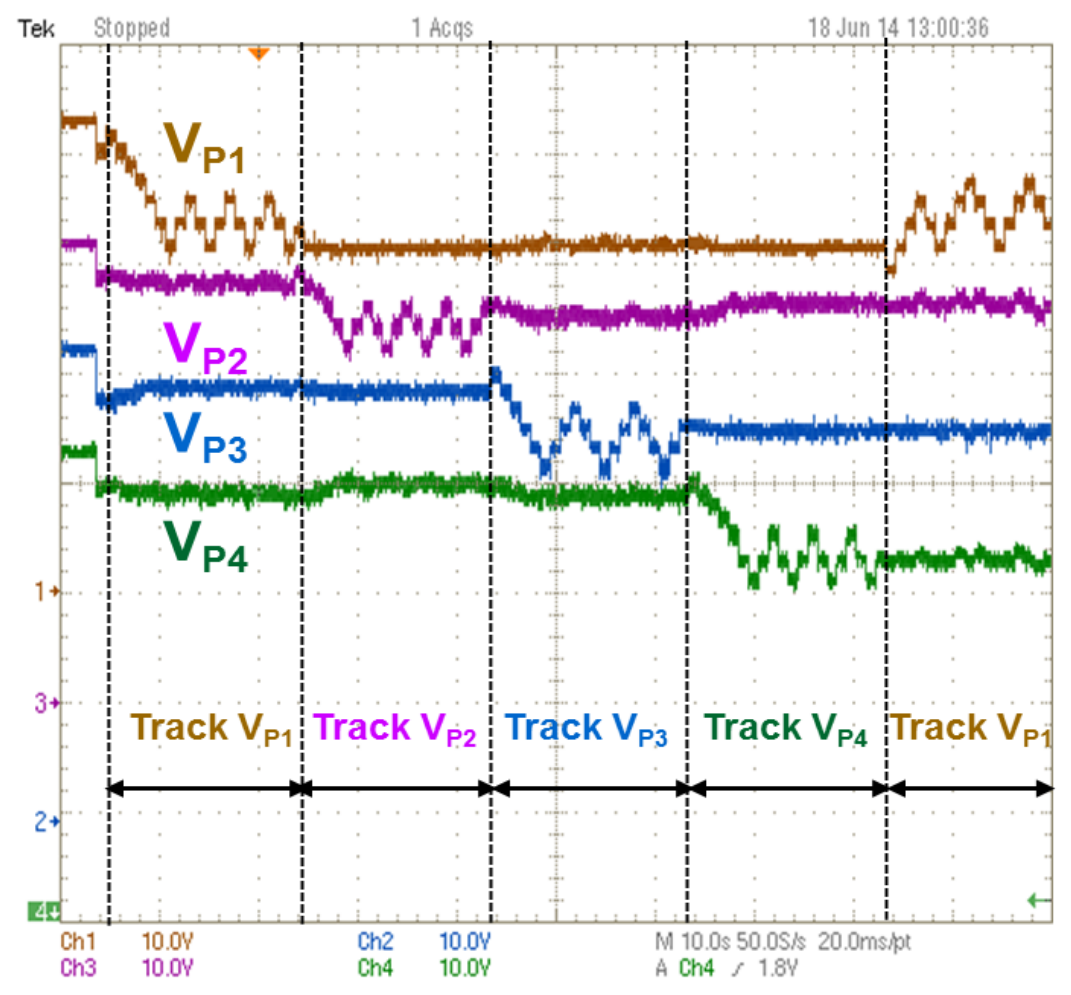

(b) Startup voltage waveforms of four panels 


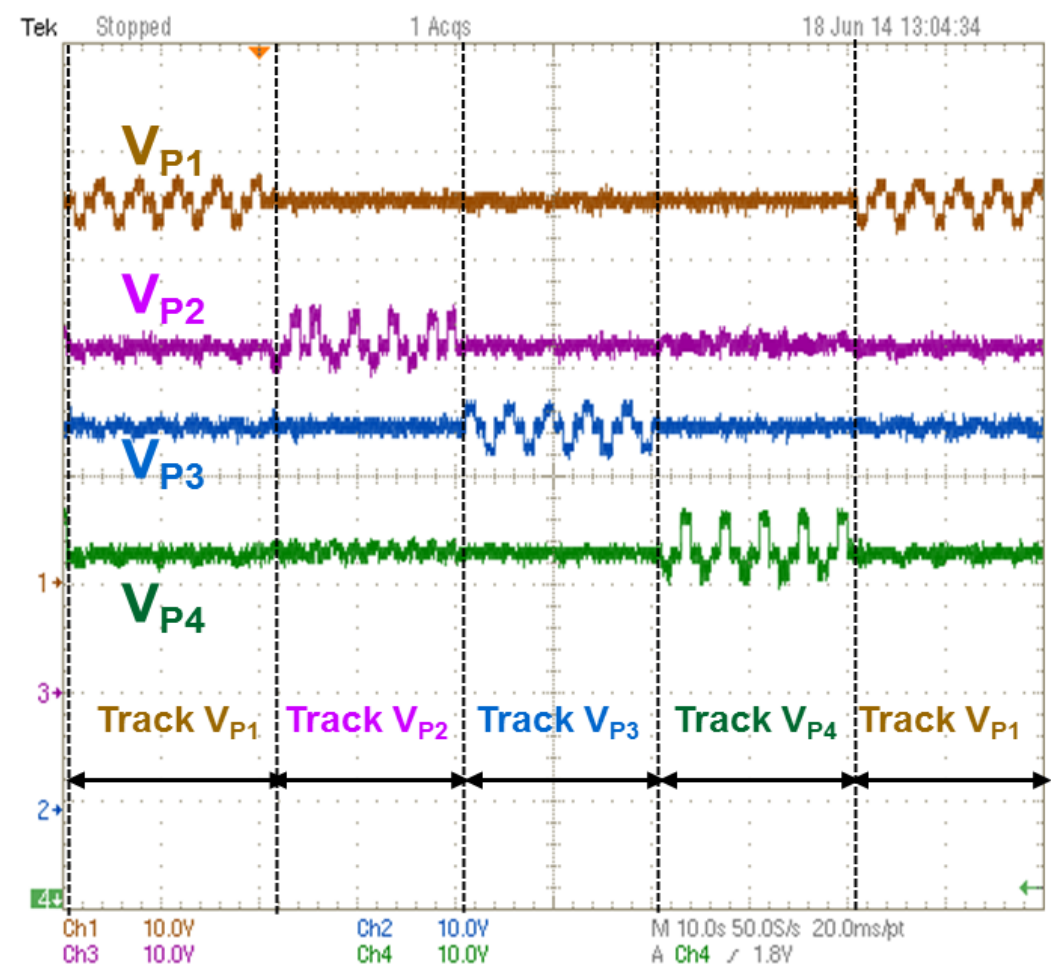

(c) Steady state voltage waveforms of four panels

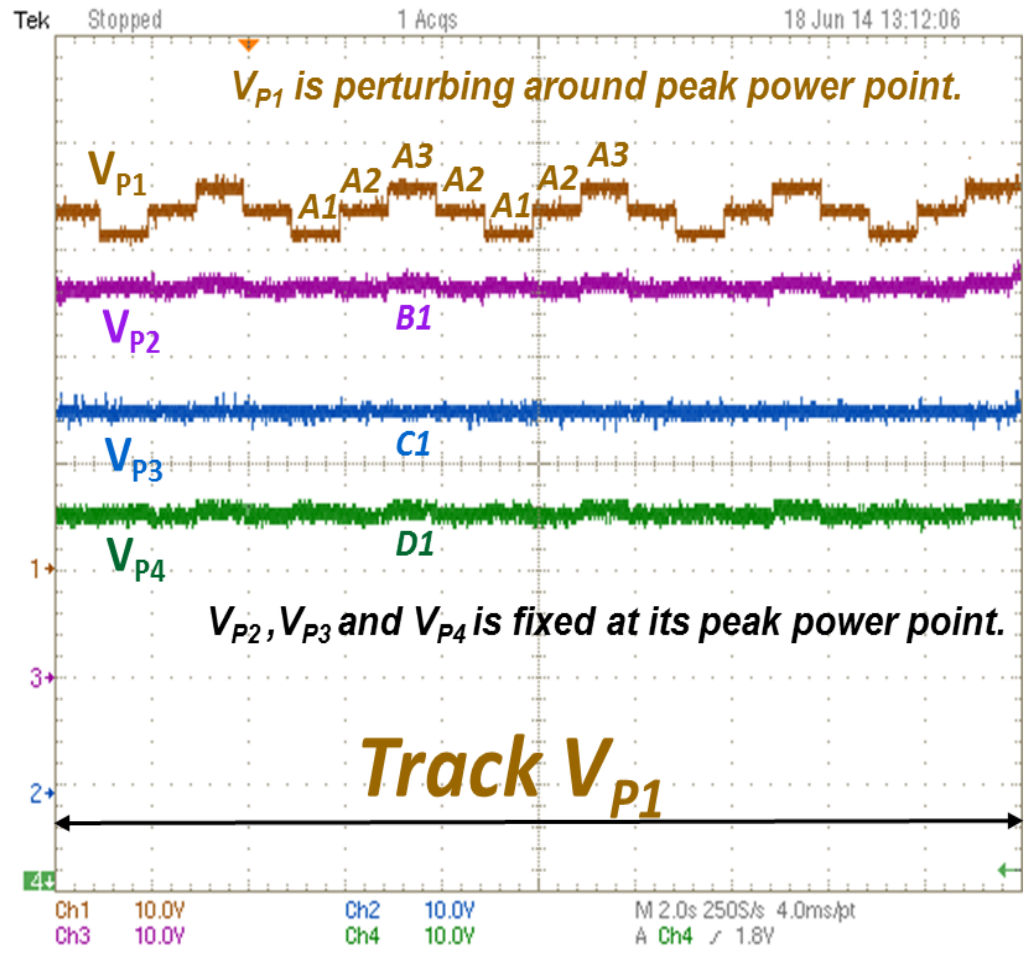

(d) Steady state voltage waveforms during tracking $V_{P 1}$ period

Figure 3.26 Test waveforms of four-phase smart converter 
Fig.3.26 (b) gives the startup voltage waveforms of four panels. The controller firstly tracks MPP for $\mathrm{P}_{1}$ while fix output power of the other three panels. After the MPP for $\mathrm{P}_{1}$ is settled, the controller tracks MPP for $\mathrm{P}_{2}$ while fix output power of the other three panels. Therefore, the controller can track the MPP of each panel in turn.

Fig.3.26 (c) shows the steady state waveforms of panel output voltage which vibrates around its peak power point. Fig.3.26 (d) is the detailed waveform of the tracking $V_{P 1}$ period in Fig.3.26 (c). According to the operating points of four panels on P-V curve given in Fig.3.26 (a), during tracking $\mathrm{V}_{\mathrm{P} 1}$ period, $\mathrm{V}_{\mathrm{P} 1}$ is perturbed among three points, $\mathrm{A} 1, \mathrm{~A} 2$ and $\mathrm{A} 3$, which are very close to its peak power point. Meanwhile, the voltage of other panels are fixed at their peak power point, which are noted as B1, C1 and D1 on the P-V curve. By using the same method, the controller can always deliver maximum power from each panel during other periods.

Fig.3.27 shows the efficiency curve versus panel output power when there is no shading on PV array. In this condition, the panels receive uniform irradiance, and each smart converter has the same operation condition. The test condition is given as follows:

(i) Determine converter input voltage.

Fig.3.23 shows the panel voltage of peak power point varies from 30 37V due to different irradiance. To simplify analysis, the input voltage in efficiency test is set to $35 \mathrm{~V}$.

(ii) Determine converter output voltage.

Fig.3.22 shows the system structure of 5kW PV system. The DC bus voltage varies from $360 \sim 400 \mathrm{~V}$. To simplify analysis, the DC bus voltage is set to $380 \mathrm{~V}$, and then each converter outputs $27 \mathrm{~V}$. Therefore, the duty cycle for each converter is 0.77 . 
(iii) Determine converter output power.

According to datasheet of PV panel listed in Table 2.1 and irradiance data shown in

Fig.3.16, the PV panel output power varies from 0 195W.

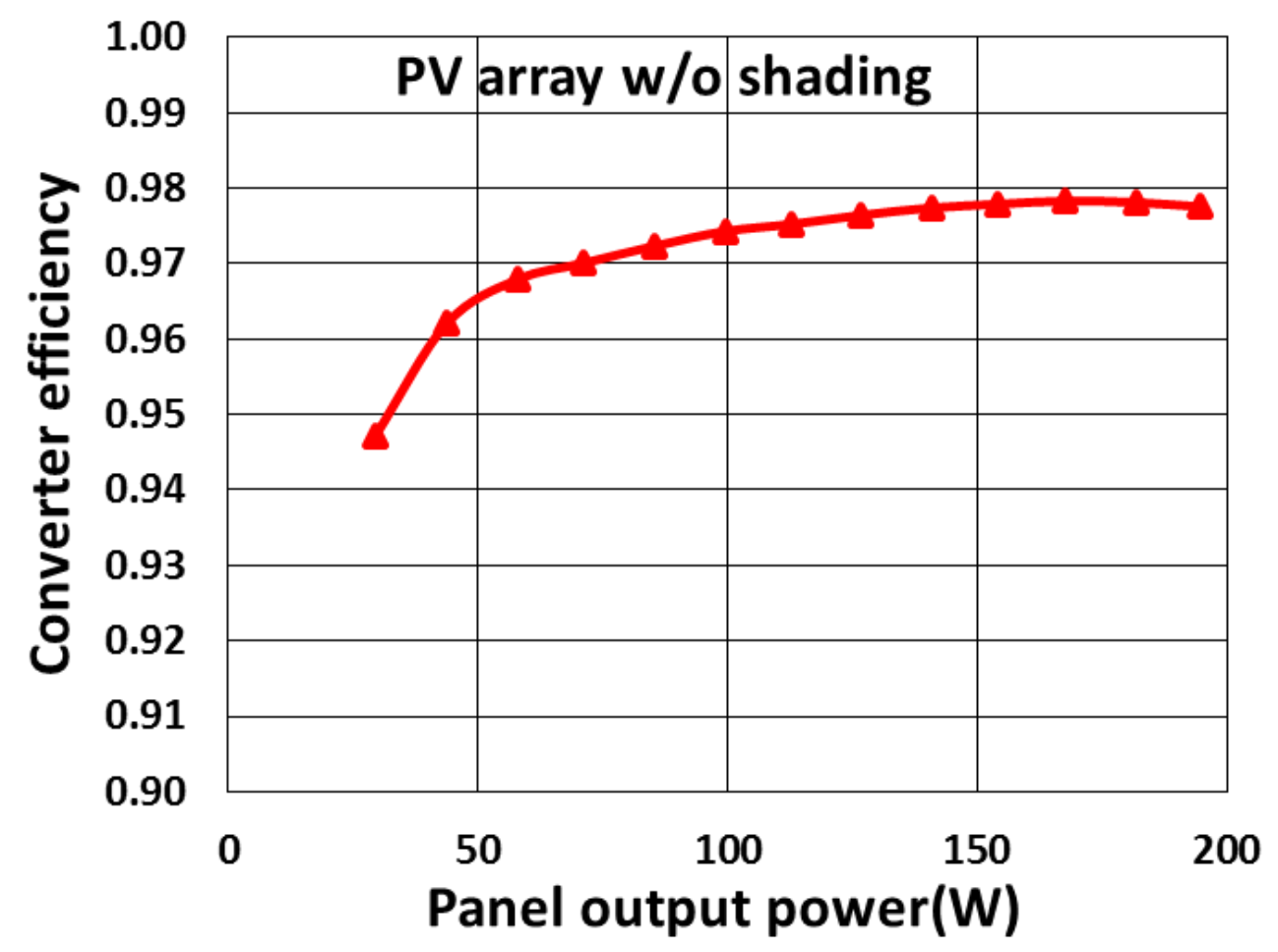

Figure 3.27 Efficiency curve for non-shading condition

Fig.3.28 shows the efficiency curve versus panel output power when there is partial shading on PV array. The test condition is given as follows:

(i) Determine converter input voltage.

Fig.3.23 shows the panel voltage of peak power point varies from $30 \sim 37 \mathrm{~V}$ due to different irradiance. To simplify analysis, the input voltage in efficiency test is set to $35 \mathrm{~V}$. 
(ii) Determine converter output voltage.

If all the converters output the same power, the output voltage is $27 \mathrm{~V}$ as noted before. However, the output power of each converter is different in partial shading condition. In this case, the converter processing high power has high output voltage because of series connection, and vice versa.

In order to connect to $380 \mathrm{~V}$ DC bus, the output voltage of converter transferring high power is higher than $27 \mathrm{~V}$ but lower than its input voltage $35 \mathrm{~V}$, and the output voltage of converter transferring low power is lower than $27 \mathrm{~V}$.

For example, a converter with high output power $180 \mathrm{~W}$ outputs $30 \mathrm{~V}$, and then its output current is $6 \mathrm{~A}$. Therefore, the other converter also outputs $6 \mathrm{~A}$. In this case, the output voltage of converter equipped with heavy shaded panel is much lower than $27 \mathrm{~V}$, and the duty cycle is very small.

(iii) Determine converter output power.

The converter output power falls down as the shading condition goes heavy. Since the peak power of panel without shading can be high to $195 \mathrm{~W}$, the converter output power in shading case is assumed to vary from 0 to $165 \mathrm{~W}$. Both output voltage and duty cycle of converter will be variant due to different output power. 


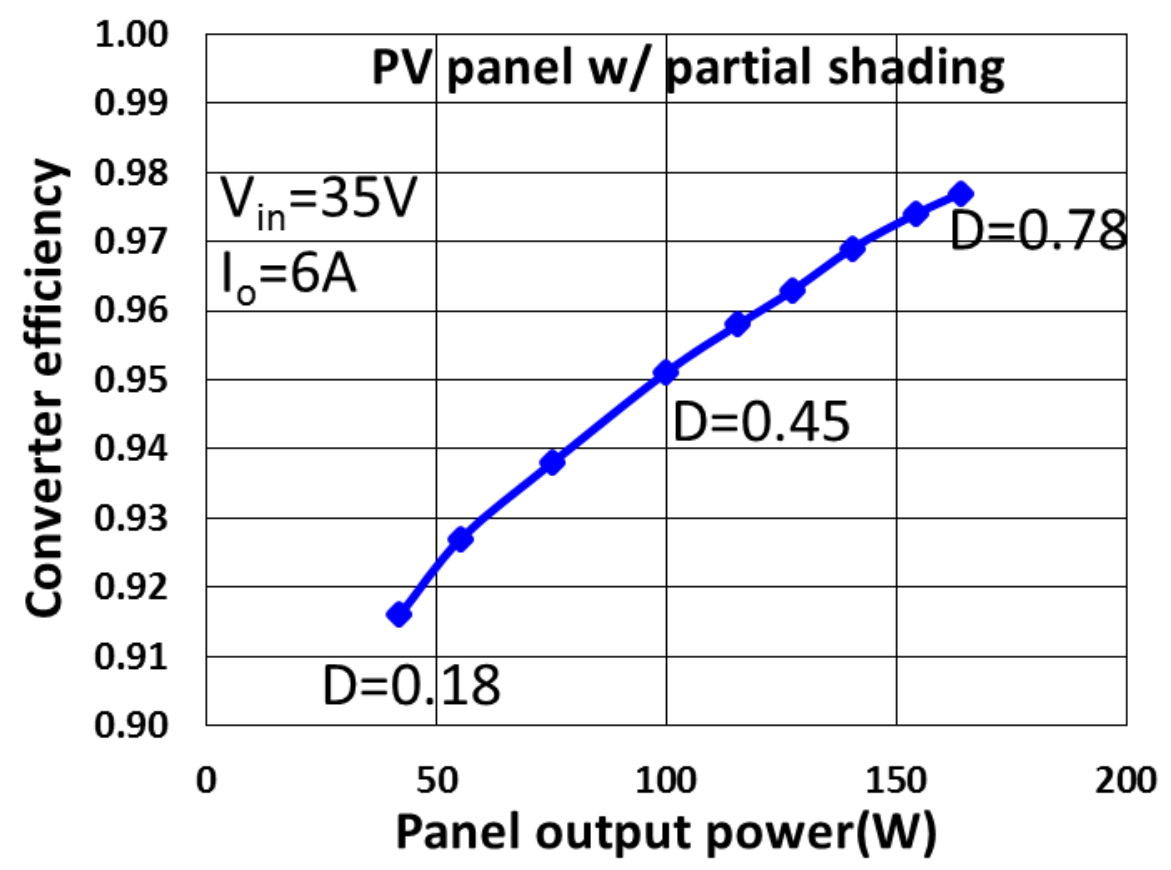

Figure 3.28 Efficiency curve for partial shading condition

\subsection{Summary}

The chapter presents the concept and solution of multi-phase smart converter, which can reduce cost but still have panel level MPPT performance. Simulation of single multi-phase smart converter and cascaded multi-phase smart converter PV system verifies that the proposed solution can improve energy production even if the panel mismatch exists. After that, simulation of multi-phase smart converter under variant solar irradiance demonstrates that the proposed solution can handle changing solar irradiance with good MPPT performance. Moreover, simulation of nine-phase smart converter gives an example that the concept of multi-phase smart converter can be extended to other architecture. Finally, the design consideration for the hardware implementation is analyzed and test results shows that four-phase can successfully deliver maximum power form four panel with single controller. 


\section{Chapter 4. Summary}

The traditional centralized PV system in DC nano-grid has poor energy harvesting performance if panel mismatch happens. The smart converter PV system, a more state-of-art system shows better MPPT efficiency under partial shading and mismatch condition. However, due to its cascaded architecture, some challenges still exists in the smart converter PV system, which includes energy reduction in heavy mismatch and the necessity of $2^{\text {nd }}$ stage MPPT converter.

Solution to these challenges are introduced based on a case study of $5 \mathrm{~kW}$ rooftop PV system. The analysis of output characteristics of PV system shows that an optimized system architecture can deliver peak power from PV system and connect PV array to DC bus without $2^{\text {nd }}$ stage MPPT converter.

Based on the optimized system architecture, this thesis presents a multi-phase smart converter for PV system, which saves current and voltage sensors, and MPPT controllers on the premise of guaranteeing that each panel can still output peak power. Simulation and experimental verification are conducted which indicates the feasibility of the proposed MPPT method. In the future, the proposed MPPT method will be further verified and optimized based on testing over larger scale system. 


\section{References}

[1] Bimal K. Bose, "Global warming: energy, environmental pollution, and the impact of power electronics”, IEEE Industrial Electronics Magazine, March 2010, P6 P17.

[2] D. Boroyevich, I. Cvetkovic, Dong D., R. Burgos, F. Wang, F. C. Lee, "Future Electronic Power Distribution Systems --- A contemplative view," in IEEE 12th International Conference on Optimization of Electrical and Electronic Equipment, 2010, pp. 1369-1380.

[3] Dong Dong, F. Luo, W. Zhang, D. Boroyevich, P. Mattavelli, I.Cvetkovic, L. Jiang, P. Kong, "Passive filter topology study of singlephase ac-dc converters for DC nanogrid applications", Applied Power Electronics Conference and Exposition (APEC), 2011 Twenty-Sixth Annual IEEE, 2011 , Page(s): $287-294$.

[4] European Renewable Energy Council, May, 2004 [Online]. Available: http://www.erecrenewables.org/documents/targets_2040/EREC_Scenario\%202040.pdf, Renewable Energy Scenario to 2040 [Online].

[5] Yi Huang, Fang Z. Peng , "Survey of the Power Conditioning System for PV Power Generation", Power Electronics Specialists Conference, 2006.

[6] Peter, P.K.; Agarwal, V. "Current Equalization in Photovoltaic Strings With Module Integrated round-Isolated Switched Capacitor DC-DC Converters", Photovoltaics, IEEE Journal of, On page(s): 669 - 678 Volume: 4, Issue: 2, March 2014.

[7] T. Shimizu, M. Hirakata, T. Kamezawa, H. Watanabe, "Generation Control Circuit for Photovoltaic Modules“, IEEE Trans. on Power Electronics, 2001, vol. 16, no. 3, pp. 293-300.

[8] G. R. Walker and J. C. Pierce, "PhotoVoltaic DC-DC module integrated converter for novel cascaded and bypass grid connection topologies-Design and optimisation," in 37th IEEE Power Electronics Specialists Conf., PESC ’06, June 18-22, 2006, pp. 1-7.

[9] Nimni, Y.; Shmilovitz, D.; , "A returned energy architecture for improved photovoltaic systems efficiency," Proceedings of 2010 IEEE International Symposium on Circuits and Systems (ISCAS), pp.2191-2194, May 30 2010-June 2010.

[10] J. Cao, N. Schofield, and A. Emadi, "Battery balancing methods: A comprehensive review," in Vehicle Power and Propulsion Conference, 2008. VPPC '08. IEEE, 2008, pp. 1-6. 
[11] R. K. Hester, C. Thornton, S. Dhople, Z. Zheng, N. Sridhar, and D. Freeman, "High efficiency wide load range buck/boost/bridge photovoltaic microconverter," in Proc. Appl. Power Electron. Conf. Expo., 2011, pp. 309-313.

[12] G. R. Walker and P. C. Sernia, "Cascaded DC-DC converter connection of photovoltaic modules," IEEE Trans. Power Electron., vol. 19, no. 4, pp. 1130-1139, Jul. 2004.

[13] Pinde Fu and Paul M.Rich, "Design and Implementation of the Solar Analyst: an ArcView Extension for Modeling Solar Radiation at Landscape Scales. "

[14] B. N. Alajmi, K. H. Ahmed, S. J. Finney, and B. W. Williams, "A maximum power point tracking technique for partially shaded photovoltaic systems in microgrids," IEEE Trans. Ind. Electron., vol. 60, no. 4, pp. 1596-1606, Apr. 2013.

[15] Feng Wang, Pengju Kong, Fred C. Lee, and Fang Zhuo, "Analysis and optimization of module integrated MPPT converter based residential PV system", Power Electronics and Applications (EPE), 2013 15th European Conference, pp. 1 - 7, Sept. 2013.

[16] F. Wang, et al., "Analysis of Unified Output MPPT Control in Subpanel PV Converter System," IEEE Trans. Power Electron., vol. 29, no. 3, pp. 1275-1284, Mar. 2014.

[17] L. Jiang, et al., "R-based MPPT method for smart converter PV system," in Proc. IEEE Appl. Power Electron. Conf. Expo., 2012, pp. 2072-2079. 


\section{Appendix}

\section{Main function for MCU controller}

interrupt void cpu_timer0_isr(void) //MPPT function based on Perturbation \& Observation Algorithm \{

CpuTimer0.InterruptCount++; // acknowledge this interrupt to receive more interrupts from group 1

PieCtrlRegs.PIEACK.all = PIEACK_GROUP1;

TIMER0CNT++;

if (TIMEROCNT < MPPTCNT)

//MPPT period for each phase: MPPTCNT $*$ TIMER0CNT $=20000 * 1000 \mathrm{~ms}=20 \mathrm{~s}$.

$/ /$ panel 1 is controlled during 0-20s.

\{

// Perturb \& Observe Method for MPPT

if $(($ TIMER0CNT \% MPPTCNTDIV $)==1)$

//update PV panel voltage reference every MPPTCNTDIV(1000) CPU TIMER0 interruption

\{

if $\left(\left(\mathrm{P} 1>=\mathrm{P} 1 \_\mathrm{Pre}\right) \& \&\left(\mathrm{Vp} 1>=\mathrm{Vp} 1 \_\mathrm{Pre}\right)\right) \quad / / \mathrm{P} 1$ is total power of panel 1 and panel 2

\{

$$
\text { Vp1_Pre = Vp1; }
$$$$
\mathrm{Vp} 1=\mathrm{Vp} 1+\mathrm{DVp}
$$

\} // if increasing Vp1 makes P1 larger, then continue to increase Vp1

else if $\left(\left(\mathrm{P} 1>=\mathrm{P} 1 \_\right.\right.$Pre $) \& \&\left(\mathrm{Vp} 1<\mathrm{Vp} 1 \_\right.$Pre $\left.)\right)$

\{

$$
\text { Vp1_Pre = Vp1; }
$$$$
\mathrm{Vp} 1=\mathrm{Vp} 1-\mathrm{DVp}
$$

\} // if decreasing Vp1 makes P1 larger, then continue to decrease Vp1

else if $\left(\left(\mathrm{P} 1<\mathrm{P} 1 \_\mathrm{Pre}\right) \& \&\left(\mathrm{Vp} 1<=\mathrm{Vp} 1 \_\right.\right.$Pre $\left.)\right)$

\{

$$
\text { Vp1_Pre = Vp1; }
$$$$
\mathrm{Vp} 1=\mathrm{Vp} 1+\mathrm{DVp}
$$

\} //if decreasing Vp1 makes P1 smaller, then increase Vp1,

else if $\left(\left(\mathrm{P} 1<\mathrm{P} 1 \_\mathrm{Pre}\right) \& \&\left(\mathrm{Vp} 1>\mathrm{Vp} 1 \_\mathrm{Pre}\right)\right)$ 


$$
\begin{aligned}
& \text { Vp1_Pre }=\text { Vp1; } \\
& \text { Vp1 = Vp1 - DVp; } \\
& \text { // if increasing Vp1 makes P1 smaller, then decrease Vp1 }
\end{aligned}
$$

P1_Pre $=$ P1;

Dutyupdate(); //generate duty cycle based on output voltage and panel voltage reference \}

else

\section{Dutyupdate();}

// update panel voltage reference on the first TIMER0 interruption.

//During the last 999 TIMER0 interruption, keep voltage reference constant.

\}

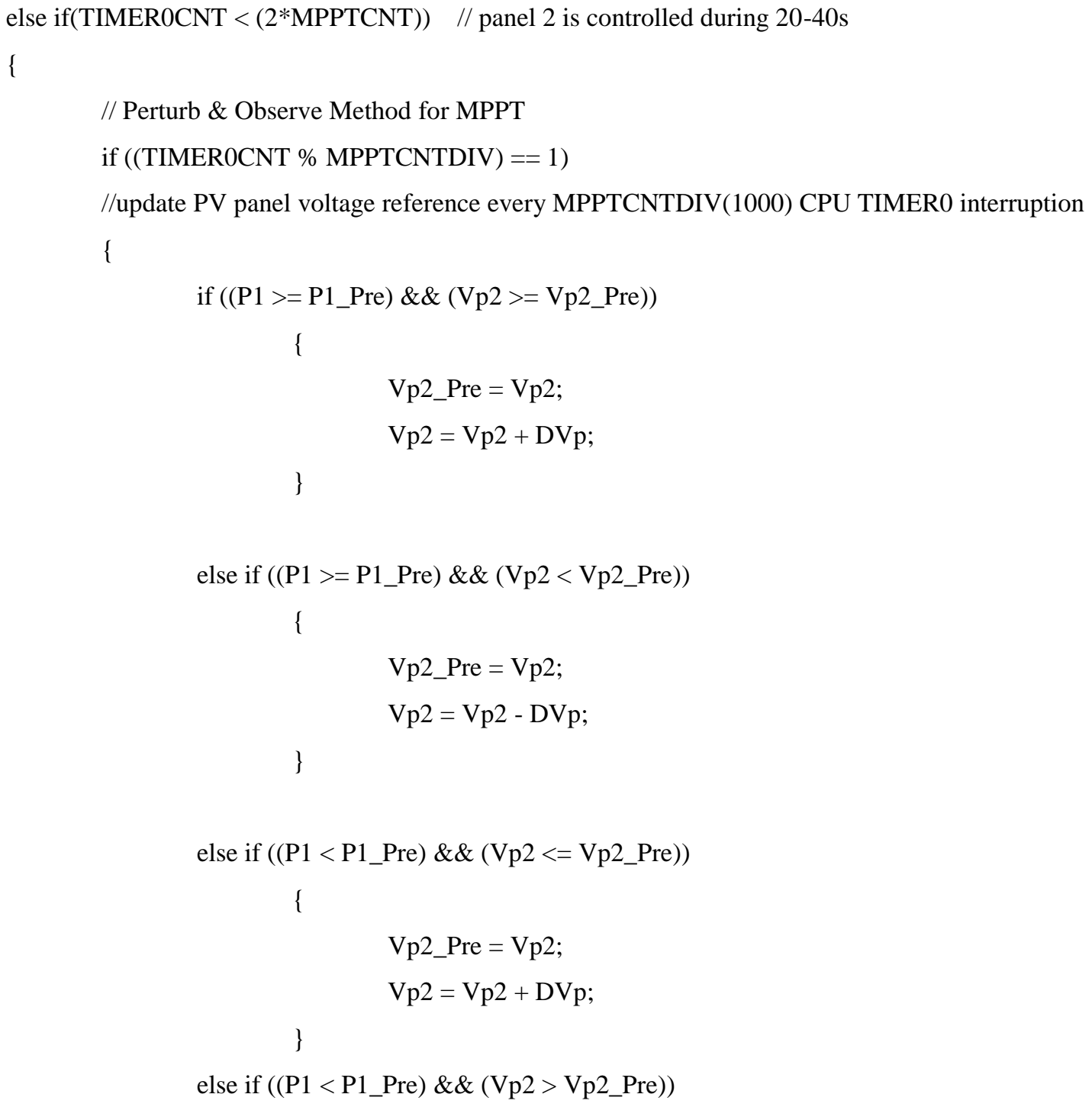




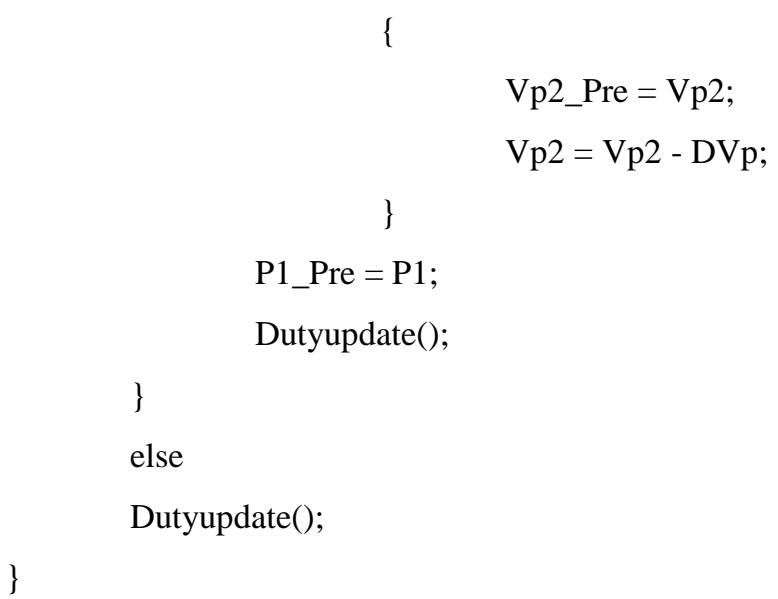

$$
\begin{aligned}
& \text { Vp3_Pre = Vp3; } \\
& \text { Vp3 = Vp3 - DVp; }
\end{aligned}
$$


P2_Pre = P2;

Dutyupdate();

\}

else

Dutyupdate();

\}

else if (TIMER0CNT < $(4 *$ MPPTCNT) $)$ // panel 4 is controlled during 60-80s

\{

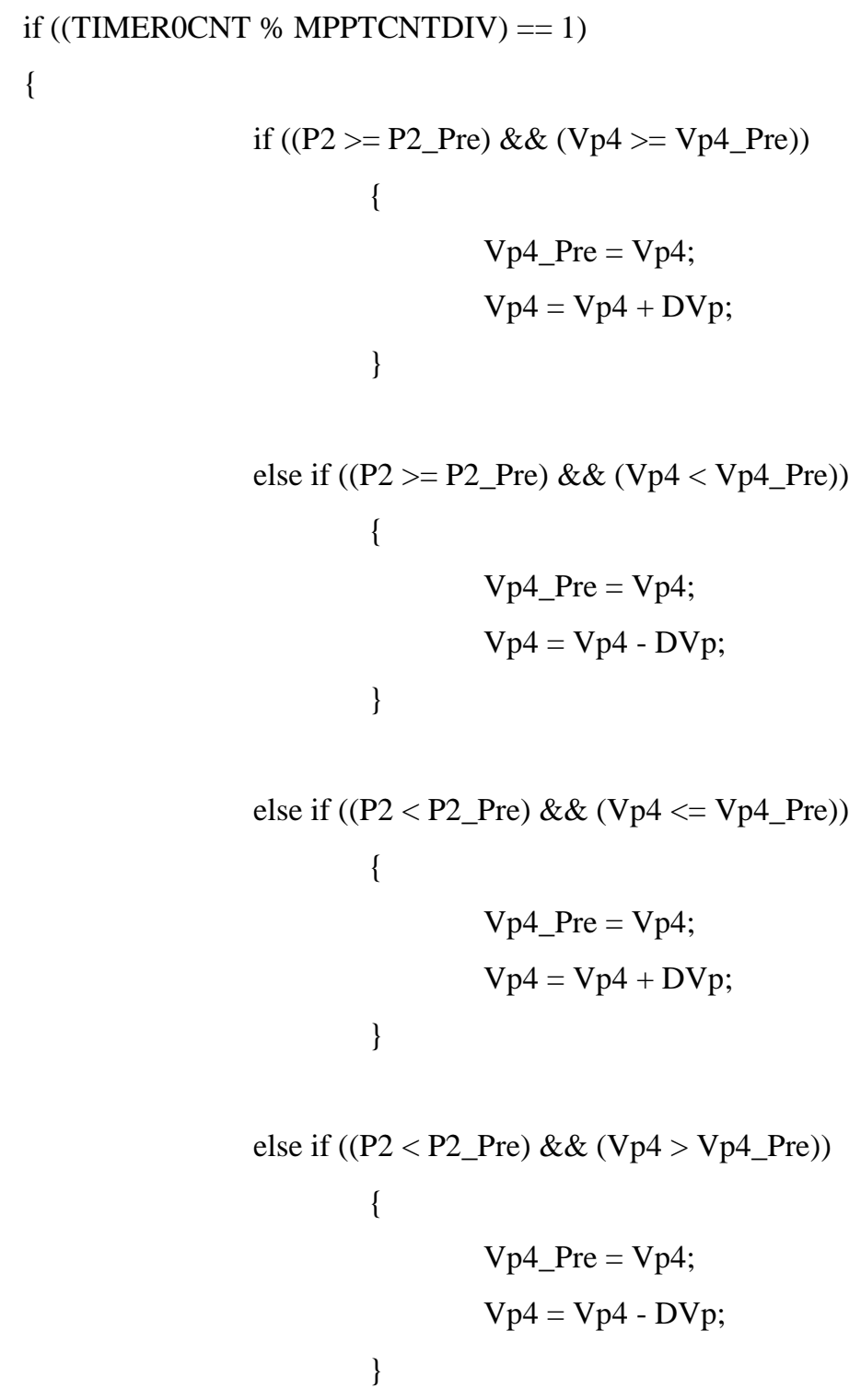


P2_Pre $=$ P2;

Dutyupdate();

\}

else

Dutyupdate();

\}

else // if TIMER0CNT is larger than $4 * 20000$, then it is set to zero.

\{

TIMEROCNT $=0$;

return;

\}

\}

void Dutyupdate() // generate duty cycle for each phase

\{

Duty1 $=\left(\left(\mathrm{V}_{0} 2-\mathrm{V}_{0} 1\right) *\right.$ Period $) / \mathrm{Vp} 1 ; \quad / /$ duty cycle $=$ output voltage $/$ input panel voltage reference

Duty2 $=(($ Vo2-Vo1 $) *$ Period $) / \mathrm{Vp} 2$;

Duty3 $=($ Vo1 $*$ Period $) / \mathrm{Vp} 3$;

Duty4 = $(($ Vo1 $*$ Period $) / \mathrm{Vp} 4)$;

//deadtime compensation

Duty1 = Duty1 + Deadtime; $\quad$ //increase duty cycle to compensate the deadtime effect

Duty2 = Duty2 + UPDeadtime;

Duty3 = Duty3 + Deadtime;

Duty4 = Duty4 + Deadtime;

EPwm1Regs.CMPA.half.CMPA = Duty 1 // set duty cycle for each pwm signal

EPwm2Regs.CMPA.half.CMPA = Duty2;

EPwm3Regs.CMPA.half.CMPA = Duty3;

EPwm4Regs.CMPA.half.CMPA = Duty4;

\} 